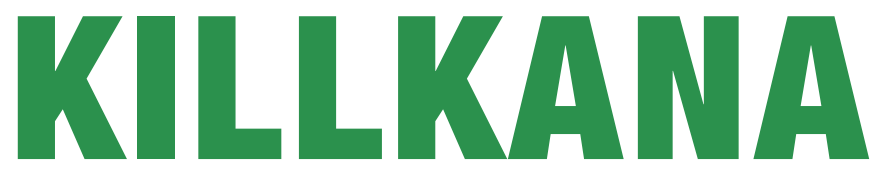

$S A L U D \quad Y \quad B I E N E S T A R$

Volumen 5, Número 1,

ISSN impreso: 2528-8016

ISSN electrónico: 2588-0640

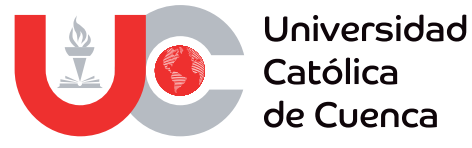

Cuenca, enero de 2021 
Revista Killkana Salud y Bienestar

ISSN IMPRESO: 2528-8016

ISSN ELECTRÓNICO: 2588-0640

Departamento de Posgrado, Investigación Vinculación con la Sociedad y Publicaciones de la Universidad Católica de Cuenca

Av. de Las Américas y Humbolt

Código Postal 010101, Cuenca - Ecuador

killkana.investigacion@ucacue.edu.ec

Central telefónica:

$+593(7)$ 2-830-751

$+593(7) 2-824-365$

$+593(7) 2-826-563$

http://www.ucacue.edu.ec

http://killkana.ucacue.edu.ec

Volumen 5, Número 1

Publicación trianual

\section{Director de la revista}

Lic. Tania Cecilia Bustamante Saavedra, Mgs.

\section{Editor de la revista}

Lic. Tania Cecilia Bustamante Saavedra, Mgs.

\section{Diseño, diagramación y maquetación}

D.G. Alexander Campoverde Jaramillo

\section{English texts revision/edition}

Lic. Tania Cecilia Bustamante Saavedra, Mgs.

Impresión: Editorial Universitaria Católica (EDUNICA)
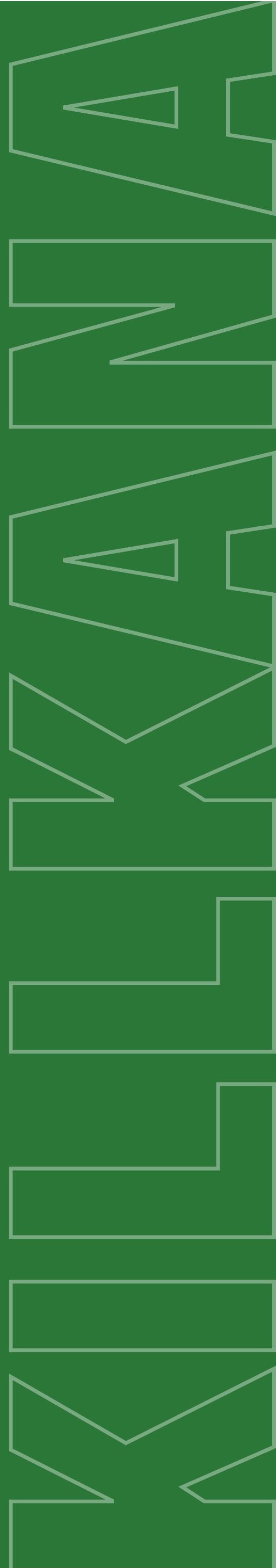


\section{Contenido}

Asociación entre el sindrome metabólico y Severidad de la periodontitis en adultos

July J. Vega, Jorge R. Colchado, Gabriela F. Escudero, Juan E. Huamaní

Ansiedad al tratamiento odontológico en adultos mayores a 65 años, de la parroquia Cañaribamba, Cuenca-Ecuador, 2017-2018.

Alejandra Naranjo, Santiago Vintimilla, Patricia Pinos

Conocimiento de las úlceras por presión del personal de enfermería.

Ronaldo Gracia G., Liliana Holguín, Miguel Martínez, Mauricio Guillén.

\section{ÍNDICE} GENERAL

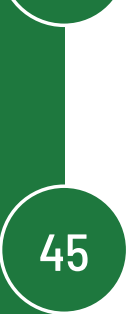

45

61

75

Evaluación del sellado apical de Bioroot RCS, Tubliseal y Top Seal: estudio in vitro

Fernanda Sacoto, Paula Cárcamo, Raúl Alcántara

Tratamiento restaurador atraumático: Eficacia clínica de ionómeros de vidrio en cavidades clase I.

Katia Medina; Jorge Colchado; Luis Vicuña, Ezzard Alvarez

Odontoma compuesto: reporte caso clínico.

Piedra-Sarmiento, Xavier Bernardo; Moncayo-Pinos, Jaime

Bernardo; Gonzalez-Campoverde, Lorena Alexandra

Parametrización de avances funcionales asociados a frenectomía lingual: reporte de un caso.

José Aguilar, Doris Gordillo, Jonathan Altamirano, Cristina Crespo

Reimplante dentario ulterior a su avulsión, reporte de caso clínico.

Byron Morales, Ma. Augusta Cordero, Patricia Pinos.

Paralelismo entre el plano de Camper y el plano oclusal según biotipo facial en una población del sur del Perú.

Juan Huamani, Jorge Colchado, Cecil Massiel, José Huamani 



\title{
Asociación entre el síndrome metabólico y Severidad de la periodontitis en adultos
}

\author{
Association between metabolic syndrome \\ and Severity of Periodontitis in Adults
}

July J. Vega', Jorge R. Colchado ${ }^{2}, 3$, Gabriela F. Escudero ${ }^{4}$, Juan E. Huamani ${ }^{3}$

1 Maestrando en Estomatología Universidad Nacional Mayor de San Marcos. Av. Carlos Germán Amézaga 375, Ciudad Universitaria, Lima 15081, Perú.

2 Laboratorio Bioquímica. Facultad de Odontología, Universidad Nacional Mayor de San Marcos. Av. Carlos Germán Amézaga 375, Ciudad Universitaria, Lima 15081, Perú

3 Doctorando en Estomatología Universidad Nacional Mayor de San Marcos. Av. Carlos Germán Amézaga 375, Ciudad Universitaria, Lima 15081, Perú

4 Departamento de Endocrinología y Enfermedades Metabólicas del Hospital Nacional PNP Luis N. Sáenz, Lima 15081, Perú.

*jcolchadoc@unmsm.edu.pe

DOI: https://

\section{Resumen}

El síndrome metabólico (SM) aumenta el riesgo de padecer patologías como la diabetes mellitus y la enfermedad cardiovascular. El objetivo fue determinar la asociación entre el síndrome metabólico y la severidad de la periodontitis en adultos. Se realizó un estudio de casos y controles con 80 historias clínicas de pacientes adultos ( 40 con síndrome metabólico y 40 controles sanos) de ambos sexos, atendidos en el servicio de endocrinología y enfermedades metabólicas del HN-PNPLNS, Lima-Perú. Se evaluaron la presencia de indicadores del SM como aumento de: circunferencia abdominal (CA), glicemia en ayunas (GA), presión arterial (PA), triglicéridos (TG) y disminución del HDL colesterol (HDL-C); así como la periodontitis según su severidad, inicial, moderada y severa; la edad y el sexo fueron controlados. Los resultados mostraron que la periodontitis se presentó en el 100\% del grupo con SM y solo en el $50 \%$ del grupo control, el $57,5 \%$ del grupo con SM presentó periodontitis inicial y 3 indicadores (CA,GA,PA), el 25\% presentó periodontitis moderada y 4 indicadores ( $C A, G A, P A, T G$ ), el $17.5 \%$ presentó periodontitis severa y 5 indicadores ( $C A, G A, P A, T G, H D L-C)$, la relación fue altamente 
significativa $(p<0.0001)$ entre periodontitis y SM, así como entre la severidad de la periodontitis y $S M(p<0.0001)$. En conclusión, estos resultados sugieren que existe una relación significativa entre el síndrome metabólico y la periodontitis; y que esta relación es altamente significativa a medida que aumenta la severidad de la periodontitis y al presentarse un mayor número de indicadores del síndrome metabólico.

Palabras clave. Síndrome metabólico, periodontitis, circunferencia abdominal, glicemia en ayunas, presión arterial, triglicéridos, HDL colesterol.

\section{Abstract}

The metabolic syndrome (MS) increases the risk of suffering from diseases such as diabetes mellitus and cardiovascular disease. The objective was to determine the association between the metabolic syndrome and the severity of periodontitis in adults. A case-control study was carried out with 80 medical records of adult patients ( 40 with metabolic syndrome and 40 healthy controls) of both sexes, treated at the endocrinology and metabolic diseases service of the HN-PNPLNS, Lima-Peru. The presence of MS indicators were evaluated such as an increase in abdominal circumference $(A C)$, fasting glycemia $(F G)$, blood pressure $(B P)$, triglycerides (TG) and a decrease in $\mathrm{HDL}$ cholesterol (HDL-C); as well as periodontitis according to its severity, initial, moderate and severe; age and sex were controlled. The results showed that periodontitis occurred in $100 \%$ of the group with MS and only in $50 \%$ of the control group, $57.5 \%$ of the group with MS had initial periodontitis and 3 indicators (CA, FG, BP), the $25 \%$ had moderate periodontitis and 4 indicators (CA, FG, BP, TG), $17.5 \%$ had severe periodontitis and 5 indicators ( $C A, F G, B P, T G, H D L-c)$, the relationship was highly significant $(p<0.0001$ ) between periodontitis and MS, as well as between the severity of periodontitis and MS ( $p<0.0001)$. In conclusion, these results suggest that there is a significant relationship between metabolic syndrome and periodontitis; and that this relationship is highly significant as the severity of periodontitis increases and as a greater number of indicators of metabolic syndrome appear.

Keywords. Metabolic syndrome, periodontitis, abdominal circumference, fasting glycemia, blood pressure, triglycerides, HDL cholesterol. 


\section{Introducción}

El síndrome metabólico es un conjunto de anomalías metabólicas, como la resistencia a la insulina, obesidad, hipertensión arterial y dislipidemia que aumenta el riesgo de padecer patologías como la diabetes mellitus y la enfermedad cardiovascular (1). La prevalencia del síndrome metabólico (SM) a menudo resulta paralela a la diabetes mellitus tipo 2 y la obesidad, se estima en la actualidad que la prevalencia del SM es de aproximadamente la cuarta parte de la población mundial (2). En el Perú el SM tiene una prevalencia aproximada del $16,8 \%$ con un IC $95 \%$ de la población (3). Para establecer el diagnóstico del SM se establecieron ciertos criterios, de los cuales el principal es el aumento de la circunferencia abdominal (2), el cual difiere según el sexo, en hombres es mayor a $90 \mathrm{~cm}$ y en mujeres es mayor a $85 \mathrm{~cm}$, además debe considerarse por lo menos 2 criterios, como el aumento de la glucosa en ayunas, mayor o igual a $100 \mathrm{mg} / \mathrm{dL}$; presión arterial elevada, mayor o igual a $130 \mathrm{~mm} \mathrm{Hg}$ (sistólica) y $85 \mathrm{~mm} \mathrm{Hg}$ (diastólica); aumento de triglicéridos, mayor o igual a $150 \mathrm{mg} / \mathrm{dL}$ y disminución de la lipoproteína de alta densidad que transporta el colesterol conocida como HDL colesterol, teniendo en cuenta que, los valores normales en hombres es menor a $40 \mathrm{mg} / \mathrm{dL}$ y en mujeres es menor a $50 \mathrm{mg} / \mathrm{dL}$ (1).

Por otro lado, la periodontitis es una patología periodontal caracterizada por pérdida de los tejidos de soporte de la pieza dental, asociada a microorganismos y mediada por el huésped; el inicio y la progresión de la periodontitis dependen de los cambios que alteran el microbioma en respuesta a los nutrientes de los productos inflamatorios y de la degradación del tejido gingival que enriquecen algunas especies, así como los diversos mecanismos de defensa del huésped que intentan contener el desafío microbiano dentro del surco gingival una vez que se ha iniciado la inflamación (4).

Según informes dados por el Global Burden of Disease Study en el 2016; la periodontitis fue considerada la undécima patología más prevalente en el mundo; se estima que a nivel mundial su prevalencia oscila entre el $20 \%$ y $50 \%$ (5); en el Perú la prevalencia de la enfermedad periodontal oscila alrededor del $85 \%$ de la población (6).

En una posible relación que pueda existir entre el síndrome metabólico y la periodontitis, se plantea como vinculo, la generación de citocinas y el estrés oxidativo propias del SM lo que pueden en conjunto generar una reducción en la sensibilidad a la insulina, alterando de esta manera la respuesta fisiológica ante una agresión bacteriana, lo cual podría conllevar a una posible periodontitis (7), ante esto, el objetivo de nuestra investigación fue determinar la asociación entre el síndrome metabólico y la severidad de la periodontitis en adultos.

\section{Materiales y métodos}

La investigación fue observacional, retrospectiva, con diseño de casos y controles. La muestra fue calculada por la ecuación estadística para poblaciones finitas y estuvo conformada por 80 historias clínicas de pacientes adultos (40 con diagnóstico de síndrome metabólico y 40 controles sanos), de 35 años a más, de ambos sexos, que fueron atendidos en el Servicio de Endocrinología del Hospital Nacional PNP Luis N. Sáenz (HNPNP-LNS) Lima-Perú, entre los 
meses junio a agosto del 2020; el muestreo fue probabilístico aleatorio simple, con lo cual se garantizó que los integrantes de la población en estudio tengan las probabilidades de formar parte de la muestra. Fueron incluidas en este estudio las historias clínicas de pacientes adultos con el diagnóstico de síndrome metabólico, de ambos sexos, de 35 años a más, que asistieron al servicio de endocrinología del HNPNP-LNS. Fueron excluidas las historias clínicas de pacientes con depresión severa, esquizofrenia, síndrome de Down, autismo, parálisis motora, historias clínicas de pacientes con síndrome metabólico con edentulismo total, con tratamiento previo de antibióticos y AINES en los últimos 3 meses a la evaluación, en estado de gestación, con tratamiento anticonvulsivante con osteoporosis, con enfermedades psiquiátricas, historias clínicas de pacientes con síndrome metabólico que se encuentren con tratamiento de quimio y/o radioterapia, fumadores (7).

La técnica de investigación utilizada en la investigación fue documental, mediante el uso de una ficha de recolección de datos, la cual contó con la validación de tres especialistas, quienes formaron parte del juicio de expertos. Una vez validado el instrumento, realizamos la prueba piloto, con el solo objetivo de evaluar la confiabilidad de este, se llevó a cabo en un número reducido de pacientes, los cuales no formaron parte del estudio en sí. Luego, procedimos a realizar la recolección de datos, es decir, toda la información fue recopilada de las historias clínicas de los pacientes con síndrome metabólico que acudieron a atenderse en el departamento de endocrinología y enfermedades metabólicas del HNPNP-LNS. La técnica investigación documental comprendió las siguientes fases:

1. Planeación. Se recurrió a la base de datos del departamento de endocrinología y enfermedades metabólicas, con la finalidad de determinar el número de historias clínicas de los pacientes que fueron diagnosticados con síndrome metabólico que acudieron entre los meses de junio y agosto del 2020.

2. Recolección de la información. Una vez obtenido el número de historias clínicas se seleccionaron todas aquellas cuyas edades fueran de 35 años a más, además para evitar el sesgo de confusión, se emparejó la muestra por edad y sexo

3. Análisis e interpretación de la información. Se procedió a revisar cada historia clínica con la finalidad de verificar si contenía datos como la edad (adulto medio y adulto mayor), el género, así como los parámetros del síndrome metabólico como circunferencia abdominal, glicemia en ayunas, presión arterial, triglicéridos y HDL colesterol; además de la evaluación periodontal.

4. Redacción y presentación. Para esta parte se utilizó la ficha de recolección de datos en donde se registraron la edad (adulto medio o adulto mayor); sexo (masculino o femenino); síndrome metabólico, en este punto para determinar si el paciente padecía de síndrome metabólico, además del diagnóstico establecido en la historia clínica, debió recopilarse la información sobre el registro de por lo menos 3 indicadores de esta patología, considerando como indicador principal el aumento de la circunferencia abdominal y adicionalmente la presencia de dos o más indicadores en el siguiente orden: aumento de la 
glicemia en ayunas, aumento de la presión arterial, aumento de los triglicéridos y disminución del HDL colesterol (1);en lo referente a la periodontitis se registró el diagnostico establecido en la historia clínica según el nivel de gravedad de la periodontitis es decir inicial, moderada, severa (8).

\section{Análisis estadísticos}

Primero se realizó una tabla individual de las variables; se realizaron los gráficos de cada variable tanto para los pacientes con síndrome metabólico como del grupo control. El análisis del síndrome metabólico fue mediante la presencia de los indicadores del síndrome metabólico (circunferencia abdominal, glicemia en ayunas, presión arterial, triglicéridos, HDL colesterol) en relación a la variable severidad de la periodontitis, para determinar si el paciente padece de síndrome metabólico se consideró la presencia de por lo menos 3 indicadores de este, por lo tanto, se analizaron los indicadores del síndrome metabólico en conjuntos de 3; 4 y 5 . Posteriormente, se analizaron las relaciones entre las variables mediante la prueba del chi cuadrado.

Aspectos éticos de la investigación. La investigación contó con la autorización de la Jefatura del Departamento de Endocrinología y Enfermedades Metabólicas del HNPNP-LNS; además se asumió con responsabilidad el papel individual y académico que significa el estudio como aporte social; la identidad de los participantes en el estudio fue preservadas y únicamente se utilizaron con fines de la investigación, se garantizó la veracidad en todas las etapas en que se encuentra estructurada la investigación.

\section{Resultados}

La muestra estuvo conformada por 80 pacientes ( 40 controles y 40 individuos con síndrome metabólico), de los cuales el 50\% eran mujeres y 50\% eran hombres. La edad media fue de 62,03 \pm 10.627 años, en el grupo control fue de 62,30 $\pm 10,090$ años mientras que en el grupo con síndrome metabólico (SM) fue de $61,75 \pm 11,261$; la edad en los grupos control y SM fue dividida según etapas de la edad adulta en adulto medio y adulto mayor cada con igual número de integrantes (Tabla 1).

Tabla 1. Características de los grupos en estudio

\begin{tabular}{|c|c|c|c|c|}
\hline \multicolumn{5}{|c|}{ Grupo en estudio } \\
\hline Características & & $\begin{array}{l}\text { Control } \\
(n=40)\end{array}$ & $\begin{array}{c}\text { SM } \\
(n=40)\end{array}$ & $\begin{array}{l}\text { Total } \\
(n=80)\end{array}$ \\
\hline Promedio (DS) Edad & & $62,30 \pm 10,09$ & $61,75 \pm 11,26$ & $62,03 \pm 10,62$ \\
\hline Escala & A. medio, n(\%) & $20(50 \%)$ & $20(50 \%)$ & $40(50 \%)$ \\
\hline de edad & A. mayor, n (\%) & $20(50 \%)$ & $20(50 \%)$ & $40(50 \%)$ \\
\hline \multirow[t]{2}{*}{ Sexo } & Masculino, $\mathrm{n}(\%)$ & $20(50 \%)$ & $20(50 \%)$ & $40(50 \%)$ \\
\hline & Femenino, $\mathrm{n}(\%)$ & $20(50 \%)$ & $20(50 \%)$ & $40(50 \%)$ \\
\hline
\end{tabular}

DS: desviación estándar 
El 57,5\% de los pacientes con SM presentó 3 indicadores del SM, es decir aumento de: circunferencia abdominal (CA), glicemia en ayunas (GA) y presión arterial (PA), el 25\% presentó 4 indicadores del SM, aumento de: CA, GA, PA y triglicéridos (TG), mientras que el $17.5 \%$ presentó 5 indicadores del SM, aumento de: CA, GA, PA, TG y disminución de HDL colesterol (HDL-c); ningún participante del grupo control presentó indicadores del SM (Tabla 2 y Figura 1).

Tabla 2. Número de indicadores del SM según grupos

\begin{tabular}{|c|c|c|c|}
\hline \multicolumn{4}{|c|}{ Indicadores del SM } \\
\hline Grupo & & $\mathrm{n}$ & $\%$ \\
\hline \multirow[t]{2}{*}{ Control } & Ningún indicador & 40 & 100,0 \\
\hline & $\begin{array}{l}3 \text { indicador SM: } \\
\text { aumento de CA, GA, PA }\end{array}$ & 23 & 57,5 \\
\hline \multirow{4}{*}{$\begin{array}{l}\text { Síndrome } \\
\text { Metabólico }\end{array}$} & 4 indicadores SM: & 10 & 250 \\
\hline & aumento de CA, GA, PA,TG & & \\
\hline & $\begin{array}{l}5 \text { indicadores SM } \\
\text { aumento de CA, GA, PA,TG y disminu- } \\
\text { ción HDL-C }\end{array}$ & 7 & 17,5 \\
\hline & Total & 40 & 100,0 \\
\hline
\end{tabular}

El 100\% de los pacientes con SM presentó periodontitis mientras en comparación con el grupo control, donde solo el $50 \%$ presentó la patología local (Tabla 3).

Tabla 3. Periodontitis en grupos control y SM

\begin{tabular}{llll}
\hline \multirow{2}{*}{ Grupo } & \multicolumn{2}{c}{ Periodontitis } & \\
\hline \multirow{3}{*}{ Control } & No presenta & $\mathrm{n}$ & $\%$ \\
\hline \multirow{2}{*}{ Síndrome Metabólico } & 20 & 50,0 \\
& Presenta & 20 & 50,0 \\
& Total & 40 & 100,0 \\
& Presenta & 40 & 100,0 \\
\hline \multicolumn{5}{l}{} \\
& $\mathrm{n}=$ frecuencia, \%=porcentaje &
\end{tabular}

El $57,5 \%$ de los pacientes con SM presentaron periodontitis inicial, el $25 \%$ periodontitis moderada y sólo el 17,5\% periodontitis severa, en comparación con el grupo control en donde el 50\% no presentó periodontitis, el $32,5 \%$ presentó periodontitis inicial, el $12,5 \%$ periodontitis severa y solo $5 \%$ periodontitis moderada (Tabla 4 y Figura 2 ). 
Tabla 4. Periodontitis según severidad en grupos control y SM

\begin{tabular}{llll}
\hline \multirow{2}{*}{ Grupo } & \multicolumn{2}{c}{ Severidad de la Periodontitis } & \\
\hline Control & & $\mathrm{n}$ & $\%$ \\
& No presentó & 20 & 50,0 \\
& Periodontitis inicial & 13 & 32,5 \\
& Periodontitis moderada & 2 & 5,0 \\
& Periodontitis severa & 5 & 12,5 \\
& Total & 40 & 100,0 \\
Síndrome Metabólico & Periodontitis inicial & 23 & 57,5 \\
& Periodontitis moderada & 10 & 25,0 \\
& Periodontitis severa & 7 & 17,5 \\
& Total & 40 & 100,0 \\
\hline
\end{tabular}

$n=$ frecuencia , \%=porcentaje

El $57,5 \%$ de los pacientes con SM presentó 3 indicadores del SM y periodontitis inicial, el $25 \%$ presentó 4 indicadores de SM y periodontitis moderada y el 17,5\% presentó los 5 indicadores de SM y periodontitis severa (Tabla 5 y Figura 3).

Tabla 5. Indicadores del SM según severidad de la periodontitis en grupos control y SM

\section{Severidad de la Periodontitis}

\begin{tabular}{llcccccc} 
Grupo & & & No presenta & P. inicial & P. moderada & $\begin{array}{c}\text { P. } \\
\text { severa }\end{array}$ & TOTAL \\
\hline Control & Ningún & $\mathrm{n}$ & 20 & 13 & 2 & 5 & 40 \\
& indicador & $\%$ & 50 & 32,5 & 5 & 12,5 & 100 \\
& Total & $\mathrm{n}$ & 20 & 13 & 2 & 5 & 40 \\
& & $\%$ & 50 & 32,5 & 5 & 12,5 & 100 \\
Síndrome & 3 indicadores & $\mathrm{n}$ & 0 & 23 & 0 & 0 & 23 \\
Metabólico & SM & $\%$ & 0 & 57,5 & 0 & 0 & 57,5 \\
& 4 indicadores & $\mathrm{n}$ & 0 & 0 & 10 & 0 & 10 \\
& SM & $\%$ & 0 & 0 & 25 & 0 & 25 \\
& 5 indicadores & $\mathrm{n}$ & 0 & 0 & 0 & 7 & 7 \\
& SM & $\%$ & 0 & 0 & 0 & 17,5 & 17,5 \\
& Total & $\mathrm{n}$ & 0 & 0 & 10 & 7 & 40 \\
& & $\%$ & 0 & 0 & 25 & 17,5 & 100 \\
\hline
\end{tabular}

$n=$ frecuencia,$\%=$ porcentaje 

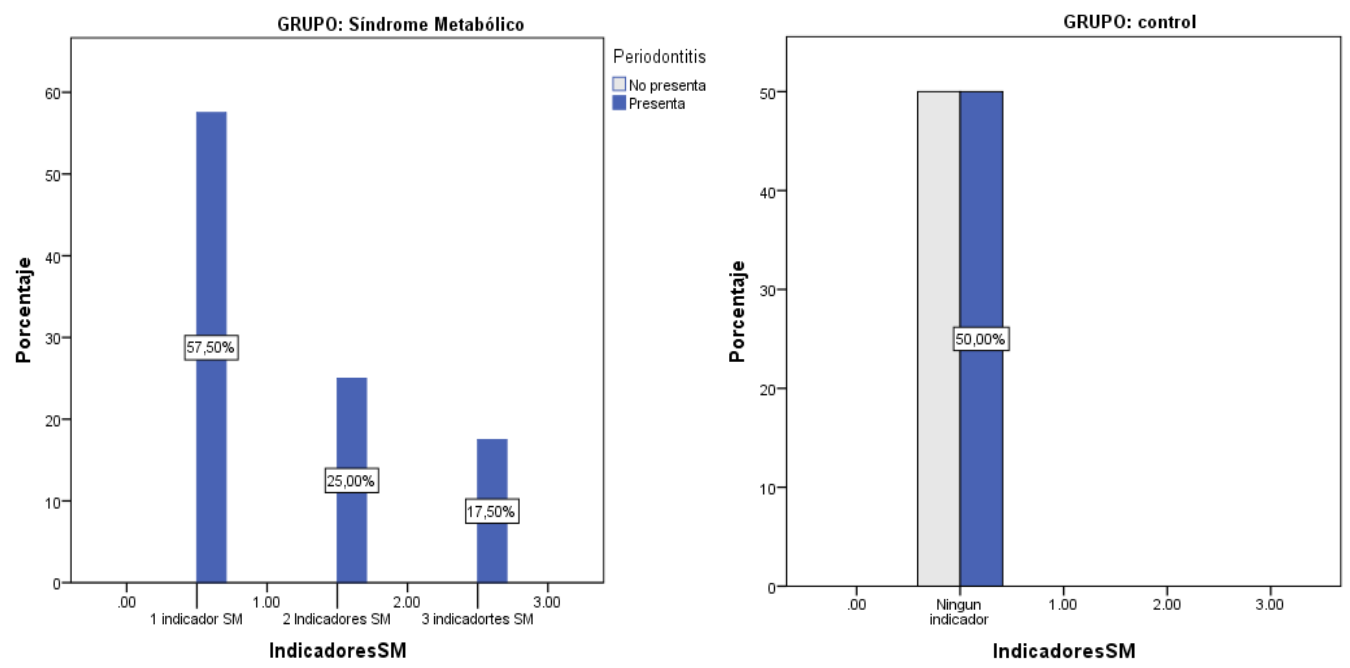

Figura 1. Número de indicadores del SM según grupos
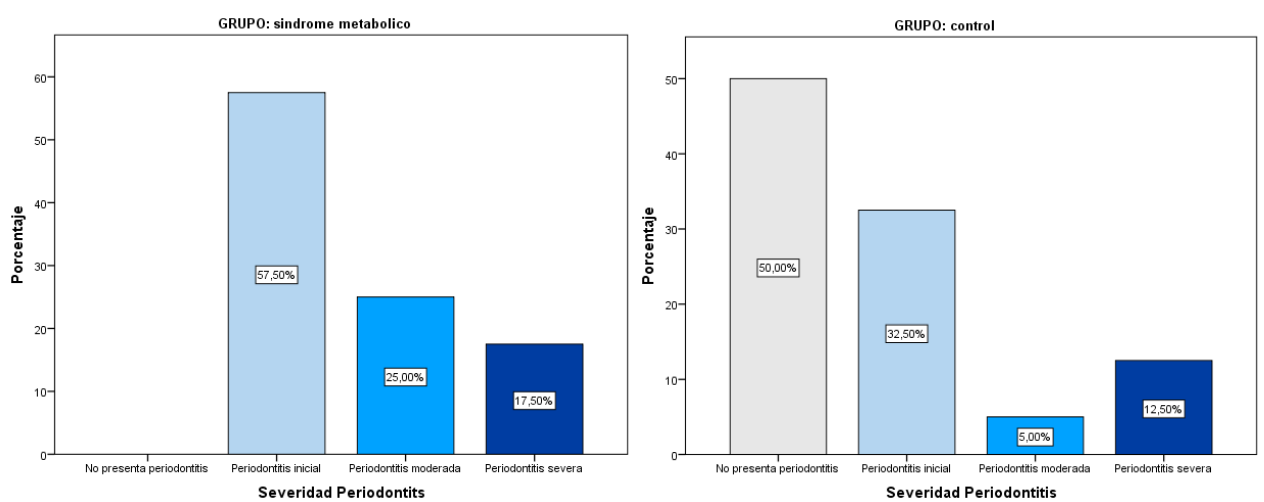

Figura 2. Severidad de la periodontitis según grupos
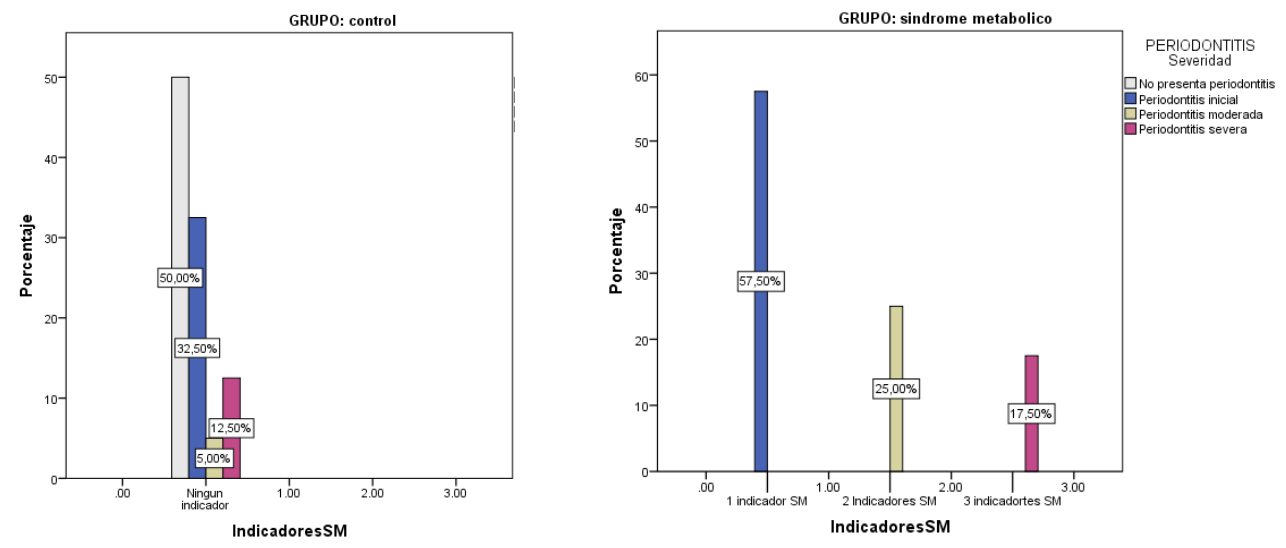

Figura 3. Indicadores del SM según severidad de la periodontitis en grupos control y SM 
La relación entre la periodontitis y el síndrome metabólico fue altamente significativa, $p$-valor $=0,000001$ (Tabla 6), asimismo la relación entre la severidad de la periodontitis y el síndrome metabólico fue altamente significativa, p-valor=0,000001 (Tabla 7).

Tabla 6. Relación Periodontitis y Síndrome Metabólico

\begin{tabular}{|c|c|c|c|c|c|}
\hline \multicolumn{6}{|c|}{ Pruebas de chi-cuadrado } \\
\hline & Valor & $\mathrm{gl}$ & $\begin{array}{l}\text { Significación } \\
\text { asintótica (bilateral) }\end{array}$ & $\begin{array}{c}\text { Significación } \\
\text { exacta (bilateral) }\end{array}$ & $\begin{array}{c}\text { Significación } \\
\text { exacta (unilateral) }\end{array}$ \\
\hline Chi-cuadrado de Pearson & $26,667^{a}$ & 1 & 0,000 & & \\
\hline Corrección de continuidad & 24,067 & 1 & 0,000 & & \\
\hline Razón de verosimilitud & 34,522 & 1 & 0,000 & & \\
\hline Prueba exacta de Fisher & & & & 0,000 & 0,000 \\
\hline N de casos válidos & 80 & & & & \\
\hline
\end{tabular}

a. 0 casillas $(.0 \%)$ han esperado un recuento menor que 5 . El recuento mínimo esperado es 10.00 . b. Sólo se ha calculado para una tabla $2 \times 2$

Tabla 7. Relación Severidad de la periodontitis y síndrome metabólico

\begin{tabular}{lccc}
\hline & \multicolumn{2}{c}{ Pruebas de chi-cuadrado } & \\
& Valor & gl & $\begin{array}{c}\text { Significación asintótica } \\
\text { (bilateral) }\end{array}$ \\
\hline Chi-cuadrado de Pearson & $28,444^{\mathrm{a}}$ & 3 & 0,000 \\
Razón de verosimilitud & 36,697 & 3 & 0,000 \\
$\mathrm{~N}$ de casos válidos & 80 & & \\
& & & \\
\hline
\end{tabular}

a. 0 casillas $(.0 \%)$ han esperado un recuento menor que 5 . El recuento mínimo esperado es 6.00 . 


\section{Discusión}

El síndrome metabólico es un conjunto de afecciones que aumentan el riesgo de enfermedad cardiovascular y diabetes mellitus como lo indica Daudt et al. (9). Es una combinación de trastornos que incluyen resistencia a la insulina, hipertensión arterial, intolerancia a la glucosa y dislipidemia, lo cual aumenta el riesgo de desarrollar a futuro enfermedades cardiovasculares y diabetes mellitus tipo 2, como lo refiere Rochlani et al. (1). Por otro lado, la periodontitis es el resultado de una respuesta exacerbada de microorganismos agresores a nivel del periodonto que puede provocar la destrucción del aparato del sostén de la pieza dentaria, como lo sostienen las investigaciones de Tonetti et al. (4).

El objetivo principal de nuestra investigación fue determinar la relación entre el síndrome metabólico y la severidad de la periodontitis, los resultados hallados indican que existe una relación muy significativa $(p<0,001)$ entre ambas variables en estudio (Tabla 6 ), lo cual corroboran los hallazgos encontrados en otras investigaciones que respaldan la asociación entre el síndrome metabólico y la gravedad de la periodontitis, Gomes-Filho et al. indican que la periodontitis está asociada con el síndrome metabólico y que la prevalencia de esta patología está relacionada con la severidad de la periodontitis (10); además Gobin et al., sostiene que aquellos pacientes que presentan enfermedad periodontal, conforman una población de riesgo para la detección del síndrome metabólico (11), de la misma manera los resultados hallados por Khader et al. indican que, la severidad de la enfermedad periodontal se incrementa en forma gradual de acuerdo al tiempo que presentan el síndrome metabólico en comparación con aquellas pacientes que no lo padecen (12); sin embargo, es necesario precisar, que toda respuesta inflamatoria del periodonto puede conducir a una inflamación sistémica producto de la bacteriemia generada por microorganismo periodonto-patógenos, como lo sostienen los estudios de Van Dick et al. (13), además, es preciso considerar que lo hallado en la investigación, aumenta con la resistencia a la insulina, característica en pacientes con síndrome metabólico, como lo indican Preshaw et al., en donde la hiperglicemia deteriora la respuesta inflamatoria del paciente al generar productos provenientes de la reacción de la glucosa con los lípidos o proteínas, conocidos como productos de glicación avanzada, en diversos tejidos como el periodonto, lo cual estimula a su vez la producción de citocinas proinflamatorias (14); este aumento en la glicemia tiende a generar deficiencias inmunológicas por una disminuida y/o alterada fagocitosis leucocitaria, según la investigación de Colchado J. (15); del mismo modo las investigaciones de Bullon et al., fundamentan la relación entre SM y la periodontitis, como etapas que concuerdan en brindar una respuesta la que conduce a un aumento de neutrófilos en el huésped, pero que se ven afectados por el estrés oxidativo, el cual es un vínculo hallado entre el síndrome metabólico y los pacientes con enfermedad periodontal, dañando de esta forma varios mecanismos biológicos de defensa (16). Sin embargo, nuestros hallazgos, no coinciden con los resultados de Thanakun et al. (17), en donde no hallaron algún riesgo significativo, cuando cada indicador del síndrome metabólico fue relacionado por separado con la periodontitis, excepto al relacionarlos con la presión arterial elevada, esta discordancia se puede deber a que evaluaron en conjunto a pacientes con síndrome metabólico que tenían hábitos de fumar, lo que podría afectar la evolución de la severidad de la enfermedad periodontal, como lo indican las pesquisas realizadas por Zuk et al. (18). 
En lo que respecta a la asociación entre el síndrome metabólico y con la presencia de periodontitis, así como de la asociación entre el síndrome metabólico y la severidad de la periodontitis, en ambas asociaciones los resultados evidenciaron una relación altamente significativa $(p<0.001)$ entre las variables en estudio (Tabla 7); nuestros resultados son similares a los hallados por D'Aiuto et al., en donde el diagnostico de síndrome metabólico aumentó 1,12 veces por aumento del $10 \%$ en el sangrado gingival y 1,13 veces por el aumento del $10 \%$ en la proporción de bolsas periodontales (19); además los estudios de Nesbitt et al., evidenciaron que todo paciente que presente una periodontitis de moderada a severa tenía más probabilidades de padecer de síndrome metabólico (20), esta asociación se fundamenta porque los microrganismos etiopatogénicos de la periodontitis pueden predisponer numerosos procesos inmunes e inflamatorios que exacerban los cuadros del síndrome metabólico como lo refiere Han et al.,(21); además los estudios realizados por Kaye et al., asociaban la gravedad de la periodontitis con la pérdida del nivel de inserción clínica y la movilidad dental en pacientes con síndrome metabólico (22); D’Aiuto por su lado, concuerda con lo establecido, al indicar que la prevalencia del síndrome metabólico aumenta a medida que aumenta la gravedad de la periodontitis (19), es decir, que esta patología sistémica se relaciona con la presencia de una periodontitis más extensa y severa, como el estudio realizado por Alhabashneh et al. (23); de forma similar los resultados obtenidos por Li et al., indicaban que, la severidad en la periodontitis que presentaban los pacientes con síndrome metabólico estaba relacionada con la pérdida de hueso alveolar (24); sin embargo Genco et al., sostenían que, la reabsorción ósea se veía incrementada en la infección periodontal por la presencia de hormonas y citosinas pro inflamatorias generadas por el exceso de triglicéridos y colesterol de baja densidad que se acumulan a nivel arterial, alterando la circulación sistémica y local (25). Es preciso recalcar que los resultados hallados en el estudio se ven respaldados por la evidencia científica que considera que la periodontitis es una afección crónica caracterizada por etapas de exacerbación y latencia, además de tener un vínculo muy fuerte con implicancia sistémica, como lo refiere Tonetti et al. y Fenesy K. $(4,26)$, todo esto promovido por la actividad de diversas especies bacterianas que generan una respuesta inflamatoria e inmune con liberación de IL-1 $\beta$ y el factor de necrosis tumoral $\alpha$, esta última, una interleucina relacionada con la resistencia a la insulina, que se encuentra incrementada en pacientes que padecen de obesidad, diabetes y síndrome metabólico (27). Es necesario indicar que, los indicadores del síndrome metabólico que evaluamos como la hiperglicemia, dislipidemia, obesidad visceral e hipertensión arterial, mantuvieron una asociación producto del resultado de una fuerte respuesta inflamatoria, como lo refieren los estudios de Gay et al. (28), por otro lado, una de las características sistémicas de este tipo de pacientes es la deficiente o reducida absorción de la glicemia, la alta concentración de ácidos grasos libre, así como la interferencia de los efectos antinflamatorios generados por la insulina (29).

Por lo tanto, de acuerdo con los resultados podemos afirmar que aparentemente existe una asociación significativa entre el síndrome metabólico y la severidad de la periodontitis; y que esta asociación es altamente significativa a medida que aumenta la severidad de la periodontitis y al presentarse un mayor número de indicadores del síndrome metabólico. Es preciso aclarar que, la identificación de las relaciones de causa-efecto requeriría de un estudio longitudinal, por lo cual esta sería considerada una limitación de la presente investigación. Sin embargo, debido a las 
limitaciones sanitarias por motivo de la pandemia del COVID-19, en cuanto en la evaluación clínica de pacientes, la elección de realizar un estudio retrospectivo mediante técnica documental parece estar justificada y apropiada a la luz de los resultados obtenidos.

Se necesitan un mayor número de investigaciones para poder establecer una visión integral en cuanto a la asociación causa efecto entre el síndrome metabólico y la periodontitis, teniendo en cuenta la importancia de ambas patologías como problemas de salud pública a resolver para beneficio de la población.

\section{Referencias Bibliograficas:}

1. Rochlani Y, Venkata N, Kovelamundi S MJ. Metabolic syndrome: pathophysiology, mana gement, and modulation by natural compounds. Ther Adv Vaccines. 2017;11(8):215-25.

2. Saklayen M. The global epidemic of the metabolic syndrome. Curr Hypertens Rep. 2018;20(12):1-8.

3. Arbañil Hugo. Síndrome metabólico - Definición y prevalencia. Rev Peru Ginecol Obstet. 2011;57(4):233-6.

4. Tonetti MS, Greenwell H, Kornman KS. Staging and grading of periodontitis: Framework and proposal of a new classification and case definition. J Periodontol. 2018;89.

5. James SL, Abate D, Abate KH, Abay SM, Abbafati C, Abbasi N, et al. Global, regional, and national incidence, prevalence, and years lived with disability for 354 Diseases and Injuries for 195 countries and territories, 1990-2017: A systematic analysis for the Global Burden of Disease Study 2017. Lancet. 2018;392(10159):1789-858.

6. Girano J, Robello J. Relación entre obesidad y enfermedad periodontal: revisión de la literatura. Horiz Médico. 2020;20(3):e1081.

7. Lamster IB, Pagan M. Periodontal disease and the metabolic syndrome. Int Dent J. 2017;67(2):67-77.

8. Caton J, Armitage G, Berglundh T, Chapple ILC, Jepsen S, S. Kornman K, et al. A new classification scheme for periodontal and peri-implant diseases and conditions - Intro duction and key changes from the 1999 classification. J Clin Periodontol. 2018;45(Mar ch):S1-8.

9. Daudt L, Musskopf M, Méndez M, Remonti L, Leitão C, Gross J. et al. Association between metabolic syndrome and periodontitis: a systematic review and meta-analysis.Braz Oral Res. 2018; 32: e35.

10. Gomes-Filho I, das Mercês M, de Santana Passos-Soares J. Severity of Periodontitis and Metabolic Syndrome: Is There an Association? J Periodontol. 2016; 87(4): 357-366.

11. Gobin R, Tian D, Liu Q, Wang J. Periodontal Diseases and the Risk of Metabolic Syndrome: An Updated Systematic Review and Meta-Analysis. Front Endocrinol. 2020; 11:336.

12. Khader $Y$, Khassawneh B, Obeidat B. Periodontal status of patients with metabolic syndrome compared to those without metabolic syndrome. J Periodontol. 2008; 79:20482053. 
13. Van Dyke T, Van Winkelhoff A. Infection and inflammatory mechanisms. J Clin Periodontol. 2013; 40(14): 1-7.

14. Preshaw P, Alba A, Herrera D, Jepsen S, Konstantinidis A, Makrilakis K. Periodontitis and diabetes: a two-way relationship. Diabetología. 2012; 55 (1): 21-3.

15. Colchado Jorge R. Alteraciones en la fagocitosis de los leucocitos creviculares de pacientes diabéticos con enfermedad periodontal. Odontol Sanmarquina. 2008;11(1):14-8.

16. Bullon P, Morillo J, Ramirez-Tortosa M. Metabolic syndrome and periodontitis: is oxidative stress a common link? J Dent Res. 2009; 88:503-518.

17. Thanakun $\mathrm{S}$, Watanabe $\mathrm{H}$, Thaweboon $\mathrm{S}$, Izumi Y. Association of untreated metabolic syndrome with moderate to severe periodontitis in Thai population. J Periodontol. 2014; 85:1502-1514.

18. Zuk A, Quiñonez C, Lebenbaum M. The association between undiagnosed glycemic abnormalities and cardiometabolic risk factors with periodontitis: results from 2007-2009 canadian health measures survey. J Clin Periodontol. 2017; 44:132-141

19. D'Aiuto F, Sabbah W, Netuveli G. Association of the metabolic syndrome with severe periodontitis in a large U.S. populationbased survey. J Clin Endocrinol Metab. 2008; 93:3989-3994.

20. Nesbitt M, Reynolds MA, Shiau H, Choe K, Simonsick EM, Ferrucci L. Association of periodontitis and metabolic syndrome in the Baltimore Longitudinal Study of Aging. Aging Clin Exp Res. 2010; 22:238-242.

21. Han D, Shin H, Kim M. Group of serum inflammatory markers and periodontitis-metabolic syndrome coexistence in Koreans. J Periodontol. 2012; 83:612-620.

22. Kaye E, Chen N, Cabral H, Vokonas P, Garcia R. Metabolic Syndrome and Periodontal Disease Progression in Men. J Dent Res. 2016; 95(7): 822-828.

23. Alhabashneh $R$, Khader $Y$, Herra $Z$, et al. The association between periodontal disease and metabolic syndrome among outpatients with diabetes in Jordan. J Diabetes Metab Disord. 2015; 14:67

24. Li Y, Lu Z, Zhang X. Metabolic syndrome exacerbates inflammation and bone loss in periodontitis. J Dent Res. 2015; 94:362-370

25. Genco R, Grossi S, Ho A, Nishimura F, Murayama Y. A proposed model linking inflammation to obesity, diabetes, and periodontal infections. J Periodontol. 2005; 76(11): 2075-2084.

26. Fenesy K. Periodontal diseases: An overview for physicians. Mt Sinai J Med. 1998; 65:362-9.

27. Mohammadi M, Gozashti MH, Aghadavood M, Mehdizadeh MR, Hayatbakhsh MM. Clinical Significance of Serum IL-6 and TNF- $\alpha$ Levels in Patients with Metabolic Syndrome. Rep Biochem Mol Biol. 2017;6(1):74-79.

28. Gay I, Tran D, Cavender A, Weltman R, Chang J, Luckenbach E, et al. The effect of periodontal therapy on glycemic control in a hispanic population with type 2 diabetes: $A$ randomized controlled trial. J Clin Periodontol. 2014; 41:673-80. 
29. Gallagher $E$, Leroith D, Karnieli E. The metabolic syndrome-from insulin resistance to obesity and diabetes. Med Clin North Am. 2011; 95(5):855- 873 


\title{
Ansiedad al tratamiento odontológico en adultos mayores a 65 años, de la parroquia Cañaribamba, Cuenca-Ecuador, 2017-2018
}

\section{Dental treatment anxiety in adults over 65 years of age, from Cañaribamba parish, Cuenca-Ecuador, 2017-2018.}

\author{
Alejandra Naranjo", Santiago Vintimilla², Patricia Pinos². \\ 1 Estudiante de Odontología en la Universidad Católica de Cuenca. \\ 2 Docente de Odontología en la Universidad Católica de Cuenca. \\ *mayale93@hotmail.es
}

DOI: https://

\section{Resumen}

Objetivo: Determinar la prevalencia de ansiedad al tratamiento odontológico en adultos mayores a 65 años, de la parroquia Cañaribamba, Cuenca-Ecuador, agosto 2017- abril 2018. Materiales y Métodos: Se realizó un estudio de enfoque cuantitativo y descriptivo, de campo, comunicacional y retrospectivo. Se evaluó a 320 personas mayores a 65 años (114 mujeres y 206 hombres), las mismas que llenaron el test de auto reporte escala de ansiedad dental versión corta. Las encuestas se realizaron de manera aleatoria a los habitantes de la parroquia de Cañaribamba. Resultados: Se determinó una prevalencia de ansiedad al tratamiento odontológico con un 58\%. El nivel de ansiedad leve fue el que mayor predominio tuvo en la población $(27,19 \%)$, seguido por la ansiedad moderada $(15,31 \%)$. El nivel de ansiedad predominante en la mujeres fue el leve con un $35,96 \%$, al igual que en los hombres con el $22,33 \%$. Existe una relación estadísticamente significativa $(a \quad p<0,05)$ entre el género y el nivel de ansiedad dental $\left(X^{2} p=0,0068\right)$. Las principales causas que provocaron ansiedad en los adultos mayores fueron en el momento en que el odontólogo alista el carpule con anestesia $(19,28 \%)$, pensar que 
el odontólogo va a utilizar la turbina en su boca $(16,05 \%$ ), y pensar que el odontólogo le va a extraer el diente (15,70\%). Conclusión: Se concluyó que existe un alto porcentaje de ansiedad al tratamiento odontológico en los adultos mayores a 65 años (58\%), respecto a estudios realizados en países más desarrollados ( $4 \%$ a $36 \%$ ).

Palabras clave: Prevalencia, ansiedad, causas, tratamiento.

\section{Abstract}

Objective: To determine the prevalence of anxiety in dental treatment in adults over 65 years of age, from the Cañaribamba Parish, Cuenca - Ecuador, August 2017-April 2018. Materials and Methods: Quantitative and descriptive approach, field study, communicational and retrospective. A total of 320 people over 65 years of age were evaluated (114 women and 206 men), who completed the self-report SDAI (dental anxiety scale short version). The surveys were carried out in a random way to the inhabitants of the parish of Cañaribamba. Results: A prevalence of anxiety in dental treatment was determined with $58 \%$. The level of anxiety was higher in the population $(27,19 \%)$, followed by moderate anxiety $(15,31 \%)$. The predominant level of anxiety in women was $35,93 \%$, as in men with $22,33 \%$. There is a statistically significant relationship $(\alpha<0.05)$ between the gender and the level of dental anxiety $(X 2=0,0068)$. The main factors that caused anxiety in the elderly were at the time when the dentist enrolled the carpule with anesthesia $(19,28 \%)$, see that the dentist will use the turbine in his mouth $(16,05 \%)$, and think that the dentist is going to extract the tooth $(15,70 \%)$. Conclusion: It concluded that there is a high percentage of anxiety in dental treatment in adults over 65 years (58\%), compared to studies conducted in more up to date countries ( $4 \%$ to $36 \%$ ).

Keywords: Prevalence, anxiety, causes, treatment. 


\section{Introducción}

En la actualidad las enfermedades bucodentales son un problema de salud pública, debido a su elevada prevalencia y el costo que implica recurrir a una atención odontológica. ${ }^{1-3}$ Los fac- $^{-}$ tores que influyen en los pacientes durante el tratamiento odontológico es la preocupación de sentir dolor, ser herido, atorarse 0 ahogarse, incluso las experiencias traumáticas que pudo haber tenido en la niñez, inducen a los pacientes a postergar sus citas interrumpiendo el tratamiento, o por último a la anulación. ${ }^{8-10}$ Estos comportamientos negativos son las señales de un paciente temeroso ${ }^{8}$, es importante considerar a tiempo el nivel de ansiedad que adquirió el paciente de manera que si no se trata este fenómeno a tiempo, corren el riesgo de tener problemas de salud oral, ${ }^{8-10,17,19}$ como la caries y la enfermedad periodontal, teniendo como consecuencias físicas, económicas, sociales y psicológicas, interfiriendo en la calidad de vida de los pacientes debido a la inasistencia a sus citas, y su retraso a la eficacia del tratamien-

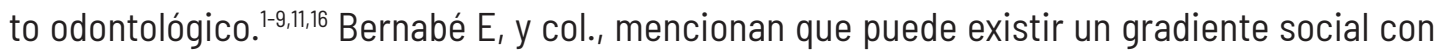
aquellos de grupos socioeconómicos más bajos que experimentan más ansiedad dental y por lo tanto más caries dental. ${ }^{1-}$

Luego de identificar a un paciente ansioso o temeroso, puede ponerse en funcionamiento una serie de medidas, para que pueda ser atendido en el área odontológica, el odontólogo deberá empezar por tratamientos simples como una profilaxis o limpieza dental, utilizando técnicas de relajación, respiración, y distracción, de manera que el miedo comience a desaparecer., 816,23

Existen pocos estudios de la situación actual de salud oral en nuestra sociedad, motivo por el cual fue necesario hacer un estudio descriptivo epidemiológico, con el propósito de saber la magnitud del problema de ansiedad frente al tratamiento odontológico en la parroquia Cañaribamba de la ciudad de Cuenca.

Con la elaboración de este estudio se determinó cuál es la prevalencia de ansiedad frente al tratamiento odontológico en adultos mayores a 65 años. Se utilizó la escala de ansiedad dental versión corta (SDAI de Stouthard), una escala de 9 ítems con respuestas dicotómicas (SI-NO), que clasifica la ansiedad de los participantes ante la perspectiva de una visita al dentista, cuando los pacientes están en la sala de espera, pensar que el odontólogo va a utilizar la turbina en su boca, en el momento en que el odontólogo alista el carpule con anestesia. Las respuestas variaron de no ansiosas (0) a extremadamente ansiosas ( $>0)$.

El presente tema de investigación surgió a partir de la continua búsqueda de información de la línea basal planteado por el departamento de investigación de la carrera de Odontología de la Universidad Católica de Cuenca, para poder establecer técnicas que nos ayuden a disminuir la ansiedad de los pacientes en nuestro medio, promoviendo atención primaria en salud oral, y de esta manera evitar complicaciones futuras de salud oral. 


\section{Materiales y métodos}

Es un estudio de enfoque cuantitativo y descriptivo, de campo, comunicacional, participativo y retrospectivo. Que permitió obtener importante información sobre aspectos relacionados con la ansiedad frente al tratamiento odontológico. ${ }^{31}$

La investigación se realizó entre los meses agosto 2017- abril 2018, recolectando datos de encuestas que reflejaron el nivel de ansiedad y las causas más relevantes frente al tratamiento odontológico en la población de adultos mayores de 65 años, que tengan la voluntad de autorizar su entrevista previa al consentimiento informado.

Una vez terminadas las encuestas los datos fueron ingresados a una base de datos llamado programa EPI INFO, los mismos que fueron utilizados para analizarlos a través del programa Excel Microsoft Office.

La población de estudio fue de "320" fichas epidemiológicas realizadas a (114 mujeres y 206 hombres) de la parroquia Cañaribamba, que corresponde al total de fichas registradas en el estudio epidemiológico de salud bucal para esta parroquia.

La investigación de ansiedad al tratamiento odontológico busco describir cualitativamente el problema en adultos mayores de 65 años de edad, utilizando las fichas obtenidas por encuestas realizadas por estudiantes de la Universidad Católica de Cuenca en el periodo agosto 2017- abril 2018.

Los Criterios de evaluación de ansiedad se basaron en la puntuación de respuesta.

Las condiciones que se tomaron en cuenta a la hora del registro de los datos recolectados fueron:

- Puede indicar una respuesta por ítem.

- Se sumarán los puntajes de la escala de ansiedad al tratamiento odontológico.

- El rango de puntaje irá de 0 a 1 .

- Donde $>0$ es igual a ansiedad y 0 es igual a sin ansiedad.

El puntaje mayor estará asociado con niveles altos de ansiedad al tratamiento odontológico.

Para tener el valor de ansiedad se tomó en cuenta en las preguntas donde (SI) es igual a (1), Y (NO) es igual a (0).

Se realizó un análisis descriptivo de las variables, en la primera variable se determinará la prevalencia de ansiedad, en cuanto al segunda variable que es la población del estudio, se analizara con Chi cuadrado $X^{2}$ la asociación entre género y el nivel de ansiedad. 


\section{Resultados}

El presente estudio fue realizado con los datos epidemiológicos de fichas de recolección de información digital que constan en el archivo del departamento de investigación de la Unidad de Salud y Bienestar Carrera de Odontología de la Universidad Católica de Cuenca. Datos de encuestas que reflejaron el nivel de ansiedad y las causas más relevantes frente al tratamiento odontológico en población de adultos mayores a 65 años, mostrando los siguientes resultados:

\begin{tabular}{lll}
\hline Ansiedad & $\mathbf{n}$ & $\%$ \\
\hline SI & 185 & 58 \\
No & 135 & 42 \\
Total general & 320 & 100 \\
\hline
\end{tabular}

Tabla №1. Distribución de la muestra de acuerdo a la prevalencia de ansiedad frente al tratamiento odontológico en adultos mayores a 65 años de la parroquia Cañaribamba agosto 2017- abril 2018.

Se evidencia la prevalencia del tamaño de muestra. Observamos que de los 320 adultos mayores a 65 años encuestados, 185 presentan ansiedad y 135 de ellos sin ansiedad.

\begin{tabular}{lll}
\hline $\begin{array}{l}\text { Niveles de } \\
\text { Ansiedad }\end{array}$ & $\mathbf{n}$ & $\%$ \\
\hline Severa & 49 & 15.31 \\
Moderna & 49 & 15.31 \\
Leve & 87 & 27.19 \\
No tiene ansiedad & 135 & 42.19 \\
Total general & $\mathbf{3 2 0}$ & $\mathbf{1 0 0}$ \\
\hline
\end{tabular}

Tabla № 2. Niveles de ansiedad en adultos mayores a 65 años frente al tratamiento odontológico.

En este gráfico se puede observar que existe ansiedad ante el tratamiento odontológico, predominando un nivel de ansiedad leve con $27 \%$, seguida del nivel moderada con $15 \%$ y un $15 \%$ presenta ansiedad severa al dentista o tratamientos dentales, y gran parte de los pacientes no lo padecen,representando un $42 \%$ sin ansiedad de la parroquia Cañaribamba.

\begin{tabular}{cccccc}
\hline Niveles de Ansiedad & \multicolumn{2}{c}{ Femenino } & \multicolumn{2}{c}{ Masculino } & Total general \\
\hline Severa & 22 & 19,30 & 27 & 13,11 & 49 \\
Moderna & 12 & 10,53 & 37 & 17.96 & 49 \\
Leve & 41 & 35,96 & 46 & 22,33 & 87 \\
No tiene ansiedad & 39 & 34,21 & 96 & 46,60 & 135 \\
Total general & $\mathbf{1 1 4}$ & $\mathbf{1 0 0 . 0 0}$ & $\mathbf{2 0 6}$ & $\mathbf{1 0 0 . 0 0}$ & $\mathbf{3 2 0}$ \\
\hline
\end{tabular}

Tabla № 3. Distribución de la muestra según el género y el nivel de ansiedad dental durante la atención odontológica. 
Se puede evidenciar que predomina el género masculino con un $46 \%$ que no experimenta ansiedad, en relación con el género femenino con un $34 \%$ no tiene ansiedad durante la atención odontológica.

Existe un mayor indice de personas del género femenino con un nivel de ansiedad leve. El Chi 2 indico que hay relación estadísticamente significativa entre el género y el nivel de ansiedad dental.

\begin{tabular}{|c|c|c|}
\hline № & CAUSAS & $\%$ \\
\hline 1 & $\begin{array}{l}\text { En el momento en que el } \\
\text { odontólogo alista la jeringa con } \\
\text { inyección de anestesia Pensar } \\
\text { que el odontólogo va }\end{array}$ & 19.28 \\
\hline 2 & $\begin{array}{l}\text { a utilizar el taladro en su } \\
\text { boca }\end{array}$ & 16.05 \\
\hline 3 & $\begin{array}{l}\text { Pensar que el odontólogo le } \\
\text { va a extraer el diente }\end{array}$ & 15.70 \\
\hline 4 & $\begin{array}{l}\text { No conocer lo que el } \\
\text { odontólogo se encuentra } \\
\text { realizando en su boca } \\
\text { Cuando el odontólogo le }\end{array}$ & 11.37 \\
\hline 5 & $\begin{array}{l}\text { invita a sentarse en la silla } \\
\text { dental }\end{array}$ & 8.90 \\
\hline 6 & $\begin{array}{l}\text { Dejar el consultorio al penser } \\
\text { que el odontólogo no le va a } \\
\text { explicar el problema que } \\
\text { tiene en sus dientes }\end{array}$ & 8.28 \\
\hline 7 & $\begin{array}{l}\text { Suda y tiembla cuando es su } \\
\text { turno de pasar a la consulta } \\
\text { Pensar que va a estar } \\
\text { sentado en la silla dental }\end{array}$ & 6.92 \\
\hline 8 & $\begin{array}{l}\text { para un tratamiento le pone } \\
\text { nervioso }\end{array}$ & 6.80 \\
\hline 9 & $\begin{array}{l}\text { Mientras camins al } \\
\text { consultorio piensa que el } \\
\text { odontólogo no le va a } \\
\text { explicar el problema } \\
\text { que tiene en sus dientes }\end{array}$ & 6.67 \\
\hline
\end{tabular}

Tabla № 4. Causas más relevantes que influyen en la ansiedad frente al tratamiento odontológico. 


\section{Discusión}

En este estudio se pudo evidenciar que existe un mayor porcentaje de la población que presenta ansiedad al tratamiento odontológico con un $58 \%$, a diferencia de la investigación de Ríos Erazo M, et al, realizado en Santiago de Chile, indicaron bajas prevalencias de ansiedad dental en adultos chilenos que oscilaban entre los $20-70$ años, presentando un $37,9 \%,{ }^{7}$ siendo porcentajes menores en comparación de este estudio que presenta un $20 \%$ mayor de ansiedad. En el estudio de Ríos Erazo no se realizó la distribución de los niveles de ansiedad por sexo, ${ }^{7}$ a diferencia de esta investigación en el que si se distribuye la muestra de acuerdo al nivel de ansiedad según el género.

El porcentaje de ansiedad según el género que presenta este estudio es de 35,9\% mayor para el género femenino. Este estudio tiene relación con la investigación realizada por Martínez, et al, en que indican un porcentaje de ansiedad de $48,2 \%$ mayor para género femenino. ${ }^{10}$ Relacionando estos dos estudios, se puede evidenciar que existe una concordancia de ansiedad según el género, predominando el género femenino con mayor ansiedad. En el estudio de Martínez, se realizó una encuesta mediante un test de ansiedad dental de Norman Corah, ${ }^{10} \mathrm{a}$ diferencia de este estudio que se utilizó la escala de ansiedad dental versión corta SDAl, escala que nos permite saber mediante un test la ansiedad dental que experimentan los pacientes durante la consulta odontológica.

Al comparar este estudio con una investigación de Ríos Erazo M, et al. Indican que el nivel de ansiedad más frecuente observado es el moderado con un $16,1 \%$. Sus resultados son similares a este estudio el cual presentó un 15,31\% nivel de ansiedad moderado. ${ }^{7}$ A diferencia de otro estudio realizado por Martínez López, donde indica porcentajes más altos en comparación a otros estudios, presentando un $28,8 \%$ de ansiedad moderada. ${ }^{10}$

Es importante que el odontólogo considere a tiempo el nivel de ansiedad que adquirió el paciente, de manera que si no se trata este fenómeno a tiempo, corren el riesgo de tener problemas de salud oral interfiriendo en la calidad de vida de los pacientes debido a la inasistencia a sus citas, y su retraso a la eficacia del tratamiento odontológico.

El odontólogo debe aplicar una serie de medidas básicas, usando técnicas de relajación, respiración, y distracción, de manera que el miedo comience a desaparecer y que los pacientes ansiosos puedan ser atendidos en el área odontológica.

\section{Conclusiones}

Al concluir el estudio podemos decir que la prevalencia de ansiedad en adultos mayores a 65 años de la parroquia de Cañaribamba, Cuenca-Ecuador, se encuentra con un porcentaje alto (58\%) respecto a estudios realizados en países más desarrollados ( $4 \%$ a $36 \%$ ).

La ansiedad leve es uno de los niveles más altos que presentan los adultos mayores, seguida por la ansiedad moderada, siendo estos porcentajes altos para este estudio pero bajos para 
otros estudios, y por último se encuentra la ansiedad severa con un porcentaje mayor a diferencia de otros estudios.

El género femenino presenta porcentajes más altos según el nivel de ansiedad leve, moderada y severa, a diferencia del género masculino que presentan valores bajos.

Las causas de mayor predominio de ansiedad reflejadas en este estudio fueron, el momento en que el odontólogo alista la jeringa con inyección de anestesia, pensar que se va a utilizar la turbina en su boca y cuando el profesional le va a extraer el diente. Causas por la que la mayoría de pacientes referían miedo o temor al momento de la consulta 0 en tratamientos odontológicos. Estas preguntas fueron realizadas en el test de la escala de ansiedad dental versión corta SDAl.

\section{Referencias Bibliográficas:}

1. Bernabé $E$, Humphris $G$, Freeman R. The social gradient in oral health: Is there a role for dental anxiety. Community Dent Oral Epidemiol. 2017 Aug;45(4):348-355. doi: 10.1111/ cdoe.12297. Epub 2017 Mar 28. Disponible en: https://onlinelibrary.wiley.com/doi/ pdf/10.1111/cdoe.12297

2. OMS. Nota informativa $\mathrm{N}^{\circ} 318$. I Salud bucodental. Who. 2012. p. 1. Disponible en: http:// www.who.int/mediacentre/factsheets/fs318/es/.

3. Ingunza, J., et al. Calidad de vida relacionada a la salud bucal en escolares de ámbito urbano-marginal. Rev Estomatol Herediana. 2015 Jul-Set;25(3):194-204.

4. Real Academia Española de la Lengua. Ansiedad [Internet]. Diccionario de la lengua española. 2014. Disponible en: https://www.mendeley.com/research-papers/ calidad-vida-relacionada-la-salud-bucal-en-escolares-\%C3\%A1mbito-urbanomarginal-tt-oral-health-relatedqu/?utm_source=desktop\&utm_medium $=1.17 .13 \& u t m \_c a m-$ paign=open_catalog\&userDocumentld=\%7B490a6c2b-ccf0-46fe-b69a-34daed0524bc\%7D.

5. Pozo Bassi J, Pavez Tetlak C, Riquelme Tapia D, Quiroga del Pozo J. Comparación en los niveles de ansiedad en pacientes previo a la realización de terapia endodóntica y periodontal. Rev Clínica Periodoncia, Implantol y Rehabil Oral [Internet]. 2015;8(3):20812. Disponible en: https://scielo.conicyt.cl/scielo.php?script=sci_arttext\&pid=S 0718381X2016000200012

6. Amaíz Flores AJ, Flores MÁ. Abordaje de la ansiedad del paciente adulto en la consulta odontológica: propuesta interdisciplinaria. Odontol Vital [Internet]. 2016;1(24):21-8. Disponible en: http://www.scielo.sa.cr/pdf/odov/n24/1659-0775-odov-24-00021.pdf

7. Ríos-Erazo M, Herrera-Ronda A, Molina-Muñoz Y, Et al. Ansiedad dental en adultos chilenos que concurren a un servicio de salud primaria. Int. J. Odontostomat. [Internet]. 2016 Ago [citado 2018 Jun 27]; 10 (2): 261-266. Disponible en: https://scielo.conicyt. $\mathrm{cl} /$ scielo.php?script=sci_arttext\&pid=S0718-381X2016000200012\&lng=es. http://dx.doi. org/10.4067/S0718381X2016000200012. 
8. Hmud R, Lj W. Dental anxiety: causes, complications and management approaches. J Minim Interv Dent. 2009;2(1):67-78. Disponible en:https://www.researchgate.net/publication/237649777_Ansiedad_dental_causas_complicaciones_y_metodos_de_manejo

9. Caycedo C, Cortés OF, Gama R, Rodríguez H, Colorado P, Caycedo M, et al. Ansiedad al tratamiento odontológico: características y diferencias de género. Suma Psicológica Bogotá Suma Psicológica. 2008;15(15):259-78. Disponible en:http://www.redalyc.org/ articulo.oa?id=134212604011

10. Martínez López C, Et al. niveles de ansiedad en la consulta odontológica en pacientes adultos atendidos en la universidad santo tomás. Rev UstaSalud. D 13 (2), pp. 112-119, julio-diciembre 2014. Bucaramanga. Disponible en: http://revistas.ustabuca.edu.co/index.php/USTASALUD_ODONTOLOGIA/article/viewFile/1729/1319

11. Arrieta Vergara K, Díaz Cárdenas S, Verbel Bohórquez J, Hawasly Pastrana N. Factores asociados a sintomatología clínica de miedo y ansiedad en pacientes atendidos en Odontología. Rev clín med fam. 2013;6(1):17-24. Disponible en: http://scielo.isciii.es/ scielo.php?script=sci_arttext\&pid=S1699-695X2013000100004

12. Benítez-Salazar M, Montoya-Cañón S. Frecuencia de asistencia a la consulta odontológica en estudiantes de secundaria de Pereira y los factores emocionales asociado. Rev Nac Odontol. 2015;11(21):75-81. Disponible en: http:// dx.doi.org/10.16925/od.v11i21.938

13. Diaz $L$, Romina $A$, Nivel de ansiedad en pacientes de 18 a 65 años de edad atendido en la Clinica Estomatologica de la Uiversidad Privada Antenor Orrego - Trujillo, Noviembre 2015, Universidad Privada Antenor Orrego - UPAO, 28-oct 2916. Disponible en: http:// repositorio.upao.edu.pe/handle/upaorep/2024

14. Álvarez V, Lourdes P, Narváez L, Geovanna G, Evaluación del nivel de ansiedad en pacientes pediátricos que acuden a la Facultad de Odontología de la Universidad Central del Ecuador mediante estimulación musical, 2015, Editorial : Quito: UCE, Disponible en: http://www.dspace.uce.edu.ec/handle/25000/4083

15. Bermúdez P, Támara A, William J, Eficacia y seguridad de clonidina versus placebo para ansiedad en odontología, Revista Nacional de Odontologia, , Ediciones Universidad Cooperativa de Colombia, Vol. 9, Núm. 17 (2013), Disponible en: https://doi.org/10.16925/od. v9i17.550

16. Pozo J, Pavez C, Riquelme T. Quiroga J, Comparación en los niveles de ansiedad en pacientes previo a la realización de terapia endodóntica y periodontal, Revista Clínica de Periodoncia, Implantología y Rehabilitación Oral, Volume 8, Issue 3, December 2015, Pages 208-212, Disponible en: http://www.sciencedirect.com/science/article/pii/ S0718539115000701

17. Ordóñez M, Villavicencio $E$, Alvarado 0 , Vanegas $M$, Prevalencia de bruxismo de vigilia evaluado por auto-reporte en relación con estrés, ansiedad y depresión, Revista Estomatológica Herediana, Rev. Estomatol. Herediana vol.26 no.3 Lima jul. 2016, Disponible en: http://www.scielo.org.pe/scielo.php?pid=\$101943552016000300005\&script=sci_ arttext\&tlng=pt

18. Manrique $C$, César $E$, Niveles de ansiedad en sujetos que practican el malabarismo en la ciudad de Lima Metropolitana, Repositorio Institucional, 2017-08-04, Disponible en: http://repositorio.uigv.edu.pe/handle/20.500.11818/1396 
19. Díaz E, Dimensiones del miedo dental, Revista Europea de Odontológica, Publicado el: 11/01/2017 09:29:48, Disponible en: http://www.redoe.com/ver.php?id=243

20. Chaves I, Dr. Silva B, Rodrigues T, Albuquerque I, La prevalencia de la ansiedad dental y su relación con factores socioeconómicos entre las mujeres embarazadas en Joao Pessoa, Brasil, Revista Cubana de Estomatología, Rev Cubana Estomatol vol.51 no.2 Ciudad de La Habana abr.-jun. 2014, Disponible en: http://scielo.sld.cu/scielo.php?pi$\mathrm{d}=\$ 003475072014000200003 \&$ script=sci_arttext\&tIng=pt

21. Álvarez M, Casanova Y, Toledo A, Espeso N, Miedo al tratamiento estomatológico en pacientes de la clínica estomatológica docente provincial, Humanidades Médicas, Rev Hum Med v.7 n.1 Ciudad de Camaguey ene.-abr. 2007, Disponible en: http://scielo.sld.cu/ scielo.php?pid=S172781202007000100006\&script=sci_arttext\&tlng=pt

22. Sanjuán $M$, Intervenciones musicales para la ansiedad odontológica en pacientes pediátricos y adultos, Ene. vol.9 no.2 Santa Cruz de La Palma 2015, Disponible en: http:// scielo.isciii.es/scielo.php?script=sci_arttext\&pid=S1988-348X2015000200011

23. Díaz A, Eugenia M, Raposo S, Pulido R, Técnicas de distracción para reducir la ansiedad en el dentista, Revista europea de odontología, Publicado el: 27/11/2017, Disponible en: http://www.redoe.com/ver.php?id=273

24. Tobón $\mathrm{D}$, Beatriz L, Hoyos B, Comportamiento del nivel de ansiedad y del grado de dolor en pacientes con tratamiento endodóntico, Revista Ces Odontologia, Vol 18, No 1(2005) Disponible en: http://revistas.ces.edu.co/index.php/odontologia/article/view/407

25. Briceño V, Félix E, Niveles De Ansiedad Y Miedo A La Atención Odontológica En Pacientes Adultos Que Acuden A Consulta En La Clínica Estomatológica De Moche De La Universidad Nacional De Trujillo, 2008, Universidad Nacional de Trujillo Fecha: 2009, Disponible en: http://dspace.unitru.edu.pe/handle/UNITRU/401

26. González Ramírez MT, Landero Hernández R, García-Campayo J. Relación entrela depresión, la ansiedad y los síntomas psicosomáticos en una muestra de estudiantes universitarios del norte de México. Rev Panam Salud Publica. 2009;25(2):141-5. Disponible en: http://www.scielosp.org/pdf/rpsp/v25n2/v25n2a07.pdf

27. Ríos Erazo M, Herrera Ronda A, Rojas Alcayaga G. Ansiedad dental: evaluación y tratamiento. Av Odontoestomatol [Internet]. 2014;30(1):39-46. Disponible en: http://scielo. isciii.es/scielo.php?script=sci_arttext\&pid=S0213-12852014000100005

28. Al-Namankany, A.i de Souza, M. \& Ashley, P. Evidence-based dentistry: analysis of dental anxiety scales for children. Br. Dent. J., 212(5):219-22, 2012. Disponible en: https://www. nature.com/articles/sj.bdj.2012.174

29. Cázares F, Montoya B, Quiroga M. "Ansiedad dental en pacientes adultos en el tratamiento odontológico". Revista Mexicana de Estomatología. 2015 Enero; 2(2).

30. Villavicencio Caparó E, Alvear Córdova MC, Cuenca León K, y cols. El tamaño muestral para la tesis ¿Cuántas personas debo encuestar?. Revista OACTIVA UC Cuenca. Vol. 2. No. 1, pp 59-62. 2017. Disponible en: https://www.researchgate.net/publication/323649401

31. Hernández Sampieri R. Metodología de la investigación, Edit. 5 Mc Graw- Hill México 2010. Disponible en: https://www.esup.edu.pe/descargas/dep_investigacion/Metodologia\%20de\%20la\%20investigaci\%C3\%B3n\%205ta\%20Edici\%C3\%B3n.pdf 
32. Rivera I, Fernández A. Ansiedad y miedos dentales en escolares hondureños. Revista Latinoamericana de Psicología. 2005; 37(3).

33. Dhó M. Actitudes de salud bucodental en relación al nivel socoeconómico en individuos adultos. Avances en odontoestomatología. 2015 0ctubre; 31(2).

34. Gracia A, Santabárbara J, López R, Aznar T, Marcos G. Ocupación laboral y riesgo de deterioro cognitivo y demencia en personas mayores de 55 años: una revisión sistemática. Revista Española de Salud Pública. 2016 Junio; 90(21).

35. Lima M, Casanova Y. Miedo, ansiedad y fobia al tratamiento estomatológico. Humanidades Médicas. 2006; 6(1).

36. Rodrigues $\mathrm{H}$. Prevalencia y aspectos sociodemográficos de la ansiedad al tratamiento estomatológico. Revista Cubana de Estomatología. 2016 Octubre; 53(4).

37. Muza R, Muza P. Ansiedad en un servicio de emergencia dental. Horizonte de Enfermería. 2008 Enero; 1(1).

38. Villavicencío-Caparó E, Cuenca KdlÁ. ODNTOLOGÍA ACTIVA.. [Online].; 2016 [cited 2018 Enero 25. Available from:

39. http://oactiva.ucacue.edu.ec/index.php?journal=OACTIVAUCACUE\&page=article\&op=view\&path $\% 5 \mathrm{~B} \% 5 \mathrm{D}=20$

\section{Recibido:}

\section{Aceptado:}





\section{Conocimiento de las úlceras por presión del personal de enfermería}

\section{NURSING STAFF'S KNOWLEDGE ON PRESSURE ULCERS}

Ronaldo Gracia Gonzales' , Liliana Holguín Rodríguez', Miguel Martínez Alcoser', Mauricio Guillen Godoy'

1 Universidad Estatal de Milagro.

*byronmorales@yahoo.com

DOI: https://

\section{Resumen}

Las úlceras por presión en el área hospitalaria son lesiones iatrogénicas subyacentes provocadas por la presión en las pronaciones óseas más prominentes, estas a su vez pueden afectar al músculo e incluso llegar a los huesos, respecto a varias investigaciones establecen que el nivel académico y de conocimiento influye en la aparición de las lesiones, y esta a su vez incrementa gastos en el sistema de salud. Objetivo: Establecer las causas de la ineficiencia laboral del personal de enfermería en el cuidado directo y su influencia en la aparición de las úlceras por presión en pacientes hospitalizados. Población: Se escogió a los licenciados, auxiliares e internos de enfermería del hospital del IESS de la Ciudad de Milagro. Metodología: El presente estudio tiene un contexto correlacional y descriptivo. La muestra aleatoria tomó las mismas dimensiones en todos los turnos, obteniendo 100 servidores a quienes se le aplicó una encuesta basándose en el nivel de conocimiento sobre las ulceras por presión. Datos analizados en el programa SPSS-25. Resultados: profesional de la salud sobre los factores que influyen en la aparición de las UPP es de 22,2\% dicen que se da por sobrecarga horaria, mencionan que el $19,4 \%$ corresponde a la falta de conocimiento y al exceso de paciente, mientras tanto con $18,1 \%$ concierne a el exceso de pacientes hacia el personal que labora durante esa jornada, asimismo con un $15,3 \%$ pertenece a la deshumanización y finalmente con un $5,6 \%$ recae en otros factores que hacen que aparezcan las úlceras por presión. Conclusión: 
el conocimiento del personal varía según el cargo y las capacitaciones obtenidas, además el exceso de pacientes, incrementa la sobrecarga de trabajo para los enfermeros, la cual no permite brindarles las intervenciones correspondientes para cada paciente.

Palabras claves: enfermería, estadios, iatrogenias, nivel de conocimiento, úlceras por presión.

\section{Abstract}

Pressure ulcers in the inpatient area are underlying iatrogenic lesions caused by pressure on the most prominent bone pronation, which can affect the muscle and even get to the bones. Several studies suggest that the academic and knowledge level influences on the injuries incidence, increasing health care system costs. Objective: To establish the causes of nurse's staff inefficiency in providing direct care, and its influence on the occurrence of pressure ulcers in the inpatients. Sample Population: For the sample population, licensed, auxiliary nurses and interns of the IESS hospital in the city of Milagro, were chosen. Methodology: The present study has a correlational and descriptive context. The random sample had the same dimensions in all shifts, with 100 nurses who answered a survey, based on their level of knowledge on pressure ulcers. Data were analyzed in the SPSS-25 program. Results: Health professionals on the factors that influence the appearance of UPP are $22.2 \%$, they say that it is due to hourly overload, they mention that $19.4 \%$ corresponds to lack of knowledge and excess patient, meanwhile with $18.1 \%$ it concerns the excess of patients towards the personnel that works during that day, also with $15.3 \%$ it belongs to dehumanization and finally with $5.6 \%$ it falls on other factors that cause ulcers to appear due to Pressure. Conclusion: The staff's knowledge varies according to the working position and training acquired. Additionally, the large numbers of patients increase the nurses' work overload, preventing them from providing the corresponding interventions to each patient.

Keywords: nursing, phases, iatrogenesis, knowledge level, pressure ulcers. 


\section{Introducción}

A lo largo de la historia, las úlceras por presión (UPP) han acompañado al ser humano desde sus inicios, debido a que su principal causa hace relación a la interacción que tienen con su entorno. Hipócrates (460-370 a.C.) escribió el primer registro de las UPP describiendo la aparición de las lesiones en un paciente parapléjico.'

Con el pasar del tiempo y los avances que tuvieron los cuidados de la salud, se fue tomando consciencia sobre las lesiones por presión y como estas iban afectando cada vez más a los pacientes, por estos motivos diversos autores se dedicaron a estudiar la etiología de dicha condición médica.

Según diversos estudios realizados por diferentes investigadores de muchos países, han llegado a la conclusión que "Las UPP es una lesión localizada en la piel y/o tejido subyacente, producida generalmente sobre una prominencia ósea, como resultado de la presión, o de la presión en combinación con cizallamiento y/o fricción" ${ }^{\prime 2}$

Debido a la prevalencia e incidencia de esta patología varios autores manifiestan que las úlceras por presión (UPP) o también conocidas como lesiones por presión siguen siendo una preocupación muy importante en el área de salud especialmente países desarrollados, teniendo en cuenta que los porcentajes de este problema está incrementado a nivel mundial reflejando varios datos estadísticos. ${ }^{3}$

Las lesiones cutáneas para el Grupo de trabajo de úlceras por presión son: Unos de los problemas más frecuentes en el día a día de los profesionales de enfermería, por tanto son consideradas un gran problema de salud pública; también menciona que las UPP son exclusivamente responsabilidad del profesional de enfermería, porque es el que va a proveer las respectivas intervenciones con fundamentos científico que van a prevenir y tratar, por lo cual se menciona que si hay presencia de esta en los pacientes es por las malas prácticas realizadas en su desempeño laboral. ${ }^{4}$

En la actualidad hay una sobrecarga de trabajo en el personal de enfermería, debido que existe muy pocos enfermeros a cargo de una elevada cantidad de pacientes por unidad hospitalaria; por falta de personal especializado en las áreas, por lo cual puede conllevar consecuencias en la calidad de atención, afectando el rendimiento laboral del equipo de enfermería, logrando que no pueda realizar las intervenciones necesarias ajustadas a las necesidades de los pacientes. $^{5}$

Debido a diversos factores el personal de enfermería se muestra insatisfecho en su labor, esto ocasiona que presenten su rol asistencial de una manera monótona, deshumanizada, sin importarles el bienestar del paciente, solo por cumplir con su horario, entre los motivos más comunes que conllevan a la falta de humanización se encuentran: un exceso de pacientes, jornadas laborales de 12 horas sin descanso suficiente, actividades administrativas que hacen 
que el enfermero/a dedique más tiempo a actividades no propias de la profesión, obteniendo inconformidad en el paciente, y una atención de baja calidad. ${ }^{6}$

Las UPP tienen repercusiones muy negativas sobre la salud y la calidad de vida de estos pacientes, la morbimortalidad se ve aumentada, puede aumentar hasta cinco veces su estancia hospitalaria sin contar los costes derivados de ellas. La presencia de UPP se ha asociado con un riesgo de muerte de dos a cuatro veces superior a no presentar este tipo de lesiones en pacientes de edad avanzada y en unidades de cuidados intensivos. ${ }^{7}$

En Ecuador el organismo principal de salud "Ministerio de Salud Pública" manifiesta que las úlceras por presión representan un problema creciente en relación con la prevalencia, lo que desata complicaciones frecuentes en los pacientes con estancias hospitalarias y al mismo tiempo amenaza la eficiencia de su tratamiento. ${ }^{8}$ De igual forma manifiesta que el $95 \%$ de los casos suscitados en centros de salud gubernamentales relacionados con las UPP pueden ser evitados por el profesional de enfermería.

El grupo escogido para nuestra investigación está conformado por las licenciadas, auxiliares de enfermería e internos rotativos del área, que laboran en el Hospital General IESS "Federico Bolaños Moreira" de cantón milagro. Al ser una investigación manejable se tomó una muestra de 100 profesionales al azar, quienes conforman el estudio para medir el nivel de conocimiento de las ulceras por presión por parte del personal de enfermería.

La deficiencia en los conocimientos por parte del personal de enfermería repercute en la salud del paciente, aunque tienen bases y conocimientos sólidos sobre el tratamiento de las UPP, demuestran tener falta de conocimiento en la clasificación de las úlceras, así como cuáles eran los principales factores de riesgo que pueden ocasionar esta lesión, en cuanto menor nivel académico tienen menor es el conocimiento que poseen. ${ }^{9}$

Este estudio nos brindará información actual lo cual nos dará un amplio conocimiento de esta condición médica, además de fomentar en el personal de enfermería el uso de técnicas terapéuticas y recursos materiales que impidan la aparición de lesiones por presión. Beneficiará tanto a los profesionales y futuros profesionales de enfermería como a los pacientes, siendo éstos últimos, los que ganarían un mayor beneficio debido a que mejoraría la calidad de la atención del área y se reduciría la incidencia de UPP.

Los resultados mencionados en esta investigación demostrarán que por medio de simples cambios y con la ayuda de un amplio análisis de campo, es probable que se prevenga y se reduzca la tasa de incidencia de éstas afecciones de la piel en pacientes con poca movilidad, además de ofrecer al personal involucrado alternativas en la obtención de conocimientos y procedimientos en la atención de las lesiones por presión, aportando información en el personal de enfermería para que mejore su labor profesional. 
Tal como lo señalan Ortiz Arjona, Fernandez Berchez, Ortiz y Farouk Allam ${ }^{10}$ en su investigación, afirman que las úlceras por presión "Son lesiones de la piel que pueden afectar al músculo e incluso al hueso y están causadas por una combinación de factores entre los que destacan la presión, tracción y el cizallamiento, siendo determinante la relación presión/tiempo para su aparición".10

Por su historia las UPP se han asociado a la calidad de cuidados por parte de enfermería, por lo que las escaras son vistas como un problema de salud en la cual no solo afecta a las personas que la padecen, sino también a los familiares, a los profesionales de la salud y al mismo sistema de salud..$^{10}$

Las áreas donde son visibles con mayor frecuencia son aquellos lugares donde no hay sensibilidad por la presión que se ejerce sobre las prominencias óseas. Aparecen preferentemente en área sacro - coxígea, talones, cara posterior de pantorrillas, brazos y codos. Se distinguen como una decoloración de la piel en forma de pera, mariposa o de herradura; tienen bordes irregulares, de inicio repentino y progreso muy rápido, el color puede variar desde el purpura, al rojo, pasando por el amarillo e incluso el azul o el negro."

Cuando aparecen estas laceraciones, la calidad de vida de estos pacientes decae y por ende disminuye la esperanza de vida, ésta va a afectar su autonomía, libertad y su autoestima ya sean por las diferentes complicaciones que se desencadenan. El personal que deberá estar atento ante este suceso serán los/as enfermeros/as los cuales brindaran un cuidado integral para cada paciente, es por eso que:

Las acciones del personal de enfermería, deben dirigir exclusivamente a su prevención y enfocarse específicamente a la identificación del riesgo, la higiene, correctos cambios posturales, la hidratación de la piel, una adecuada alimentación nutricional, la protección de puntos de presión y la valoración constante de la piel para así evitar que los pacientes adquieran las UPP dentro de la entidad hospitalaria. ${ }^{12}$

\section{Clasificación de las Úlceras por Presión.}

Las heridas por presión son afectaciones sobre la piel y tejido subyacente, en las cuales se describen cuatro etapas:

Estadio 1: En esta primera etapa, las lesiones no se encuentran abiertas, estas pueden presentar dolencias leves, pero sin aberturas. La piel aparece enrojecida y no se oscurece, esta pierde el color momentáneamente cuando se presiona con el dedo. En una persona de piel oscura, el área puede aparecer de un color distinto. ${ }^{8}$

Estadio 2: La piel se parte, se deteriora y forma una llaga, que generalmente es sensible y doloroso. ${ }^{8}$ 
En este periodo hay pérdida parcial del grosor de la piel, la cual se presenta como una herida abierta y profunda de color rojo o rosado sin suciedad, también se puede presentar como una burbuja llena de líquido la cual puede estar ilesa o abierta.

Estadio 3: En esta fase hay pérdida total o parcial de la piel, en la que el tejido adiposo es evidente en la llaga y a menudo hay tejido de granulación, las áreas del tejido adiposo son expuestas a desarrollar lesiones graves y profundas. El musculo las fascias, tendón, el ligamento, cartílago y/o el hueso están expuestos. ${ }^{13}$

Estadio 4: En esta fase la piel pierde el grosor total y existe la pérdida del tejido, con fascias exhibida o directamente tangible, músculo, tendón, ligamento, cartílago o hueso que se evidencia en la úlcera. Este estadio puede dañar conjuntamente los tejidos tendones y articulaciones más profundas. ${ }^{9}$

\section{Úlceras por presión y el personal de enfermería}

Para la OMS la aparición o presencia de ulceras por presión es un indicador de la prestación del rol asistencial en enfermería, en donde se puede evaluar la calidad del cuidado impartido en pacientes que tienen un deterioro en su salud. ${ }^{14}$

El principal objetivo del personal de enfermería es reducir o eliminar el sufrimiento que padecen los usuarios que se aproximan a las instituciones hospitalarias, realizando técnicas y procedimientos que requieren del debido uso de las normas de bioseguridad y bioética del profesional de enfermería. ${ }^{1}$

Las lesiones cutáneas para el Grupo de trabajo de úlceras por presión, (2009) son: Unos de los problemas más frecuentes en el día a día de los profesionales de enfermería, por tanto, son consideradas un gran problema de salud pública; también menciona que las UPP son exclusivamente responsabilidad del profesional de enfermería, porque es el que va a proveer las respectivas intervenciones con fundamentos científico que van a prevenir y tratar. ${ }^{4}$

\section{Falta de conocimiento}

Mediante la búsqueda exhaustiva de acciones 0 actividades que ayuden a ofrecer una atención de calidad en la prestación de servicios, varios autores vienen resaltando la importancia y la necesidad de conocimientos científicos por parte de los profesionales de enfermería, debido a que a nivel internacional mediante diferentes investigaciones se muestra que, a pesar del avance de tecnología científica del personal de salud, se considera como insuficiente el nivel de conocimiento de enfermería en relación a la actividades de prevención, promoción y los respectivos tratamiento de las ulceras por presión (Miyazaki, Caliri, \& Santos, 2015) ${ }^{14}$

En Canadá, un estudio realizado para identificar el conocimiento en relación con la prevención de las UPP se demostró ser insuficiente al obtener un puntaje global de $64.4 \%$, mientras que en Nueva York, se obtuvo resultados favorables en cuanto a los conocimientos aptos del personal sobre previsión y tratamiento de laceraciones cutáneas, con un $89 \%$ en aquellos que 
tenían cursos en cuidado de heridas y un $76.5 \%$ en los que no, lo cual demostró que existe una mínima diferencia entre el nivel académico de la enfermera y los años en práctica. (Zulkowski KD, Ayello EA, \& Wexler SM, 2017) ${ }^{15}$

Asimismo en dos investigaciones que se dieron lugar en Brasil, en donde los resultados demostraron deficiencias en los conocimientos, ya que a pesar de que los profesionales tenían bases y conocimientos solidos sobre el tratamiento, demostraron tener falta de conocimiento en la clasificación de las úlceras, no sabían diferenciar entre grado II y III, así como cuáles eran los principales factores de riesgo que pueden ocasionar esta lesión, de las mismas pero que cuanto menor nivel académico tienen menor es el conocimiento que poseen. $(\mathrm{MH}, 2014)^{16}$

En la actualidad hay una sobrecarga de trabajo en el personal de enfermería, debido que existe muy pocos enfermeros a cargo de una elevada cantidad de pacientes por unidad hospitalaria; por falta de personal especializado en las áreas, por lo cual puede conllevar consecuencias en la calidad de atención, afectando el rendimiento laboral del equipo de enfermería, logrando que no pueda realizar las intervenciones necesarias ajustadas a las necesidades de los pacientes. (Arango G, Peña B, \& Vega Y, 2015)

La Enfermería es una profesión que está encaminada a satisfacer las necesidades que presenten los pacientes en el área de salud, por lo cual no puede ser sólo técnica, porque es el encargado de ver no solo lo físico, sino también mental, espiritual del paciente, por lo cual humanizar es un valor ético fundamental en esta profesión valores que ayudan a concientizar y sensibilizar la atención de los usuarios, supliendo sus necesidades. (Bermejo \& Higuera, $2014)^{17}$

\section{Materiales y Métodos}

Se realizó un estudio cuantitativo, tipo investigativo y exploratorio durante el periodo 2019, que de acuerdo a teología de Hernández Sampier ${ }^{18}$ sobre estos enfoques consiste en el "uso de la recolección de los datos para probar la hipótesis con base en la medición, para establecer numérica y el análisis estadístico, para establecer patrones de comportamiento y probar teorías ${ }^{\prime 19}$, ya que, tiene como fin de conocer el nivel de conocimiento de las úlceras por presión del personal de enfermería del Hospital del Instituto Ecuatoriano de Seguridad Social del cantón Milagro, tomando con referencia los datos recolectados con anterioridad.

La alineación de este enfoque a su vez se pudo comprobar protocolos estipulados por las autoridades hospitalaria con las úlceras por presión (UPP) y, además, de teorías en cuidados humanizados con la finalidad de comprobar si dichos protocolos y teorías son aplicadas por el profesional de enfermería en pacientes con este padecimiento, teniendo en cuenta que la población es el personal de salud, especialmente el personal de enfermería que labora en dicha entidad hospitalaria.

La selección de la muestra se efectúo a través de un muestreo no probabilístico por conveniencia, asimismo estuvo conformada por 100 servidores públicos con cargos de licenciados, 
auxiliares de enfermería con varios años de experiencia y además se incluyó a los internos de enfermería, teniendo en cuenta su jornada laboral y académicas de donde aceptaron participar de forma voluntaria en el estudio.

La toma de datos fue realizada por un grupo de estudiantes universitarios, lo cual permitió la variabilidad de la información por lo que, para facilitar la recogida de datos de esta investigación, se desarrolló como herramienta un corto cuestionario teniendo como guías los protocolos de prevención y atención de ulceras por presión del Ministerio de Salud Pública de la República del Ecuador, con la finalidad que ésta a su vez sea acorde a la profesión de cada uno de los servidores público.

La estructura del recurso utilizado contenía datos de identificación de los profesionales de este estudio y otros criterios del cumplimiento con respecto al conocimiento de la ulceras por presión en el área hospitalaria, a su vez este instrumento fue apoyado por los "protocolos de prevención y atención de ulceras por presión del MSP" que contiene las directrices e instrucciones que nos ayudaron en la realización de esta técnica, asimismo, el cuestionario incluía las siguientes variables: edad, sexo, cargo que desempeña, horario laboral, nivel de estudio entre otras, de modo que una vez hecha la recopilación de la muestra se tomó encuesta los siguientes estándares: cambios posturales, áreas donde que producen, capacitaciones de las UPP, y todos los medios necesarios para prevenirla, etc.

La información fue recopilada en una hoja Excel inicialmente, con el fin de agilizar al momento de ingresar los datos en el paquete estadístico SPSS versión 25. Con la finalidad de varios tener resultados con el cruzamiento de variables y a su vez reflejando datos iniciales con una varianza estadística de 0,421 en el conocimiento de UPP presentando un rencuentro mínimo de 0,15 en la comprobación de los datos descriptivos (chip- cuadrado) con el cual se cumplió los objetivos propuestos y comprobar la hipótesis planteada en el estudio.

Para la distinción de los datos se empleó estadística descriptiva para obtener información del nivel de instrucción sobre las UPP, definiendo el perfil del profesional, y analizando exhaustivamente cuales son las acciones necesarias que debe tener cuando hay un caso de pacientes con UPP identificando los factores asociados a la misma, se utilizaron medidas de tendencia central como porcentajes y media matemática para las variables discretas, y medidas de dispersión como desviación estándar paras las variables continuas. De modo que la evaluación de los niveles de conocimiento busca obtener la información necesaria para establecer el cumplimiento estipulados en el objetivo manteniendo las consideraciones éticas del estudiante y de la institución hospitalaria donde se realizó el estudio. 


\section{Resultados}

Se tomaron todas las unidades de análisis (licenciadas, auxiliares e internos en enfermería) disponibles al momento de la aplicación de las encuesta y observación, que correspondió a 100 licenciadas, auxiliares e internos en enfermería que laboran brindando cuidados a los pacientes en la entidad hospitalaria.

Los datos evidenciados por el programa estadístico SPSS nos muestra que el $39 \%$ son profesionales masculinos y el $61 \%$ son femenino obtenidos de la muestra $(n=100)$. Los resultados mostraron que de acuerdo a las variables edad con ( $n=100, I C=95 \%=1,88 ; 2,24)$ y cargo que desempeña ( $n=100, I C=95 \%=1,66 ; 1,98$ ) reflejaron datos que el $44 \%$ son licenciados de enfermería, el $30 \%$ son auxiliares y el $26 \%$ son internos de enfermería, siendo el $35 \%$ de la población profesionales jóvenes (tabla 1).

Cabe recalcar que en la base estadística se descartaron algunos datos, por el motivo que en la encuesta aplicada a los profesionales tenía una variable piloto en donde se reflejó que el $72 \%$ del personal si se les ha presentado casos de úlceras por presión, mientras el $28 \%$ manifiestan que no se les ha presentado ningún caso de UPP puesto que este resultado dio en las encuestas de los internos en enfermería.

En la tabla 2 se evidencia que el personal de salud de acuerdo al cargo que desempeña tiene un nivel de conocimiento de las UPP de $27,8 \%$ es alto, en lo general el $56,9 \%$ presenta un nivel de conocimiento medio y finalmente el $15,3 \%$ es del nivel bajo, siendo así que el personal que tiene el porcentaje alto en el conocimiento son los licenciados en enfermería con un dato de $61,1 \%$. En la tabla 3 se observa que los criterios del profesional de la salud sobre los factores que influyen en la aparición de las UPP es de $22,2 \%$ dicen que se da por sobrecarga horaria, mencionan que el $19,4 \%$ corresponde a la falta de conocimiento y al exceso de paciente, mientras tanto con $18,1 \%$ concierne a el exceso de pacientes hacia el personal que labora durante esa jornada, asimismo con un $15,3 \%$ pertenece a la deshumanización y finalmente con un $5,6 \%$ recae en otros factores que hacen que aparezcan las úlceras por presión.

En la Tabla 4 señala que las áreas donde más se dan la úlceras por presión son las sacras con un valor de $43,2 \%$, del mismo modo con $33,3 \%$ en la región del talón, igualmente con un $15,3 \%$ se dan en la región de la cadera, con un 4, $\%$ pertenece que se dan en otras zonas del cuerpo, además el 2,8\% se manifiestan en el hombro, y finalmente se manifiestan en la cara con un $1,4 \%$.

Tabla 1. Edades que presentan los profesionales de la salud con el cargo que desempeñan en la entidad hospitalaria 


\section{Cargo que desempeña la persona encuestada}

\begin{tabular}{|c|c|c|c|c|c|c|}
\hline & & & $\begin{array}{l}\text { Licenciado en } \\
\text { enfermería }\end{array}$ & $\begin{array}{l}\text { Auxiliar de } \\
\text { enfermería }\end{array}$ & $\begin{array}{l}\text { Interno de } \\
\text { enfermería }\end{array}$ & TOTAL \\
\hline & & & $\mathrm{n} \quad \%$ & $\mathrm{n} \quad \%$ & $\mathrm{n} \quad \%$ & $\%$ \\
\hline \multirow{8}{*}{$\begin{array}{l}\text { Edad de la } \\
\text { persona } \\
\text { encuestada }\end{array}$} & \multirow{2}{*}{$\begin{array}{l}20-25 \\
\text { años }\end{array}$} & Recuento & 4 & 11 & 20 & 35 \\
\hline & & $\begin{array}{l}\% \text { dentro de edad de la } \\
\text { persona encuestada }\end{array}$ & 11,4 & 31,4 & 57,1 & 100,0 \\
\hline & \multirow{2}{*}{$\begin{array}{l}26-30 \\
\text { años }\end{array}$} & Recuento & 16 & 8 & 5 & 29 \\
\hline & & $\begin{array}{l}\% \text { dentro de edad de la } \\
\text { persona encuestada }\end{array}$ & 55,2 & 27,6 & 17,2 & 100,0 \\
\hline & \multirow{2}{*}{$\begin{array}{l}\text { 31-35 } \\
\text { años }\end{array}$} & Recuento & 2 & 9 & 1,0 & 31 \\
\hline & & $\begin{array}{l}\% \text { dentro de edad de la } \\
\text { persona encuestada }\end{array}$ & 67,7 & 29,0 & 3,2 & 100,0 \\
\hline & \multirow{2}{*}{$\begin{array}{l}36 \\
\text { años }\end{array}$} & Recuento & 3 & 3 & 0 & 5 \\
\hline & & $\begin{array}{l}\% \text { dentro de edad de la } \\
\text { persona encuestada }\end{array}$ & 60 & 40,0 & 0,0 & 100,0 \\
\hline \multirow[t]{2}{*}{ Total } & & Recuento & 44 & 30 & 26 & 100 \\
\hline & & $\begin{array}{l}\% \text { dentro de edad de la } \\
\text { persona encuestada }\end{array}$ & 44,0 & 30,0 & 26,0 & 100,0 \\
\hline
\end{tabular}

Tabla 2. Nivel de conocimiento de las UPP de los encuestados de acuerdo al cargo que desempeñan en la entidad hospitalaria.

Nivel de conocimiento de las UPP

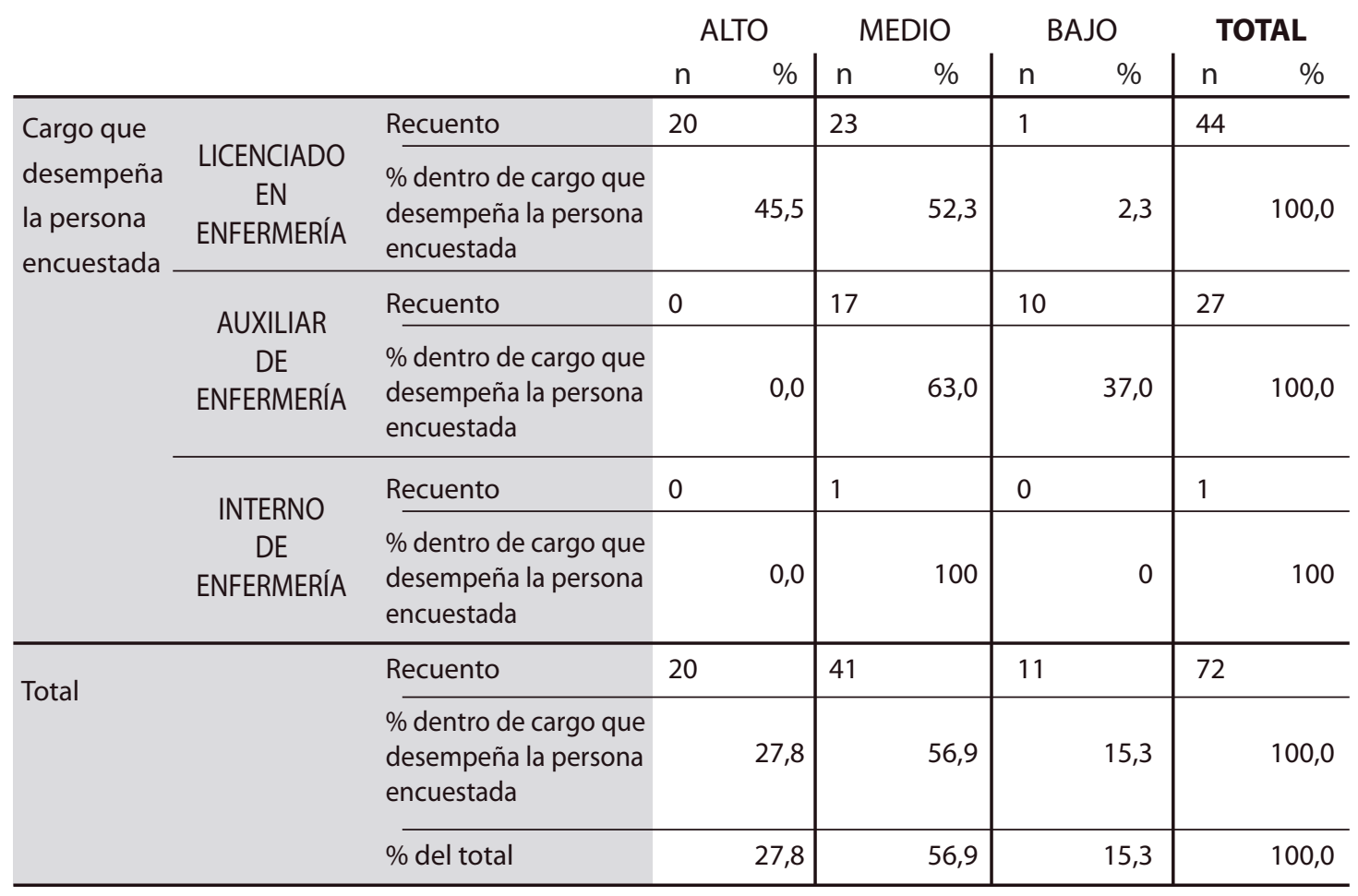


Tabla 3. Factores que influyen en la aparición de las ulceras por presión de acuerdo al nivel de conocimiento del profesional de salud.

\begin{tabular}{|c|c|c|c|c|c|c|c|c|c|c|}
\hline & & & \multicolumn{8}{|c|}{ Cargo que desempeña la persona encuestada } \\
\hline & & & \multicolumn{2}{|c|}{$\begin{array}{c}\text { Licenciado en } \\
\text { enfermería }\end{array}$} & \multicolumn{2}{|c|}{$\begin{array}{l}\text { Auxiliar de } \\
\text { enfermería }\end{array}$} & \multicolumn{2}{|c|}{$\begin{array}{l}\text { Interno de } \\
\text { enfermería }\end{array}$} & \multicolumn{2}{|c|}{ TOTAL } \\
\hline & & & $\mathrm{n}$ & & $\mathrm{n}$ & $\%$ & & $\%$ & $\mathrm{n}$ & $\%$ \\
\hline \multirow{13}{*}{$\begin{array}{l}\text { Factores } \\
\text { que } \\
\text { influyen } \\
\text { en } \\
\text { las UPP }\end{array}$} & \multirow[b]{2}{*}{$\begin{array}{l}\text { SOBRECARGA } \\
\text { HORARIA }\end{array}$} & Recuento & 11 & & 5 & & 0 & & 16 & \\
\hline & & $\begin{array}{l}\% \text { dentro de factores } \\
\text { que influyen en las UPP }\end{array}$ & & 68,8 & & 31,3 & & 0,0 & & 100,0 \\
\hline & \multirow{2}{*}{$\begin{array}{l}\text { EXCESO DE } \\
\text { PACIENTES }\end{array}$} & Recuento & 8 & & 5 & & 0 & & 1 & \\
\hline & & $\begin{array}{l}\% \text { dentro de factores } \\
\text { que influyen en las UPP }\end{array}$ & & 61,5 & & 38,5 & & 0,0 & & 100,0 \\
\hline & \multirow{2}{*}{$\begin{array}{l}\text { EXCESO DE } \\
\text { TRABAJO }\end{array}$} & Recuento & 7 & & 6 & & 1 & & 1 & \\
\hline & & $\begin{array}{l}\% \text { dentro de factores } \\
\text { que influyen en las UPP }\end{array}$ & & 50,0 & & 42,9 & & 7,1 & & 100,0 \\
\hline & \multirow{2}{*}{$\begin{array}{l}\text { FALTA DE } \\
\text { CONOCIMIENTO }\end{array}$} & Recuento & 8 & & 6 & & 0 & & 1 & \\
\hline & & $\begin{array}{l}\% \text { dentro de factores } \\
\text { que influyen en las UPP }\end{array}$ & & 57,1 & & 42,9 & & 0,0 & & 100,0 \\
\hline & \multirow{2}{*}{$\begin{array}{l}\text { DESHUMANI- } \\
\text { ZACION }\end{array}$} & Recuento & 8 & & 3 & & 0 & & 1 & \\
\hline & & $\begin{array}{l}\text { \% dentro de factores } \\
\text { que influyen en las UPP }\end{array}$ & & 72,7 & & 27,3 & & 0,0 & & 100,0 \\
\hline & \multirow{3}{*}{ OTRAS } & Recuento & 2 & & 2 & & 0 & & 4 & \\
\hline & & $\begin{array}{l}\% \text { dentro de factores } \\
\text { que influyen en las UPP }\end{array}$ & & 50,0 & & 50,0 & & 0,0 & & 100,0 \\
\hline & & $\%$ del total & & 2,8 & & 2,8 & & 0,0 & & 5,6 \\
\hline \multirow{3}{*}{ Total } & & Recuento & 4 & & 2 & & 1 & & 7. & \\
\hline & & $\begin{array}{l}\% \text { dentro de factores } \\
\text { que influyen en las UPP }\end{array}$ & & 61,1 & & 37,5 & & 1,4 & & 100,0 \\
\hline & & $\%$ del total & & 61,1 & & 37,5 & & 1,4 & & 100,0 \\
\hline
\end{tabular}


Tabla 4. Áreas del cuerpo humano donde aparecen con más frecuencia las ulceras por presión de acuerdo al profesional de salud.

\begin{tabular}{|c|c|c|c|c|c|c|c|c|c|c|}
\hline & & & \multicolumn{8}{|c|}{ Cargo que desempeña la persona encuestada } \\
\hline & & & \multicolumn{2}{|c|}{$\begin{array}{c}\text { Licenciado en } \\
\text { enfermería }\end{array}$} & \multicolumn{2}{|c|}{$\begin{array}{l}\text { Auxiliar de } \\
\text { enfermería }\end{array}$} & \multicolumn{2}{|c|}{$\begin{array}{l}\text { Interno de } \\
\text { enfermería }\end{array}$} & \multicolumn{2}{|c|}{ TOTAL } \\
\hline & & & $r$ & $\%$ & $\mathrm{n}$ & $\%$ & & $\%$ & $\mathrm{n}$ & $\%$ \\
\hline \multirow{12}{*}{$\begin{array}{l}\text { Áreas } \\
\text { del } \\
\text { cuerpo } \\
\text { más } \\
\text { frecuente } \\
\text { donde } \\
\text { aparecen } \\
\text { las UPP }\end{array}$} & \multirow{2}{*}{ TALÓN } & Recuento & 1. & & 8 & & 1 & & 24 & \\
\hline & & $\begin{array}{l}\text { \% dentro de áreas del } \\
\text { cuerpo más frecuentes } \\
\text { donde aparecen las UPP }\end{array}$ & & 62,5 & & 33,3 & & 4,2 & & 100,0 \\
\hline & \multirow{2}{*}{ CARA } & Recuento & 1 & & 0 & & 0 & & 1 & \\
\hline & & $\begin{array}{l}\text { \% dentro de áreas del } \\
\text { cuerpo más frecuentes } \\
\text { donde aparecen las UPP }\end{array}$ & & 100,0 & & 0,0 & & 0,0 & & 100,0 \\
\hline & \multirow{2}{*}{ SACRO } & Recuento & 1 & & 1 & & 0 & & 31 & \\
\hline & & $\begin{array}{l}\text { \% dentro de áreas del } \\
\text { cuerpo más frecuentes } \\
\text { donde aparecen las UPP }\end{array}$ & & 58,1 & & 41,9 & & 0,0 & & 100,0 \\
\hline & \multirow{2}{*}{ CADERA } & Recuento & 6 & & 5 & & 0 & & 11 & \\
\hline & & $\begin{array}{l}\text { \% dentro de áreas del } \\
\text { cuerpo más frecuentes } \\
\text { donde aparecen las UPP }\end{array}$ & & 54,5 & & 45,5 & & 0,0 & & 100,0 \\
\hline & \multirow[b]{2}{*}{ HOMBRO } & Recuento & 2 & & 0 & & 0 & & 2 & \\
\hline & & $\begin{array}{l}\text { \% dentro de áreas del } \\
\text { cuerpo más frecuentes } \\
\text { donde aparecen las UPP }\end{array}$ & & 100,0 & & 0,0 & & 0,0 & & 100,0 \\
\hline & \multirow[b]{2}{*}{$\begin{array}{l}\text { OTRA } \\
\text { ZONA }\end{array}$} & Recuento & 2 & & 1 & & 0 & & 3 & \\
\hline & & $\begin{array}{l}\text { \% dentro de áreas del } \\
\text { cuerpo más frecuentes } \\
\text { donde aparecen las UPP }\end{array}$ & & 66,7 & & 33,3 & & 0,0 & & 100,0 \\
\hline \multirow[t]{2}{*}{ Total } & & Recuento & 4 & & 2 & & 1 & & 72 & \\
\hline & & $\begin{array}{l}\text { \% dentro de áreas del } \\
\text { cuerpo más frecuentes } \\
\text { donde aparecen las UPP }\end{array}$ & & 61,1 & & 37,5 & & 1,4 & & 100,0 \\
\hline
\end{tabular}




\section{Discusión}

El objetivo principal del estudio era establecer las causas de la ineficiencia laboral del personal de enfermería en el cuidado directo y su influencia en la aparición de las ulceras por presión en pacientes hospitalizados, los resultados demuestran que la mayoría de las actividades que estudia el profesional de salud no son aplicadas correctamente por lo que según Matozinhos, et al, ${ }^{19}$ menciona que:

"Las úlceras por presión representan un desafío importante en relación con la atención brindada a los pacientes hospitalizados, ya que afectan significativamente la morbilidad / mortalidad y la calidad de vida teniendo como objetivo de estimar la tasa de incidencia de úlceras por presión y verificar los factores asociados a esa ocurrencia en una cohorte de pacientes hospitalizados." ${ }^{\prime 19}$

Asimismo, acuerdo a la literatura consultada revela que este evento es frecuente en hombres como en mujeres manifestándose los diferentes factores que hacen que se produzcan estas lesiones.

Los datos proyectados en esta investigación revelan que el total de la muestra es de $39 \%$ son profesionales masculinos y el $61 \%$ son femenino obtenidos de la muestra $(n=100)$. Los resultados mostraron que de acuerdo a las variables edad con $(n=100, I C=95 \%=1,88 ; 2,24)$ y cargo que desempeña ( $n=100, I C=95 \%=1,66 ; 1,98$ ) reflejaron datos que el $44 \%$ son licenciados de enfermería, el $30 \%$ son auxiliares y el $26 \%$ son internos de enfermería, siendo el $35 \%$ de la población profesionales jóvenes, teniendo como referencia datos con relevancia y mostrando que en la población en si mayoritaria del género femenino.

Aunque este estudio fue investigativo y exploratorio, pero tienen un análisis de datos descriptivo de modo que nos permitió alcanzar los objetivos y comprobar nuestra hipotesis ya que, es importante mencionar que la sobrecarga horaria en el personal de salud es uno de los factores predisponente en esta investigación, por lo que muchos pacientes presentan varias patologías que no permiten tener una adecuada movilización. En la revisión de la literatura nos menciona que el exceso de paciente y la sobrecarga horaria van de la mano ya que se estipula un aproximado $42 \%$ es una de los principales factores para la aparición de las UPP.

Como se mencionó el párrafo anterior, otros factores predisponentes que tiene un gran índice es la falta de conocimiento y el exceso de trabajo con un $38,8 \%$ siendo los que siguen a los datos anterior las cuales según a la literatura refieren que el incremento de la incapacidad y la dependencia hacia los cuidados. Aunque en muchos casos también depende la deshumanización que existe en el personal con los pacientes, teniendo en cuentas que esta también depende de los otros factores ya mencionados con anterioridad.

Asimismo, en otro estudio incluyó una muestra de 19,363 pacientes ingresados en unidades de cuidados intensivos, por lo que seis se clasificaron como de calidad fuerte y 11 de calidad moderada teniendo como resultado que los fatores de riesgo que apareciendo más frecuen- 
tes asociados al desarrollo de ulceras por presión incluyeron: edad, tiempo de estancia en UCl, diabetes, ventilación mecánica la duración de la ventilación, tratamiento con drogas vasoactivas etc. ${ }^{20}$

Otros de los aspectos analizados en esta investigación fue las regiones del cuerpo en donde más se aparecen las ulceras presión, presentando que el 43,2\% de presentan en la región de sacro siendo el índice más alto en este estudio, seguido de la región del talón con un 33,3\% y con un $15,3 \%$ en las caderas, manifestando que estas se dan por los factores que predisponentes mencionados anteriormente y teniendo en el nivel de conocimiento de los profesionales de enfermería.

Se tomó en cuenta otro estudio realizado por toma una muestra de 31 pacientes, el instrumento fue aplicando en 4 momentos: el ingreso, al día, a cuarto días y al séptimo día de estancia utilizando la escala Braden. Teniendo como resultado que "el 100\% de los pacientes tuvo alto riesgo al ingreso y $24 \mathrm{~h}$; se redujo en un $71 \%$ a los 7 días. El 6,4\% desarrollo úlcera por presión al ingreso, el $12,9 \%$ a las $24 \mathrm{~h}$ y el $35.5 \%$ a las $72 \mathrm{~h}$. En general el $45,2 \%$ de los pacientes considerados como de alto riesgo manifestaron úlcera por presión a los 7 días de estancia hospitalaria". ${ }^{21}$

En cuanto al estadio, se encontró que existe intervenciones clínicas en donde se realizan curaciones de las úlceras por presión teniendo en cuenta que esta técnica se basa en cura húmeda en 11 UPP de 4 pacientes egresados del hospital con su problema de salud, con lesiones grado II ( $n=6)$ y grado III $(n=5)$. Se realizará 12 curaciones cada 3 días en el domicilio de las personas, teniendo como resultado que se curaron 9 UPP de grado II, mientras que de grado III se curaron 3 , la cicatrización se dio en un lapso de 4 semanas. ${ }^{7}$

Aunque se tenía indicación clara que en la mayoría de los cuidados no existían los insumos necesarios para realizar las intervenciones acordes a las ocasiones por lo que los sistemas de calidad del mundo han identificado que las UPP como indicadores de eficacia en los profesionales de enfermería, por lo que se refiere que las organizaciones de la salud deben disponer a los profesionales a todos los recursos necesarios para evitar la úlceras por presión.

\section{Conclusiones}

De acuerdo al estudio investigativo realizado en el Hospital General del IESS "Federico Bolaños Moreira" del cantón Milagro, con la colaboración del personal de enfermería, se ha logrado determinar las causas por la cual existen una mayor relevancia de presencias de UPP en los pacientes de esta unidad hospitalaria,

Por lo que se logró determinar que la falta de conocimiento de UPP por parte del personal de enfermería, es una de las causas para que estas aparezcan en los pacientes que se encuentran hospitalizados, ya que el personal sanitario no recibe las debidas capacitaciones 
sobre prevención y tratamiento de úlceras por presión entre las cuales constan el cambio de posición constante y el uso de almohadillas que servirá para evitar lesiones cutáneas, las cuales pueden llegar a ser graves con el tiempo; además se estableció entre sus factores que el exceso de pacientes, incrementa la sobrecarga de trabajo para los enfermeros, la cual no permite brindarles las intervenciones correspondientes para cada paciente.

Además otra consecuencia que conlleva a una UPP en los pacientes que se encuentran hospitalizados, es que existe la deshumanización por parte del profesional de enfermería, ya que un gran número de enfermeros han visto en esta profesión, como algo empírico y un salario bien remunerado, olvidándose de sus valores morales éticos y que además están tratando con vidas y sentimientos de seres humanos, por la cual el brindar las debidas capacitaciones sobre UPP, evitar que el exceso de pacientes limite brindar una atención de calidad y calidez y el ser humanistas por parte del personal de enfermería al momento de tratar con los pacientes, ayudara a su pronta recuperación sobre estas lesiones cutáneas y que no se prolongue más su estadía en la unidad hospitalaria 


\section{Referencias Bibliograficas:}

1. Torra-Bou, J., Verdú-Soriano, J., Sarabia-Lavin, R., Paras-Bravo, P., Soldevilla-Ágreda, J., López-Casanova, P., \& García-Fernández, F. (2017). Una contribución al conocimiento del contexto histórico de las úlceras por presión. Gerokomos, 28(3), 151-157.

2. Brown, D., Edwards, H., Seaton, L., \& Thomas , B. (2015). Lewis's Medical-surgical Nursing: Assessment and Management of Clinical Problems. Australia and New Zealand: Elsevier Health Sciences.

3. Lombo Caicedo, J., \& Manrique Abril. (2013). Pacientes por enfermera-auxiliar y presencia de eventos adversos en unidades de cuidados intensivos de Ibague-Colombia. Enfermería Global .

4. Secretaría de Salud. (2009). Guía de Práctica Clínica para la Prevención y Tratamiento de Úlceras por Presión a Nivel Intrahospitalario. Centro Nacional de Excelencia Tecnológica en Salud.

5. Arango G, Peña B, \& Vega Y. (2015). Relación de la asignación de personal de enfermería con indicadores de resultado de la calidad de la atención en unidades de cuidados intensivos de adultos. Aquichan.

6. Orozco, S., \& Vija, M. (2018). Deshumanización en la atención de enfermería hacia los pacientes en los servicios hospitalarios. Universidad Santo Tomás.

7. Ortiz Vargas, I., García Campos, M., Beltrán Campos, V., Gallardo López, F., Sánchez Espinosa, A., \& Ruiz Montalvo, M. (2017). Cura húmeda de úlceras por presión. Atención en el ambito domiciliar. Enfermria Universitaria, 244-249.

8. Organizacion Mundial de la Salud. (2013). Úlceras por Presión: Guía de Diagnóstico y Manejo. OMS, 408-416.

9. Bracho, E., \& Garzón, S. (2015). Gestión de la Calidad sobre Prevención de errores en úlceras por presión y caídas, de los hospitales públicos, provincia de Imbabura, 2015. 1-147.

10. Ortiz Arjona, M., Fernández Berchez, M., Ortiz, O. A., \& Farouk Allam, M. (2012). Úlceras por presión y heridas crónicas. Dialnet Plus, 229-235.

11. Guinot Bachero, J., \& Furió Vizcaino, T. (2014). Poliulceración en Pacientes terminal: Úlceras de Kennedy, Plan de cuidados paliativos. Enferm Dermatol, 32-39.

12. Valero Cárdenas, H., Parra, D., Rey Gómez, R., \& Camargo Figuera, F. (3 de septiembre-diciembre de 2011). Prevalencia de úlcera por presión. Revista de la Universidad Industrial de Santander. Salud, 43(3), 249-245. Obtenido de http://www.redalyc.org/articulo. oa?id=343835703004

13. Hospital Universitario Ramón Y Cajal. (2015). Protocolos de Cuidados: Úlceras por Presión. Comunidad de Madrid, 4-12.

14. Tzuc-Guardía, A., Vega-Morales, E., \& Colli-Novelo, L. (2015). Nivel de riesgo y aparición de úlceras por presión en pacientes en estado crítico. Enfermeria Universitaria, 12(4), 204-211.Bermejo, \& Higuera . (2014). Humanización en salud. Ejes de la acreditación.

15. Miyazaki, M., Caliri, M., \& Santos, C. (2015). Conocimiento de los profesionales de enfer- 
mería sobre prevención de la úlcera por presión. Rev. Latino-Am. Enfermagem.

16. Zulkowski KD, Ayello EA, \& Wexler SM. (2017). Certification and Education: Do They Affect Pressure Ulcer Knowledge in Nursing? Skin Wound Care. Adv.

17. MH, H. V. (2014). Efeito de intervenções educativas no conhecimento dos profissionais de enfemagem sobre prevenção de úlceras pressão. Acta Paulista de Enfermagem.

18. Bermejo, \& Higuera . (2014). Humanización en salud. Ejes de la acreditación.

19. Sampier, R. H. (2013). Metodología de la I nvestigación (Vol. 6). Mexico: MCGRAW-HILL.

20. Matozinhos, F., Velasquez-Melendez, G., Tiensoli, S., Moreira, A., \& Goméz, F. (2017). Factores asociados con la Incidencia de Úlceras por Presión durante la estancia Hospitalaria. Revista da Escola de Enfermagen da USP, 51. doi:10.1590/s1980-220x201615803223

21. Serrano, M., Méndez, M., Cebollero, F., \& Rodríguez, J. (2017). Factores de riesgo asociados al desarrollo de úlceras por presión en unidades de cuidados intensivos de adultos: Revisión sistemática. Medicina Intensiva. Elsevier Medicina Intensiva, 41(6), 339-346. 



\title{
Evaluación del sellado apical de Bioroot RCS, Tubliseal y Top Seal: estudio in vitro
}

\section{Bioroot RCS, Tubliseal and Top Seal apical sealing evaluation: in vitro study}

\author{
Fernanda Sacoto* ${ }^{*}$, Paula Cárcamo², Raúl Alcántara² \\ 1 Docente de la Universidad Católica de Cuenca. \\ 1 Estudiante de la carrera de odontología de la Universidad Católica de Cuenca. \\ *kfer18_fisha@hotmail.es
}

DOI: https://

\section{Resumen}

En endodoncia, la fase de obturación radicular tiene como objetivo el sellado hermético del sistema de conductos radiculares, para conseguir esto se utilizan diversos materiales de obturación y selladores. Los selladores biocerámicos han estado disponible para su uso en endodoncia durante los últimos 30 años, tomando relevancia actualmente con el aumento del uso de la tecnología en el campo biocerámico. Este sellador ha sido ampliamente investigado por sus propiedades biocompatibles, registrándose escasa información sobre su capacidad de sellado apical. Por esta razón nuestro estudio evaluó esta característica midiendo el grado de filtración apical utilizando azul de metileno. Para ello se seleccionaron 80 dientes humanos extraídos con conducto único, se decoronaron y los conductos fueron preparados quimiomecanicamente con el sistema rotatorio Protaper Next hasta calibre X3. Previo a la obturación las muestras se dividieron en 4 grupos aleatoriamente: 1) Tubliseal, 2) Topseal, 3) BioRoot RCS y 4 ) Control positivo sin sellador. Se procedió a obturar con la técnica de cono único y los selladores respectivos excepto el grupo control. Las muestras se sumergieron en una solución de azul de metileno por 24 horas, se lavaron en agua corriente y se realizó la diafanización. Las muestras diafanizadas se observaron con estereoscopio y se midió la penetración lineal del colorante en micrones. 
Para el análisis de resultados se utilizó la prueba estadística Kruskal Wallis, mostrando que existe una diferencia significativa de los grupos experimentales con el grupo de control. A pesar, que no se presenta una diferencia significativa entre los grupos experimentales, Tubliseal tiene el mejor comportamiento como sellador apical. Los selladores BioRoot RCS y Topseal tuvieron comportamientos similares. Concluimos que se deben ajustar algunos parámetros metodológicos con el fin de obtener resultados más exactos en investigaciones futuras.

Palabras clave: Sellado apical, filtración apical, Tubliseal, Topseal, Bioroot RCS.

\section{Abstract}

In endodontics, the root filling phase aims to hermetically seal the root canal system. To achieve this, various sealing materials and sealants are used. Bioceramic sealants have been available for endodontics use during the past 30 years. Nowadays, with the increasing use of technology in the bioceramic field, these sealants have gain relevance and have been extensively investigated because of their biocompatible characteristics. However, little information is provided on their apical sealing capacity. This is why our study evaluated this characteristic by measuring the apical filtration level using methylene blue. To achieve this, 80 human teeth extracted with a single conduit were selected, their crowns were taken out, and the conduits were chemically prepared with the Protaper Next rotary system up to X3 calibre. Before the fiIling, the samples were randomly divided into 4 groups: 1) Tubliseal, 2) Topseal, 3) BioRoot RCS and 4) Positive control without sealant. The obturation was performed using the single cone technique and the corresponding sealants, except the control group. The samples were then immersed in a methylene blue solution for 24 hours, washed in fresh water and diaphanized. The diaphanized samples were observed by stereoscopy, and the dye linear penetration was measured in microns.

The Kruskal Wallis statistical test was used for the analysis of the results, revealing a significant difference between the experimental groups and the control group. Despite there being no significant difference between the experimental groups, Tubliseal performed the best as an apical sealer. BioRoot RCS and Topseal sealants had similar performance. We conclude that some methodological parameters must be adapted to obtain more accurate results in future research.

Key words: Apical sealing, apical filtration, Tubliseal, Topseal, Bioroot RCS. 


\section{Introducción}

En la terapia endodóntica, la fase de obturación está relacionada en gran medida con el éxito y fracaso del tratamiento; el objetivo de la obturación es lograr un sellado hermético del sistema de conductos radiculares. Actualmente continúa la investigación de nuevos materiales con mejores propiedades para optimizar la calidad de la obturación, razón por la cual los materiales son sometidos a diversas pruebas que garanticen la obtención de resultados favorables en su aplicación clínica.

Estudios clínicos han revelado que la filtración apical de materiales de relleno radicular es una de las principales causas de los fracasos de la terapia endodóntica'

La obturación endodóntica limita el intercambio de fluidos entre el conducto y el área peri radicular, este fenómeno se denomina filtración y determina en gran parte el éxito del tratamiento. La importancia del sellado apical se explica en función de la filtración, de manera que si el material de obturación se solubiliza en el área apical, se pierde este sellado, permitiendo la filtración, y disminuyendo el éxito del tratamiento endodóntico. ${ }^{2}$

En el mercado tenemos nuevos materiales de obturación, dentro de los cuales se encuentran los selladores biocerámicos, este sellador ha sido ampliamente investigado por sus propiedades biocompatibles, registrando escasa información sobre su capacidad de sellado apical, lo que motiva a la realización de esta investigación.

El objetivo de este estudio es evaluar la capacidad de sellado apical de cementos de conducto: Tubliseal, Topseal y BioRoot RCS al ser utilizados en la obturación radicular de piezas uniradiculares humanas extraídas con técnica de cono único.

Los resultados que se obtengan de este estudio, proporcionarán información relevante para el clínico, al momento de la selección del tipo de sellador que otorgue un mejor sellado apical

\section{Marco Teórico}

La obturación del conducto radicular es un procedimiento en el cual el espacio del conducto radicular se rellena con materiales de llenado y sellado en la etapa final del tratamiento del conducto radicular, posterior a la limpieza y la conformación adecuada del mismo. ${ }^{3}$

La obturación radicular tiene como objetivo obtener un sellado tridimensional del sistema de conductos radiculares. Un relleno insuficiente puede traducirse en una reinfección del sistema de conductos radiculares, lo que irritaría el tejido periapical y comprometería el éxito del tratamiento. ${ }^{4}$

El sellado tridimensional hermético dificulta la comunicación del interior del conducto radicular con los tejidos periapicales. ${ }^{5}$ En la literatura se ha descrito que, la eficacia de sellado se ve afectada por la técnica de sellado, el tipo del sellador y los procedimientos clínicos realizados antes del llenado del conducto radicular. ${ }^{5}$ 
Según Cohen S et al, el sellado apical inadecuado es responsable de hasta el $60 \%$ de las fallas del tratamiento endodóntico. ${ }^{4}$ Por lo que es necesario que los materiales endodónticos proporcionen un sello a largo plazo y se evite filtraciones o fugas a nivel coronal y apical. ${ }^{6}$

En endodoncia, para lograr un sellado adecuado del conducto radicular, se están utilizando diversos materiales de obturación y selladores.

Los selladores se utilizan entre la superficie de la dentina y el núcleo obturador para llenar las oquedades que se crean, debido a la inhabilidad física del material que conforma el núcleo obturador para llenar todas las áreas del sistema de conductos.

Actualmente, en la obturación del conducto radicular se emplea una material de núcleo semisólido o sólido denominado gutapercha que va cementado en el conducto radicular con un sellador ${ }^{7}$, el cuál cumple funciones como sellar vacíos y canales accesorios ${ }^{8}$, formar una unión entre el núcleo del material de relleno y la pared del conducto ${ }^{9}$, actuar como lubricante para facilitar la colocación del núcleo de relleno y sepultar a las bacterias restantes. ${ }^{10}$

Un sellador ideal, según Grossman, debe cumplir con las siguientes propiedades ${ }^{10}$ :

- Ser pegajoso durante la mezcla para proporcionar buena adherencia a la pared del conducto una vez fraguado.

- Proporcionar un sellado hermético.

- Ser radiopaco para poder ser visualizado en las radiografías.

- Las partículas del polvo deben ser muy finas para que puedan ser mezcladas fácilmente con el líquido.

- No contraerse al fraguar.

- $\quad$ No teñir la estructura dental.

- Ser bacteriostático, o por lo menos no favorecer la proliferación bacteriana.

- Fraguar lentamente.

- $\quad$ Ser insoluble en fluidos tisulares.

- Ser tolerado por los tejidos, es decir, no producir irritación del tejido peri-radicular.

- Ser soluble en un solvente común, por si es necesario removerlo del conducto radicular.

Los selladores utilizados para la obturación radicular han sido elaborados en base a: óxido de zinc-eugenol, vidrio ionómero, resina, silicona, MTA, y biocerámicos. Los selladores de nueva generación están siendo diseñados para mejorar su capacidad de penetrar en los túbulos dentinarios y adherirse. 
Recientemente, se presentó en el mercado los selladores a base de silicato de calcio que recomiendan su uso con la técnica de obturación de cono único. Estos selladores también denominados biocerámicos son preconizados por sus propiedades favorables, sin embargo estos poseen un enfoque más biológico donde el sellador interactúa con la dentina." Estudios demuestran que la técnica de cono único disminuye el estrés en el diente generado por otras técnicas de obturación, obteniendo menos grietas apicales e incluso menor porosidad. ${ }^{3}$ A pesar de ello es importante entender que las propiedades físicas, químicas y biológicas son propias de cada sellador, por lo que esta técnica de cono único podría no ser la más indicada según el caso.

Los selladores basados en eugenol todavía se usan hoy en día debido a su larga historia. Si se preparan selladores a base de eugenol, el eugenol se mezcla con óxido de zinc en presencia de agua y se produce una reacción de quelación, que da como resultado una matriz de eugenolato de zinc con moléculas de eugenol sin reaccionar atrapadas en su interior. Debido a que es una reacción reversible, cuando el cemento fraguado entra en contacto con el agua, se produce la hidrólisis de eugenolato y libera eugenol. Además de esto, se liberan moléculas de eugenol atrapadas en la matriz. ${ }^{12}$

El sellador Topseal se presenta en dos componentes pasta/pasta basado en resinas epoxyaminas. Se ha atribuído características como el sellado de larga duración, buena estabilidad dimensional, propiedades auto-adhesivas y excelente radiopacidad. ${ }^{13}$

Los selladores en base a biocerámicos han estado disponibles para su uso en endodoncia durante los últimos treinta años. Este tipo de sellador tomó relevancia con el aumento del uso de la tecnología en el campo biocerámico. Estos materiales están diseñados específicamente para uso médico y odontológico. Están compuestos por alúmina, zirconio, vidrio bioactivo, cerámica de vidrio, hidroxiapatita y fosfato cálcico. ${ }^{10}$

Estos materiales son hidrofílicos, requieren agua para establecerse y poseen biocompatibilidad y la capacidad de formación de apatita ${ }_{1}^{14}$ la formación de tejido mineralizado se produce por el alto pH alcalino alcanzado que activa y estimula la expresión de fosfatasa alcalina ${ }^{8}$. El mecanismo exacto de interacción entre el sellador biocerámico y la dentina radicular es desconocido; sin embargo, se han sugerido los siguientes mecanismos para los selladores a base de silicato de calcio ${ }^{10}$ :

- $\quad$ "Difusión de las partículas de sellador en los túbulos dentinarios (difusión tubular) para producir enlaces mecánicos de enclavamiento,

- La infltración del contenido mineral del sellador en la dentina intertubular, que da como resultado el establecimiento de un mineral en la zona de filtración, produce una desnaturalización del tejido de colágeno con un sellador alcalino fuerte,

- Reacción parcial de fosfato con hidrogel de silicato de calcio e hidróxido de calcio, producido por la reacción de silicatos de calcio en presencia de la humedad de la dentina, que da como resultado la formación de hidroxiapatita a lo largo del mineral en la zona de filtración". 
Además de la biocompatibilidad presenta otras características como osteoconductividad, capacidad de lograr un sellado hermético excelente, formación de un enlace químico con la estructura dental, insolubilidad en los fluidos tisulares, buena radiopacidad y fácil manejo que han llevado al uso generalizado de los biocerámicos en el área endodóntica..$^{10}$

Las aplicaciones para su uso varían desde el recubrimiento pulpar directo, a la apexogénesis, la apexificación y reparación de la furca. ${ }^{15}$

Los biocerámicos se pueden clasificar como ${ }^{16-17-18}$ : bioinerte, bioactivo y biodegradable.

BioRoot RCS es un sellador biocerámico, basado en silicato tricálcico hidráulico, se presenta como polvo/líquido, elaborado por la compañía francesa Septodont y existente en el mercado desde el año 2015. ${ }^{14}$

Es preconizado por propiedades bioactivas, antimicrobianas y un óptimo sellado. En su composición posee una parte líquida que es una solución acuosa de cloruro de calcio y policarboxilato y la otra es un polvo que contiene silicato de tricalcio, povidona y óxido de zirconio, éste último le da la radiopacidad. ${ }^{14}$

Este sellador está basado en agua, por lo tanto se debe usar con una técnica de obturación de un solo cono en lugar de una compactación vertical caliente porque las propiedades de sellador se cambian cuando se calientan. ${ }^{11-19}$

Este sellador es libre de resina y eugenol, además presenta propiedades hidrofílicas y permite un aumento de los valores de Ph de más de $11 .^{8}$

Aunque las ventajas de estos materiales han contribuido a su rápida propagación en el campo dental, hoy en día, no son ampliamente utilizados, y los productos comercialmente disponibles en el mercado no son aún conocidos por muchos dentistas. ${ }^{2}$

\section{Metodología}

Se realizó un estudio experimental comparativo transversal que evaluó el sellado apical entre tres tipos de cementos selladores endodónticos, para lo que se utilizaron 80 dientes humanos extraídos con conducto radicular único, ápice formado y ausencia de caries radicular.

Las muestras fueron obtenidas por donación de odontólogos de atención primaria, los cuales firmaron un consentimiento informado en el que se indicó que las muestras tenían indicación de extracción con fines terapéuticos no asociadas al estudio.

Los criterios de exclusión considerados fueron: fractura radicular, dientes con más de un conducto, desarrollo radicular incompleto, rizálisis, presencia de caries radicular, conductos con calcificaciones, curvatura radicular severa según Schneider y tratamiento endodóntico previo. 
Los dientes unirradiculares fueron lavados y limpiados mediante destartraje manual con cureta de Gracey (Hu- Friedy) teniendo la precaución de no tocar el ápice de los dientes. Luego se sumergieron durante 2 horas en hipoclorito de sodio al 5,25\% para eliminar restos de tejidos orgánicos remanentes. Las coronas se seccionaron utilizando un disco de carburo (Dentorium) con motor de baja velocidad (NSK), cerca de la unión amelocementaria. Para determinar la longitud de trabajo, los conductos se permeabilizaron con lima K \#10 (Denstply, Maillefer) hasta ser visualizada en el foramen y se descontó $1 \mathrm{~mm}$.

Los conductos se limpiaron y conformaron con limas rotatorias Protaper Next (Dentsply, Maillefer) hasta X3 (Figura 1), manteniendo la permeabilidad con lima $\mathrm{K} \# 10$ y utilizando irrigación con hipoclorito de sodio a 2,5\% - 4ml/min- el que se removió con una cánula aspiradora endodóntica (Indusbello). Los conductos fueron sometidos a un protocolo de irrigación final con EDTA al 10\% (Hertz) por 1 minuto para remoción del barro destinario e irrigación con hipoclorito de sodio al 2,5\% - 1ml por conducto. Luego se secaron con conos de papel (Gapadent).

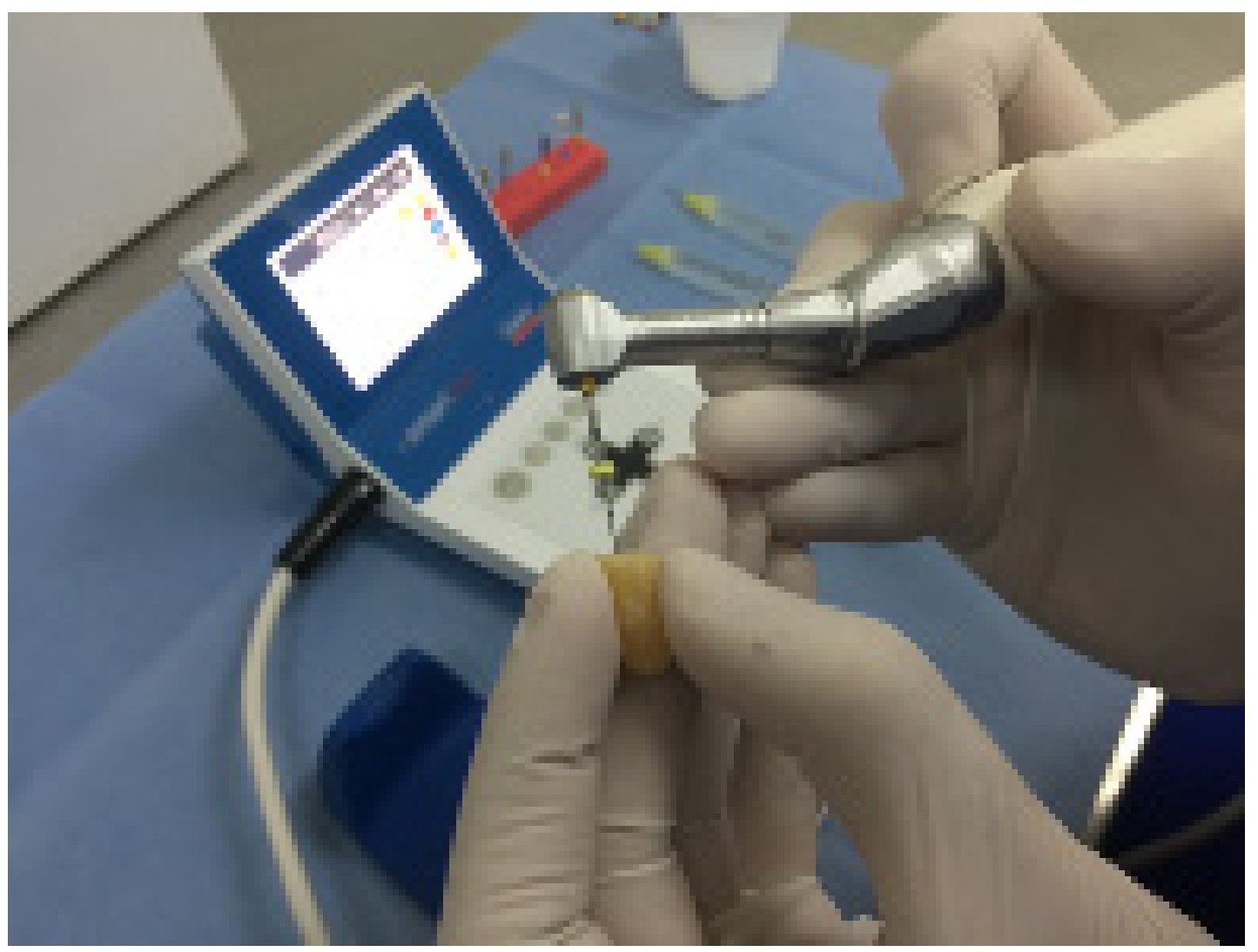

Figura 1. Proceso de preparación mecánica del conducto radicular con el sistema rotatorio Protaper Next (Dentsply/Maillefer)

Los dientes fueron divididos aleatoriamente en 3 grupos experimentales y 1 de control para ser obturados con conos de gutapercha X3 Protaper Next mediante técnica de cono único. Las muestras de los 3 grupos experimentales correspondían a: Grupo 1 (G1) Tubliseal - SybronEndo ( $n=20$ ), Grupo 2 (G2) Topseal - Denstply, Maillefer ( $n=20$ ), Grupo 3 (G3) BioRoot RCS - Septodont ( $n=20)$. Además, se contó con un grupo control positivo $(n=20)$ que corresponde a conductos obturados sin sellador (Figura 2). 


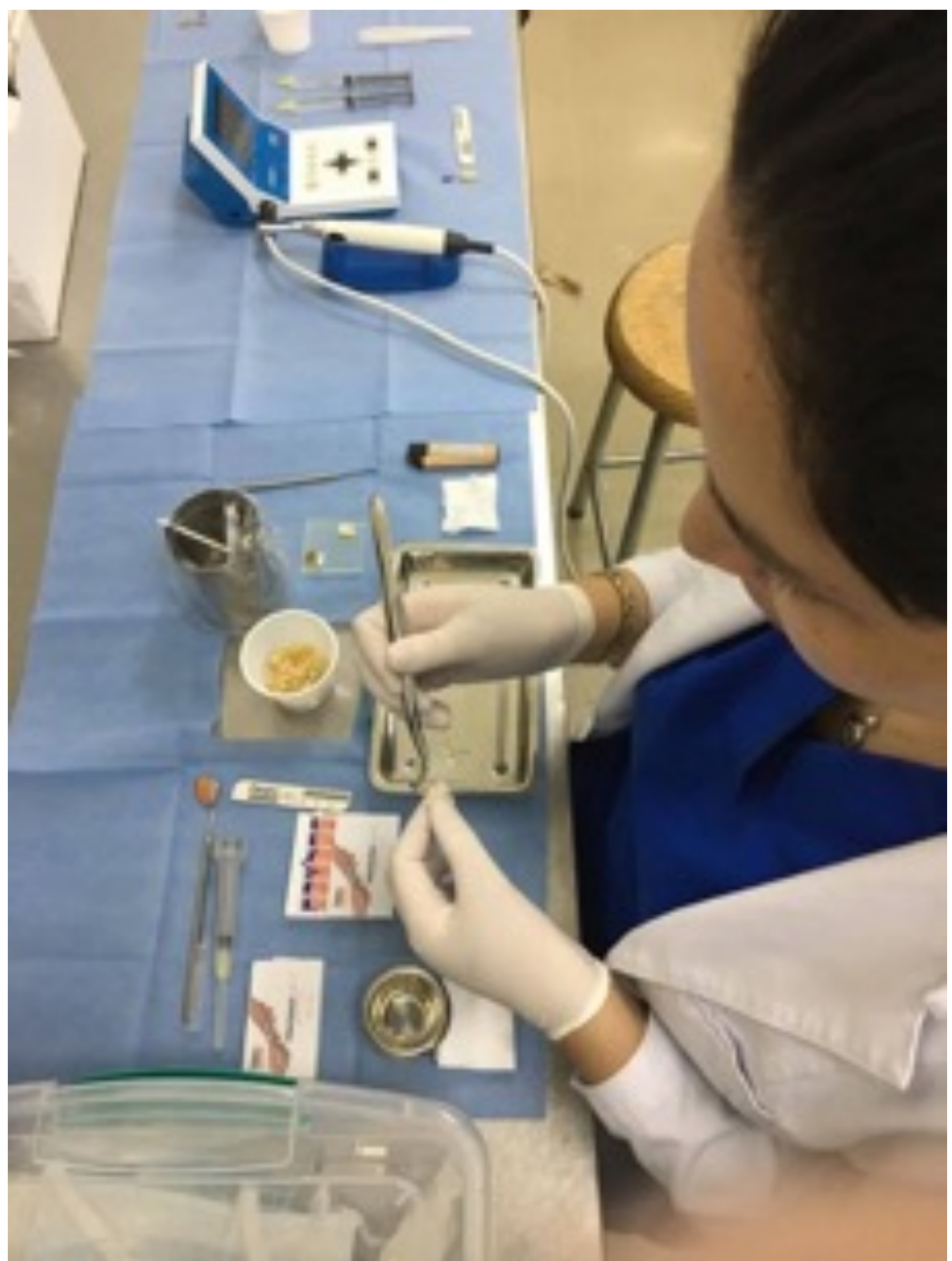

Figura 2. Proceso de Obturación con técnica de cono único

Las raíces fueron barnizadas con dos capas de esmalte de uñas (Opi) en su superficie radicular excepto en los $3 \mathrm{~mm}$ apicales. Una vez seco el esmalte, las muestras fueron sumergidas en recipientes con azul de metileno durante un periodo de 24 horas a temperatura ambiente (20+-1ํㅡ). Una vez terminado el proceso de tinción se lavó con agua corriente durante $15 \mathrm{mi}-$ nutos para eliminar los restos de azul de metileno y se retiró el esmalte de uñas transparente con bisturí (Denpher y Dochem) sin tocar el ápice.

Posteriormente las piezas se colocaron en recipientes para realizar la diafanización de acuerdo a la siguiente técnica (Figura 3 A y B):

1. Los dientes se sumergieron en Ácido Nítrico al $5 \%$ el cual se cambió cada 12 horas, a fin de lograr la descalcificación de las muestras, por 5 o 7 días según el caso, ya que algunas piezas se descalcifican más rápido que otras.

2. Luego se lavaron las muestras por 4 horas con agua corriente para retirar restos de Ácido Nítrico. Una vez limpias se secaron con secador de pelo (Gamma).

3. Todas las muestras fueron deshidratadas con metanol en concentraciones ascendentes según la siguiente secuencia: 
- Metanol al 50\%: Se sumergieron las muestras durante 2 horas.

- Metanol al 75\%: Se sumergieron las muestras durante 1 hora.

- Metanol al 90\%: se sumergieron las muestras durante 1 hora.

- Metanol al 99\%: se sumergieron las muestras durante 1 hora.

4. Una vez terminada la deshidratación se secaron con aire y se mantuvieron sumergidas en salicilato de metilo.
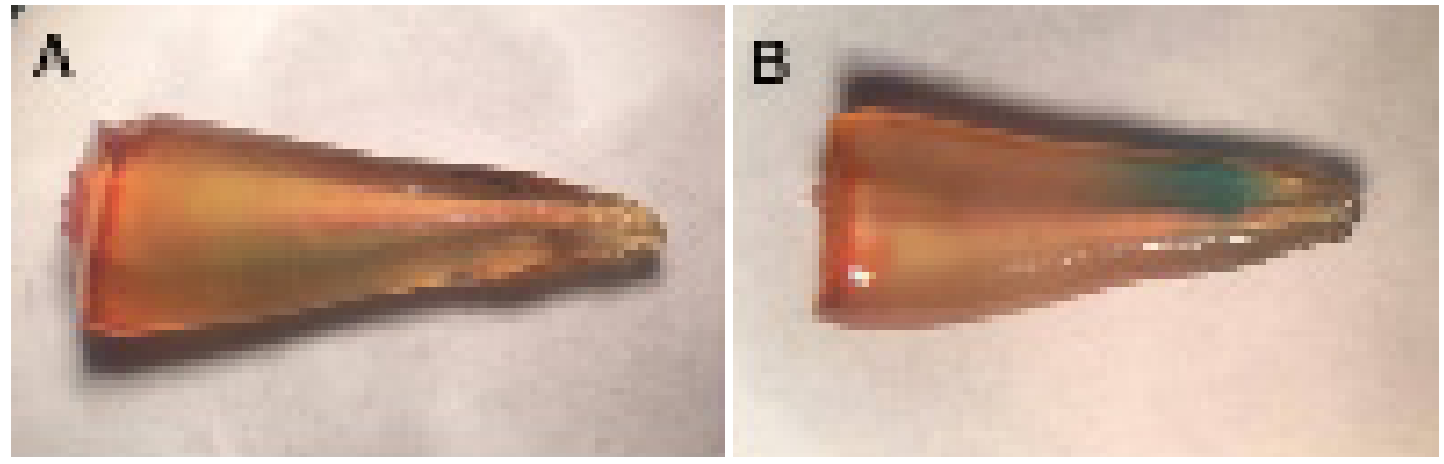

Figura 3. A y B: Raíces diafanizadas con ácido nítrico al $5 \%$ y etanol en grados crecientes.

Un único operador, que no conocía el cemento sellador empleado, observó las muestras con estereoscopio (Carl Zeiss) y midió la penetración lineal de azul de metileno en micrones ( $\mu \mathrm{m})$ mediante ocular micrométrico (Leitz Wetzlar) usando micrómetro de referencia (Spencer Lens Co.), desde el foramen. Las mediciones obtenidas de la penetración lineal del azul de metileno se registrarán en micrones ( $\mu \mathrm{m}$ )(Figura 4,5 y 6 ).
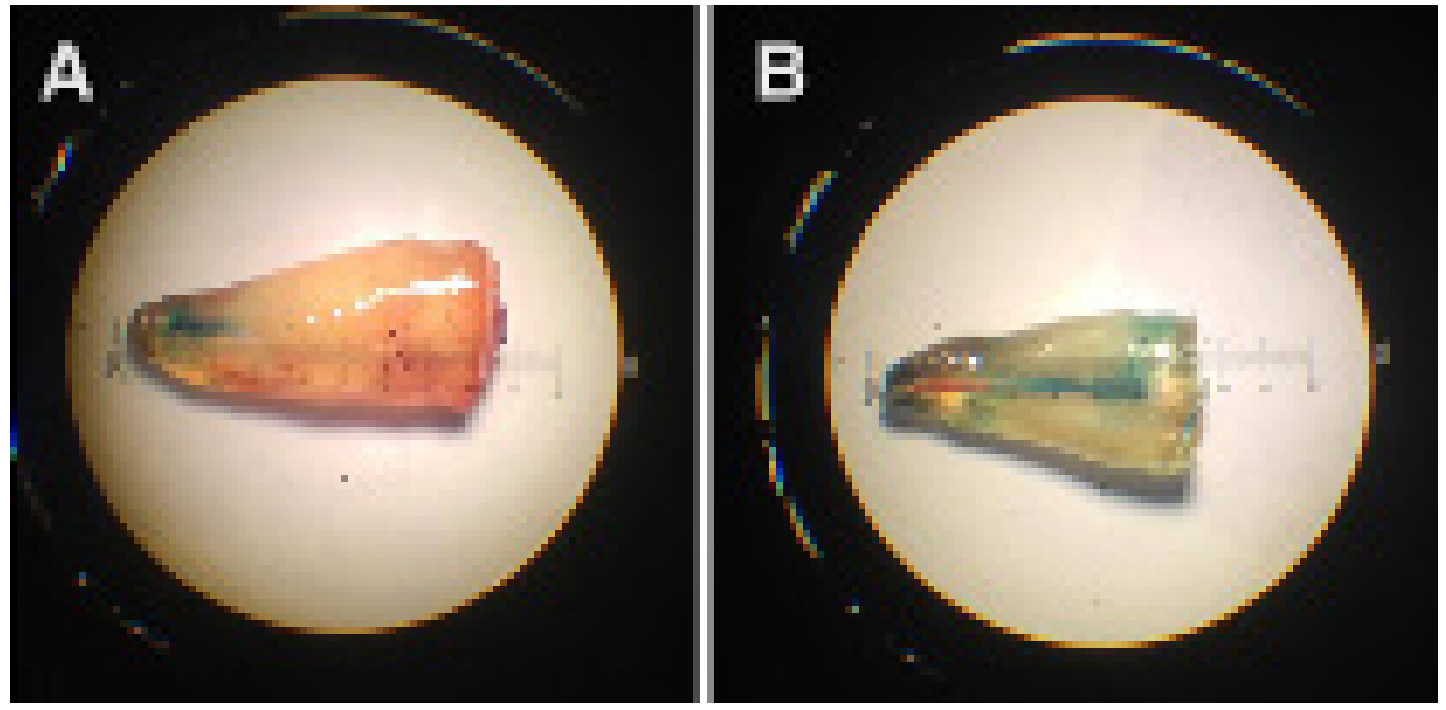

Figura 4. Raíces con sellador de conductos BioRoot. A: filtración únicamente del tercio apical, B: filtración a lo largo del conducto casi en su totalidad. 


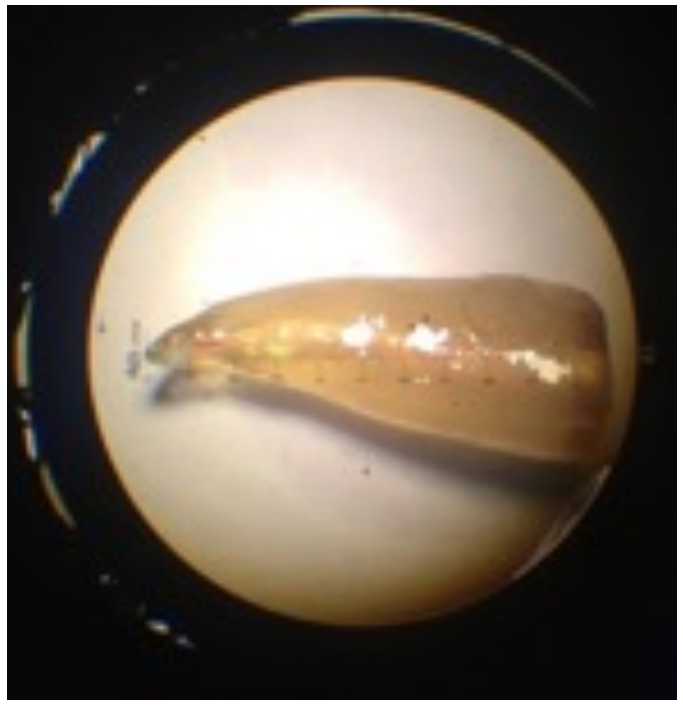

Figura 5. Raíz con sellador de conductos Tubliseal, no se observa filtración apical.
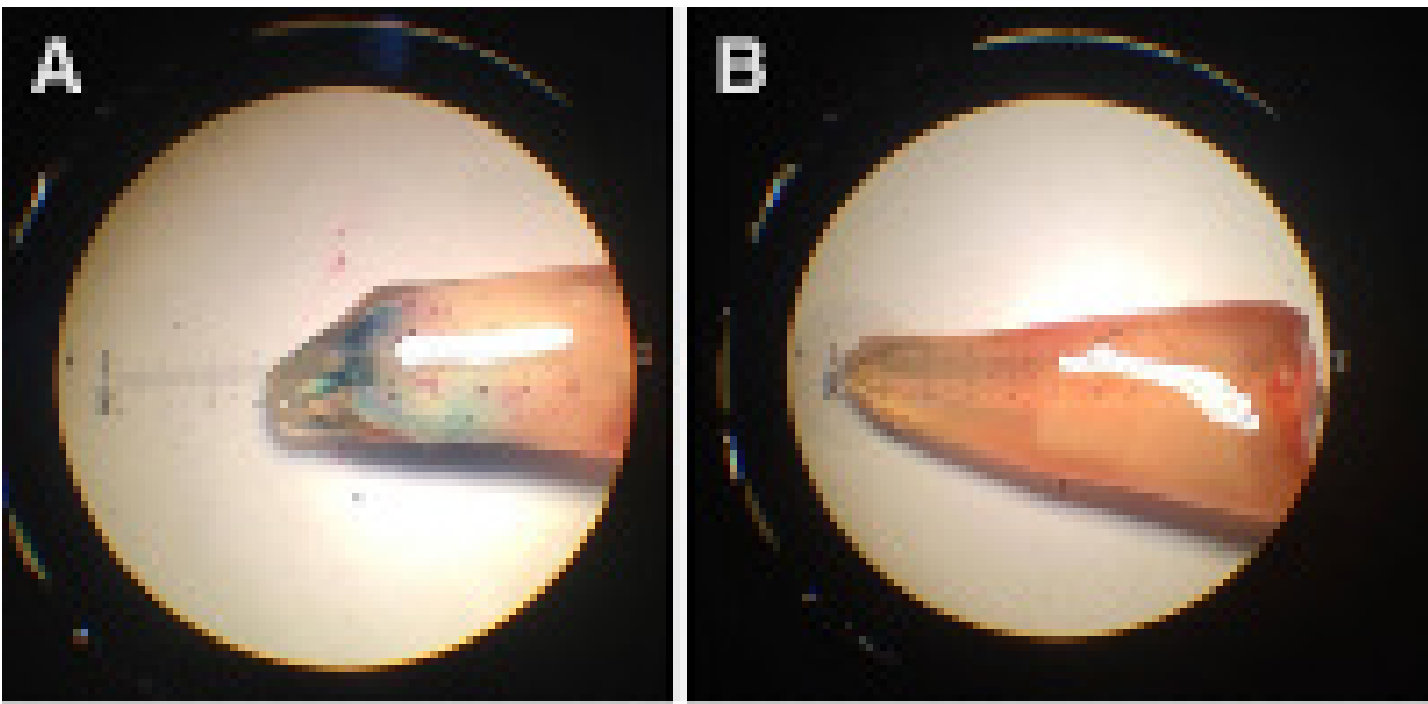

Figura 6. Raíces con sellador de conductos Topseal. A: evidencia filtración apical, B: no existe filtración apical.

Todas las muestras fueron eliminadas al término del estudio según el protocolo de manejo de residuos biológicos de la facultad de odontología de la Universidad de Concepción.

\section{Resultados}

Los datos obtenidos fueron tabulados en Microsoft ${ }^{\circledR}$ Office Excel $^{\circledR} 2015$ y analizados mediante el programa estadístico InfoStat ${ }^{\oplus} 2016$ con la prueba Kruskal Wallis con un nivel significancia del $5 \%$. Se utilizó esta prueba estadística no paramétrica porque los datos no mostraban una distribución normal.

La distribución anormal de los datos es reflejada por la gran dispersión de algunos valores en los grupos estudiados, esto se muestra en la Figura 7. 


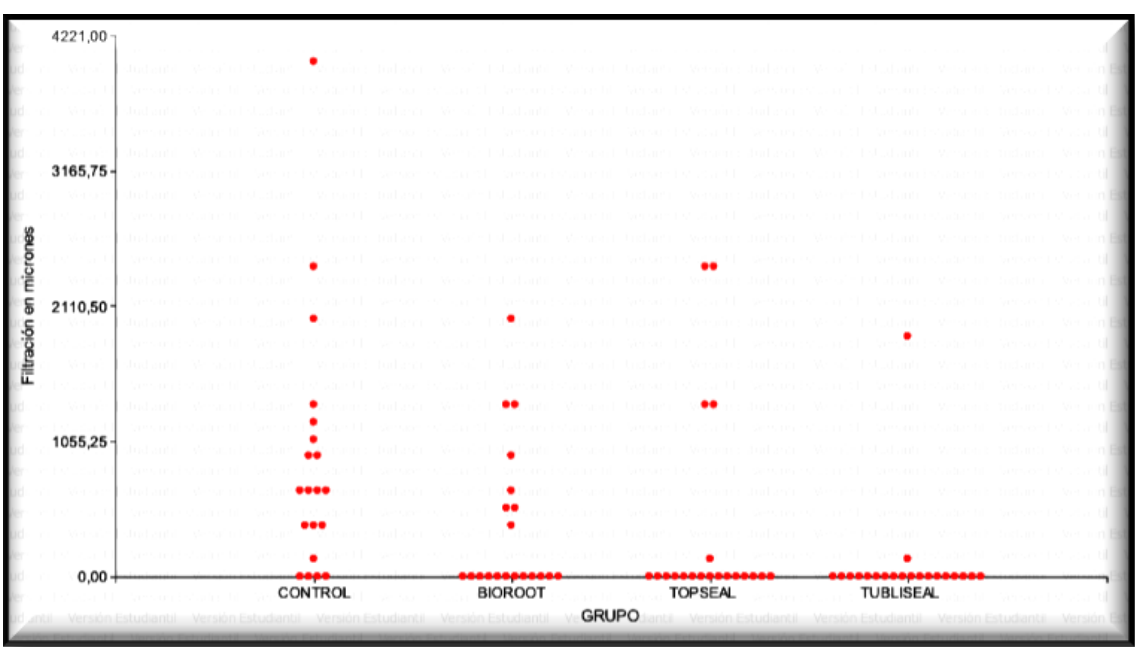

Figura 7. Dispersión de las medidas de filtración en los grupos estudiados. Los grupos experimentales BioRoot, Topseal y Tubliseal reflejan valores repetitvos, observando varios puntos en el inicio del eje ordinal del gráfico.

El grupo de control mostró la máxima penetración de la tinción, mostrando una mediana $670,00 \mu \mathrm{m}$ en comparación con los grupos experimentales que presentaron una mediana de $0,00 \mu \mathrm{m}$ (Tabla 1); la prueba evidencia que hay una diferencia estadísticamente significativa de 0,0002 entre los grupos.

\begin{tabular}{|c|c|c|c|c|c|}
\hline GRUPO & N & Medias & D.E. & Medianas & p \\
\hline BIOROOT & 20 & 388,60 & 592,77 & 0,00 & 0,0002 \\
\hline TOPSEAL & 20 & 381,90 & 805,50 & 0,00 & \\
\hline TUBLISEAL & 20 & 100,50 & 418,98 & 0,00 & \\
\hline CONTROL & 20 & 897,80 & 982,87 & 670,00 & \\
\hline
\end{tabular}

Tabla 1. Comparación entre grupos utilizando la prueba estadística Kruskal Wallis.

La diferencia estadísticamente significativa dada por la prueba estadística Kruskal Wallis establece la diferencia entre el grupo de control con los grupos experimentales que correponden a BioRoot RCS, Tubliseal - SybronEndo y Topseal - Denstply, Maillefer (Tabla 2)

\begin{tabular}{|c|c|c|}
\hline GRUPO & \multicolumn{2}{|l|}{ Ranks } \\
\hline TUBLISEAL & 28,75 & $\mathrm{~A}$ \\
\hline TOPSEAL & 36,20 & $\mathrm{~A}$ \\
\hline BIOROOT & 40,65 & $\mathrm{~A}$ \\
\hline CONTROL & 56,40 & $\mathrm{~B}$ \\
\hline
\end{tabular}

Tabla 2. Diferencia entre grupo control y grupos experimentales. 
En cuanto a la capacidad de sellado apical se observó que el grupo control presentó un valor mayor de microfiltración frente a los grupos experimentales con una media de 897,8 $\mu \mathrm{m}$. El Tubliseal es el cemento sellador que presentó una menor media de microfiltración $(100,5 \mu \mathrm{m})$ en relación a los grupos experimentales. Bioroot RCS y Topseal presentaron un comportamiento similar. Sin embargo, no hay diferencia estadísticamente significativa entre los cementos selladores de los grupos experimentales (Figura 8).

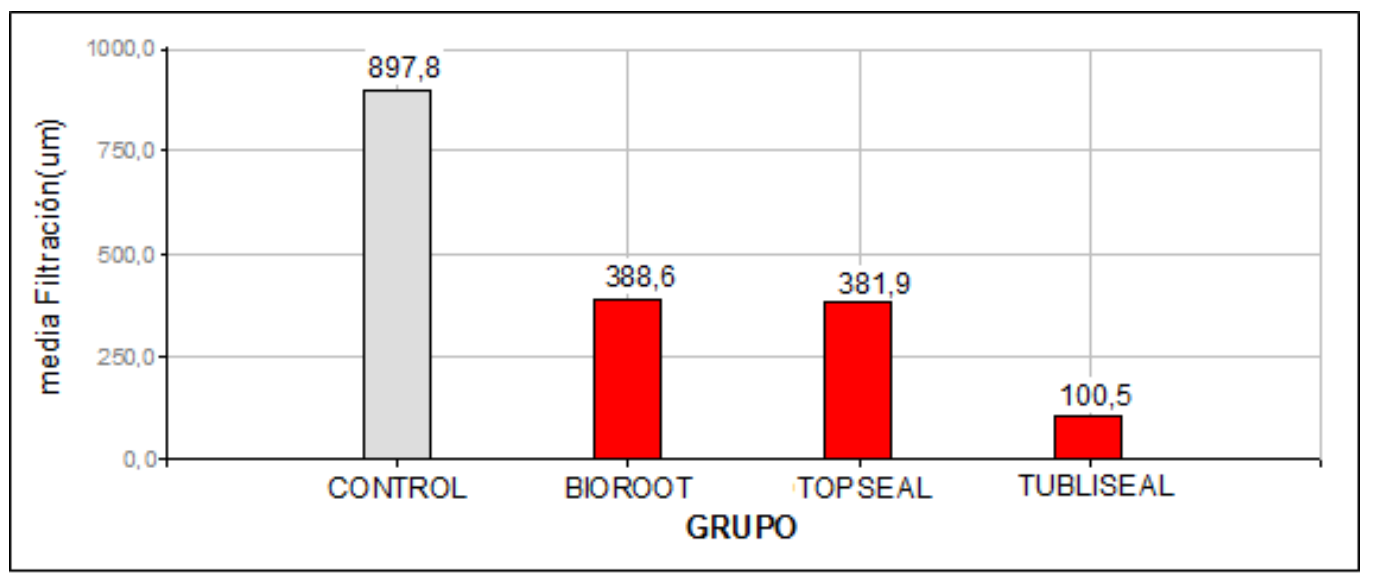

Figura 8. Media de microfiltración $(\mu \mathrm{m})$ de los grupos experimentales y grupo control

\section{Discusión}

El presente estudio evalúo la capacidad de sellado apical de diferentes selladores utilizando la técnica de obturación de cono único. La técnica de cono único en la actualidad es fundamentada por su simplicidad, puesto que se dispone de sistemas rotatorios con sus respectivos conos de gutapercha, además hay disminución de estrés en el diente, paciente y odontólogo ${ }^{20}$ En la literatura se evidencia estudios que comparan las técnicas de obturación cono único, compactación vertical caliente y compactación lateral dando como resultado que no existe diferencias significativas entre ellas. ${ }^{21}$

Al analizar los resultados de este estudio no se encontraron diferencias estadísticamente significativas entre los grupos experimentales, sin embargo se evidenció una diferencia de los grupos experimentales con el grupo control.

Consistente con nuestros resultados, Shetty $V$ et al. compararon la microfiltración apical usando la técnica de penetración de colorante, los selladores que compararon fueron Tubliseal, Sealapex y AH26. Ellos reportaron que Tubliseal mostró menor filtración en comparación a los otros selladores. ${ }^{22}$

Los grupos experimentales obturados con selladores Topseal y BioRoot presentaron valores similares de microfiltración, superiores a Tubliseal. 
Reszka P et al. menciona que las propiedades de sellado de BioRoot RCS combinadas con gutapercha son comparables a las de AHPlus, sin embargo su estudio realizado con microCT reveló un mayor volumen vacíos para BioRoot RCS que el sellador a base de resina, posiblemente debido al menor tiempo de trabajo y menor cantidad de AHPlus. ${ }^{8}$

BioRoot RCS mostró una mayor filtración que Tubliseal. Esto pudo originarse porque en la parte experimental no se consideró colocarlo en un medio con la humedad adecuada inmediato a la obturación. Siboni et al. menciona que los altos valores de solubilidad en agua destilada que presentó su grupo experimental obturado con BioRoot RCS se correlaciona con una alta liberación de $\mathrm{Ca} 2+$ y $\mathrm{OH}$-, que se disuelven dejando espacios vacíos. Cuando se sumerge en un fluido corporal simulado, los iones de calcio combinados con el fosfato forman una capa de Fosfato cálcico capaz de llenar los espacios vacíos(14). Por lo tanto la solubilidad y la porosidad de los materiales de silicato de tricálcico en agua destilada no predicen la estabilidad e integridad reales de dichos materiales in vivo. ${ }^{14}$

La evaluación de la capacidad de sellado es considerada un parámetro importante para evaluar la introducción al mercado de un nuevo sellador. Esta evaluación cada vez se ha visto desplazada por la falta de reproducibilidad en los estudios de microfiltración apical, esto se explica por las diferencias y complejidades anatómicas de los dientes investigados. ${ }^{19}$ Van der Sluis et al. demostró que existe una diferencia significativa en la filtración entre conductos ovalados y redondos, ${ }_{1}^{23}$ razón por la que nuestro estudio se pudo ver influenciado por la variación anatómica de los dientes utilizados, puesto que no se estandarizó la anatomía de los conductos previo al estudio, siendo necesario a futuro considerar esta característica.

\section{Conclusiones y recomendaciones}

En el presente estudio todos los grupos presentaron filtración apical, no obstante, el porcentaje de muestras que no filtraron en los grupos experimentales fue mucho mayor en relación a las muestras filtradas. Tubliseal mostró el mejor compartamiento de los selladores estudiados, aunque no existe una diferencia significativa con BioRoot RCS y Topseal, siendo estos útimos similares en su comportamiento.

BioRoot RCS presenta buenas propiedades de sellado, a en este estudio no se consideró simular el medio de humedad adecuado para su fraguado que a diferencia de otros selladores requiere un medio similar a los fluidos corporales con los que estaría en contacto cuando se usa in vivo.

El factor anatómico es una variable esencial a ser considerada en el diseño de estudios futuros, porque las variaciones en el tipo de diente, forma del conducto y calibre apical pueden influir directamente en los resutados de investigaciones de sellado apical. 


\section{Referencias Bibliograficas:}

1. Moradi S, Lomee M, Gharechahi M. Comparison of fluid filtraton and bacterial leakage techniques for evaluation of microleakage in endodontics. Dent Res J (Isfahan). 2015;12(2):109-14.

2. Lucian A, Bud M. The Use of Bioceramics in Endodontics - Literature Review. 2016;89(4):10-3.

3. Kim S, Kim S, Park J. Comparison of the Percentage of Voids in the Canal Filling of a Calcium Silicate-Based Sealer and Gutta Percha Cones Using Two Obturation Techniques. Mater. 2017;10(10).

4. Ahuja L. A Comparative Evaluation of Sealing Ability of New MTA Based Sealers with Conventional Resin Based Sealer: An In-vitro Study. J Clin Diagnostic Res. 2016;10(7):76-9.

5. Holland R, Murata SS. Apical Seal of Root Canals with Gutta-Percha Points with Calcium Hydroxide. Braz Dent J. 2004;15:26-9.

6. Prüllage R, Urban $K$, Schäfer E, Dammaschke T. Material Properties of a Tricalcium Silicate - containing, a Mineral Trioxide Aggregate - containing , and an Epoxy Resin - based Root Canal Sealer. J Endod. 2016;42(12):1784-8.

7. Patni PM, Chandak M, Jain P, Patni MJ. Stereomicroscopic Evaluation of Sealing Ability of Four Different Root Canal Sealers- An invitro Study. J Clin Diagnostic Res. 2016;10(8):379.

8. Reszka PB, Nowicka A, Lipski M, Dura WB, Dro A, Wo K. A Comparative Chemical Study of Calcium Silicate-Containing and Epoxy Resin-Based Root Canal Sealers. Biomed Res Int. 2016;

9. Baudry A, Richard G, Kellermann 0, Goldberg M. In vitro bioactivity of Bioroot TM RCS, via A4 mouse pulpal stem cells. Dent Mater [Internet]. 2015;31(11):1290-7. Available from: http://dx.doi.org/10.1016/j.dental.2015.08.163

10. Al-Haddad A, Aziz ZACA. Bioceramic-Based Root Canal Sealers: A Review. Int J Biomater. 2016;2016:1-11.

11. Khalil I, Naaman A, Camilleri J. Properties of Tricalcium Silicate Sealers. J Endod. 2016;42(10):1529-35.

12. Segatto A, Altmann P, Castelo V, Leitune B. Influence of Eugenol-based Sealers on Pushout Bond Strength of Fiber Post Luted with Resin Cement : Systematic Review and Meta-analysis. J Endod. 2015;41(9):1418-23.

13. Denstply/Maillefer. Topseal: Intrucciones de uso. 2008.

14. Siboni F, Taddei P, Zamparini F, Prati C, Gandolfi M. Properties of BioRoot RCS, a tricalcium silicate endodontic sealer modified with povidone and polycarboxylate. Int Endod J. 2017;0-3.

15. Swarup S, Rao A. Bioceramics in pediatric endodontics. 1st editio. Trivandrum: Lambert Academic Publishing; 2013. 53-68 p. 
16. Utneja S, Nawal RR, Talwar S, Verma M. Current perspectives of bio-ceramic technology in endodontics: calcium enriched mixture cement - review of its composition, properties and applications. Restor Dent Endod. 2015;40(1):1-13.

17. Best SM, Porter AE, Thian ES, Huang J. Bioceramics: Past, present and for the future. J Eur Ceram Soc. 2008;28(7):1319-27.

18. Badami V, Ahuja B. Review Article Biosmart Materials : Breaking New Ground in Dentistry. 2014;2014.

19. Viapiana R, Moinzadeh AT, Camilleri L, Wesselink PR, Filho MT. Porosity and sealing ability of root fillings with gutta-percha and BioRoot RCS or AH Plus sealers . Evaluation by three ex vivo methods. Int Endod J. 2016;49(8):774-82.

20. Sadr S, Golmoradizadeh A, Raoof M, Javad M. Microleakage of Single-Cone Gutta-Percha Obturation Technique in Combination with Different Types of Sealers. Iran Endod J. 2015;10(3):199-203.

21. Gordon MPJ, Love RM, Chandler NP. An evaluation of . 06 tapered gutta-percha cones for filling of . 06 taper prepared curved root canals. Int Endod J. 2005;38(3):87-96.

22. Shetty V, Hegde P, Chauhan Singh R, Rampratap Chaurasia V, Manmohan Sharma A, Taranath M. A Spectro Photometric Comparative Evaluation of Apical Sealing Ability of Three Different Sealers ; Calcium Hydroxide Based, Resin Based and Zinc Oxide Eugenol Based Sealers. J Int Oral Heal. 2015;7(2):25-7.

23. Van der Sluis $L$, Wu M, Wesselink P. An evaluation of the quality of root fillings in mandibular incisors and maxillary and mandibular canines using different methodologies. $J$ Dent. 2005;33:683-8.

Recibido:

Aceptado: 



\section{Tratamiento restaurador atraumático: Eficacia clínica de ionómeros de vidrio en cavidades clase I}

\section{Atraumatic restorative treatment: Clinical efficacy of glass ionomers in class I cavities}

Katia Luz Medina Calderón', Jorge Raúl Colchado Carhuavilca², Luis Antonio Vicuña Huaqui ${ }^{3}$, Ezzard Omar Álvarez Díaz

1 Docente Asociado Dpto. Académico Estomatología Preventiva y Social. Doctorando en Esto matología. Facultad de Odontología, Universidad Nacional Mayor de San Marcos. Av. Carlos Ger mán Amézaga 375, Ciudad Universitaria, Lima 15081, Perú.

2 Docente Auxiliar Laboratorio Bioquímica. Doctorando en Estomatología. Facultad de Odonto logía, Universidad Nacional Mayor de San Marcos. Av. Carlos Germán Amézaga 375, Ciudad Universitaria, Lima 15081, Perú.

3 Estudiante de pregrado. Facultad de Odontología, Universidad Nacional Mayor de San Marcos Av. Carlos Germán Amézaga 375, Ciudad Universitaria, Lima 15081, Perú

4 Docente Principal Dpto. Académico Ing. de Sistemas e Informática. Facultad de Ingeniería Industrial. Universidad Nacional Mayor de San Marcos. Av. Carlos Germán Amézaga 375, Ciudad Universitaria, Lima 15081, Perú

Correspondencia:

Katia Luz Medina Calderón: kmedinac@unmsm.edu.pe, +51 942762291. Universidad Nacional Mayor de San Marcos. Av. Carlos Germán Amézaga 375, Ciudad Universitaria, Lima 15081, Perú

DOI: https:// 


\section{Resumen}

La Técnica de Restauración Atraumática (TRA) es un procedimiento preventivo-restaurador mínimamente invasivo, como alternativa de tratamiento para poblaciones vulnerables con poco o nulo acceso a servicios de salud, que consiste en la remoción del tejido dentario cariado utilizando sólo instrumentos manuales y un material adhesivo de restauración: el ionómero de vidrio de alta viscosidad debido a sus propiedades físicas y químicas, como la adhesión a la estructura dental, la biocompatibilidad, la reacción de fraguado químico y el desarrollo y la liberación de fluoruro, que le confieren características preventivas. Objetivo: Revisar la evidencia sobre la eficacia clínica, mediante el desempeño clínico y la supervivencia de los ionómeros en el tratamiento restaurador atraumático en dentición decidua. Métodos: Se realizó la búsqueda de información: estudios in vitro, ensayos clínicos aleatorizados y revisiones sistemáticas con antigüedad máxima de 10 años, en las bases de datos Medline, Scielo y Scopus, con las estrategias de búsqueda ("Dental Atraumatic Restorative Treatment/therapeutic use"[Mesh] OR "Dental Atraumatic Restorative Treatment/trends"[MesH] OR ART OR PRAT) y (("Dental Atraumatic Restorative Treatment"[Mesh]) AND ("Glass Ionomer Cements"[Mesh]) OR "Ketac-Molar Quick" [Supplementary Concept]). Conclusiones: Existe evidencia científica suficiente para determinar el éxito de las restauraciones TRA en lesiones de una superficie en dentición decidua, incluso en comparación con los materiales restauradores de los tratamientos convencionales. El desempeño clínico y la supervivencia es alta cuando se utilizan ionómeros de alta viscosidad. Aún no hay consenso acerca de las ventajas del uso de ionómeros de menor costo, encapsulados, reforzados con metal y/o con propiedades mejoradas.

Palabras clave: Tratamiento restaurador atraumático; cementos de ionómero vítreo; odontología pediátrica

\section{Abstract}

The Atraumatic Restoration Technique (ART) is a minimally invasive preventive-restorative procedure, as a treatment alternative for vulnerable populations with little or no access to health services, which consists of the removal of decayed dental tissue using only manual instruments and a restorative adhesive material: the glass ionomer of high viscosity due to its physical and chemical properties, such as adhesion to tooth structure, biocompatibility, chemical setting reaction and the development and release of fluoride, which confer preventive characteristics. Objective: To review the evidence on clinical efficacy through clinical performance and survival of ionomers in atraumatic restorative treatment in deciduous dentition. Methods: We searched for information: in vitro studies, randomized clinical trials and systematic reviews with a maximum age of 10 years, in the databases Medline, Scielo and Scopus, with search strategies ("Dental Atraumatic Restorative Treatment/therapeutic use"[Mesh] OR "Dental Atraumatic Restorative Treatment/trends"[MesH] OR ART OR PRAT) and (("Dental Atraumatic Restorative Treatment"[Mesh]) AND ("Glass lonomer Cements"[Mesh]) OR "Ketac-Molar Quick" [Supplementary Concept]). Conclusions: There is sufficient scientific evidence to determine the success of ART restorations in lesions of a deciduous dentition sur- 
face, even compared to the restorative materials of conventional treatments. Clinical performance and survival is high when high viscosity ionomers are used. There is still no consensus on the advantages of using lower-cost, encapsulated, metal-reinforced, and/or improved-properties- and/or lower-cost day-on-ones.

Key words: Atraumatic restorative treatment, vitreous ionomer cements, pediatric dentistry.

\section{Introducción}

En el Perú la caries dental es una de las enfermedades más prevalentes, $87 \%$ en niños menores a 12 años ${ }^{1}$ y constituye una de las principales causas de consulta en los establecimientos de salud, siendo más acentuada esta realidad en la población que se encuentra en condiciones de pobreza y bajos recursos económicos que no acceden a los servicios de salud bucal y en los casos que acuden optan por tratamientos de remoción quirúrgica de las piezas dentarias, afectando las funciones masticatorias, fonéticas, estéticas, entre otras. ${ }^{2}$

Ante esta problemática de falta de acceso a tratamientos iniciales primarios de abordaje de la caries dental y limitación del daño se han adoptado enfoques mínimamente invasivos en población infantil y con desventaja social, mediante el tratamiento restaurador atraumático (TRA), el cual muestra evidencia consistente de adecuados resultados en comparación con la técnica tradicional; esta técnica emplea conocimientos sobre remoción parcial de caries, dentina desmineralizada, con el enfoque de la Odontología mínimamente invasiva. ${ }^{3-4}$

El material empleado para la restauración con esta técnica es el ionómero de vidrio, el cual resalta en altas tasas de supervivencia debido a sus propiedades de adhesión a tejido dentario, liberación de flúor, biocompatibilidad, propiedad térmica y mecánica, solubilidad, estética y manipulación. ${ }^{4}$ Diversos estudios de evaluación de supervivencia han permitido determinar el tiempo y el desempeño clínico que el ionómero permanece en la cavidad bucal; sin embargo, es necesario seguir evaluando otra propuesta de marca alternativa de menor costo que permitan emplearse en la salud pública, por ello, el objetivo de este estudio es revisar la evidencia disponible sobre la eficacia clínica y aceptabilidad en el tiempo de los ionómeros de vidrio en restauraciones clase I de piezas deciduas.

\section{Metodología}

Se realizó la búsqueda de información en las bases de datos Medline, Scielo y Scopus, con las palabras claves ("Dental Atraumatic Restorative Treatment/therapeutic use "[Mesh] OR "Dental Atraumatic Restorative Treatment/trends"[MesH] OR ART OR PRAT) y (("Dental Atraumatic Restorative Treatment"[Mesh]) AND ("Glass lonomer Cements"[ Mesh]) OR "Ketac-Molar Quick" [Supplementary Concept]). Se limitó a estudios de 10 años la búsqueda de las investigaciones, se incluyó estudios in vitro, ensayos clínicos aleatorizados y revisiones sistemáticas, sin restricción de idiomas y espacio geográfico. 


\section{Estado del Arte}

Técnica de Restauración Atraumática

La caries dental es una enfermedad considerada como una "disbiosis" manifestada por el elevado consumo de azúcares fermentables que provoca un desequilibrio en la proporción de los microorganismos y eventos metabólicos del biofilm oral, que generan una posterior disolución química localizada de la superficie dentaria conocido como proceso carioso; ${ }^{5}$ para disminuir el riesgo de aparición de nuevas lesiones, el control de la placa, la alimentación bajo en azúcares y la atención oportuna con el odontólogo son medidas fundamentales. ${ }^{6}$

Como parte de estas medidas, se implementó el uso del TRA en la atención en poblaciones de zonas marginadas y de difícil acceso: ${ }^{7}$ el enfoque TRA se basa en el tratamiento de dientes cariados mediante la eliminación de la dentina afectada con instrumentos de mano y sin administración de anestesia local, ${ }^{8}$ es un procedimiento alternativo de bajo costo al prescindir de tecnología convencional y se encuentra basado en el paradigma de la odontología mínimamente invasiva. ${ }^{9}$ Se presenta como un proceso agradable, brinda gran expectativa para su uso en niños y adultos temerosos y en pacientes con impedimento físico y mental, que viven en casas de reposo y abandonadas. ${ }^{10}$

\section{El ionómero de vidrio para el Tratamiento Restaurador Atraumático}

El ionómero de vidrio es un material innovador al presentar como ventaja la liberación de fluoruro, adhesión específica a esmalte y dentina y coeficiente de expansión térmica similar al diente (11) emergió como un material restaurador a principios de la década de 1970, con estética más agradable que las restauraciones metálicas; sin embargo, en áreas donde debían soportar estrés era una limitante, dado las pobres propiedades mecánicas como la baja resistencia a la fractura, tenacidad y resistencia al desgaste. ${ }^{12-13}$

Con el paso del tiempo, las propiedades han sido mejoradas y varios factores llevaron a la selección del ionómero de vidrio como un adecuado material para el TRA como la liberación de fluoruro hasta por cinco años, depósito de la absorción de iones de fluoruro tópico(14)(15) adhesión química al esmalte y a la dentina a través del intercambio iónico, biocompatibilidad con los tejidos orales, naturaleza soluble, alta resistencia a la abrasión buena humectación y rápida aplicación. ${ }^{9-10-16}$

En la actualidad, en el TRA se emplean con mayor frecuencia ionómeros de alta viscosidad como Fuji IX (GC) y Ketac Molar (3M ESPE) y en menor medida, los de baja viscosidad como Chemfil (Dentsply), Chemflex (Dentsply) y Fuji Plus (GC Int). ${ }^{2-14}$ El ionómero de vidrio Ketac ${ }^{\text {TM }}$ Molar Easymix fue desarrollado para un mezclado más rápido, una dosificación más precisa, una mejor humectación del polvo por el líquido y una menor producción de polvo durante mezclado; esto se logró mediante la granulación del polvo de Ketac Molar para que las propiedades mecánicas y liberación de iones de flúor no fueran afectadas de manera negativa, otorgándole de esta forma una alta proporción de polvo a líquido y mejora en la resistencia al desgaste, compresión, y adaptabilidad marginal..$^{14}$ 
Eficacia clínica según la supervivencia y desempeño clínico de las restauraciones con el Tratamiento Restaurador Atraumático

La literatura científica reporta como eficacia clínica la medida en la que un individuo, en una población definida, se beneficie de la resolución de un problema de salud, determinado bajo condiciones ideales de actuación, en el TRA es definido como beneficios para los preescolares después del procedimiento restaurativo, los cuales pueden calificarse como éxito o fracaso según la supervivencia y desempeño clínico. ${ }^{17-18}$

La supervivencia hace referencia al estado de la restauración realizada con el Tratamiento Restaurador Atraumático (TRA), en las cavidades de molares deciduas o permanentes posterior a cierto tiempo, para dicho fin se utilizan los códigos y criterios de calificación de Frencken et al (1996) $)^{19}$ (Gráfico 1)

\begin{tabular}{|c|c|}
\hline \multicolumn{2}{|r|}{ Supervivencia de restauraciones TRA según Frencken et al (1996) (19) } \\
\hline Código & Criterio \\
\hline 0 & Presente, bueno \\
\hline 1 & $\begin{array}{l}\text { Presente, defecto marginal y/o desgaste en la superficie leve, el cual es } \\
\text { menor de } 0.5 \mathrm{~mm} \text { de profundidad: no es necesario cambiar o reparar la } \\
\text { restauración }\end{array}$ \\
\hline 2 & $\begin{array}{l}\text { Presente, defecto marginal y/o desgaste en la superficie, el cual es más } \\
\text { profundo que } 0.5 \mathrm{~mm} \text { pero menor de } 1.0 \mathrm{~mm} \text { : es necesario reparar la restau- } \\
\text { ración }\end{array}$ \\
\hline 3 & $\begin{array}{l}\text { Presente, defecto marginal y/o desgaste en la superficie grosero, de más } \\
\text { de } 1.0 \mathrm{~mm} \text { de profundidad: es necesario reparar la restauración }\end{array}$ \\
\hline 4 & $\begin{array}{l}\text { Ausente, la restauración ha desaparecido completamente (o la mayor par- } \\
\text { te): es necesario un nuevo tratamiento. }\end{array}$ \\
\hline 5 & Ausente, se ha realizado otro tratamiento restaurador \\
\hline 6 & Ausente, el diente ha sido extraído \\
\hline 7 & $\begin{array}{l}\text { Presente, extensas áreas de la restauración se han desgastado gradual- } \\
\text { mente pero menos de } 0.5 \mathrm{~mm} \text { en el punto de mayor profundidad: no es } \\
\text { necesario la reparación de la restauración }\end{array}$ \\
\hline 8 & $\begin{array}{l}\text { Presente, extensas áreas de la restauración se han desgastado más de } \\
0.5 \mathrm{~mm} \text { de profundidad: es necesario la reparación de la restauración }\end{array}$ \\
\hline 9 & Imposible de diagnosticar \\
\hline
\end{tabular}


El desempeño clínico es la evaluación de características clínicas de la restauración como retención, color, integridad de los márgenes, forma anatómica, textura superficial, decoloración de los márgenes y caries recurrente, posterior a cierto tiempo de haber sido realizada el TRA en cavidades Clase I de molares deciduas superiores o inferiores posterior, empleando el criterio de USPHS modificado y calificándolos en Alpha A (Éxito ideal), Bravo B (Éxito satisfactorio) y Charlie $C$ y Delta $D$ (Falla insatisfactorio)..$^{7-18}$

\section{Factores que afectan el éxito del Tratamiento Restaurador Atraumático}

El éxito del Tratamiento Restaurador Atraumático dependerá del adecuado diagnóstico y la selección de la pieza dentaria a restaurar, el fracaso es atribuido a muchos factores entre ellos la limitada experiencia y entrenamiento del profesional 10, la remoción insuficiente de caries, acondicionamiento inadecuado de la cavidad e inapropiado mezclado del material (polvo/líquido); sin embargo, con mayor frecuencia estas condiciones no se registran en los estudios de seguimiento, solo se reportan tipos de fallas como la pérdida parcial o total de la restauración y diferentes tipos de desgaste o fracturas que requerirán reparación o reemplazo. ${ }^{3-20-21-22}$

Otros factores en el fracaso de las restauraciones son los relacionados al paciente, como la contaminación por saliva o sangre, tipo de aislamiento, nivel de cooperación del paciente niño, número de restauraciones por niño y falta de cumplimiento de las indicaciones post tratamiento como no ingerir líquidos o alimentos una hora después ${ }^{3-2}$ no obstante, Hilgert y col (2014) ${ }^{23}$ reportan la no existencia de diferencias significativas en los resultados de las restauraciones a pesar de haber utilizado aislamiento relativo con rollos de algodón, Roshan y Sakeenabi (2011)11, Abbass MMS y col (2019) ${ }^{21}$ consideran las limitaciones de la estructura morfológica 0 anatómica de los dientes deciduos, fallas en el control de la saliva en los niños y la susceptibilidad de las restauraciones superficiales o poco profundas, Hesse D y col (2016)22, Abbass MMS y col (2019) ${ }^{21}$ indican como relevante el factor personal o "factor operador" como la formación académica, el nivel de experiencia, el entrenamiento en el protocolo, la posición del operador y del paciente, la iluminación, el confort del operador y la accesibilidad para la eliminación de la caries, Frencken y col (2013) ${ }^{24}$ atribuyen las fallas a las características físicas del ionómero y el manejo del material por el operador.

Según Luengas-Quintero y col $(2013)^{25}$ y van Gemert-Schriks y col $(2007)^{26}$ los factores ambientales de la zona donde se realiza el procedimiento restaurativo como la temperatura ambiental, humedad atmosférica, la altitud y la localización geográfica influyen en la velocidad de la preparación y en la calidad del ionómero, en consecuencia en la supervivencia de las restauraciones. Se han reportado otros factores como: la posición del diente en las arcadas (derecho o izquierdo) y la superficie a restaurar (oclusal, vestibular, palatino) que no tienen influencia en la sobrevida de las restauraciones TRA en dientes deciduos. ${ }^{25}$

También, se señala que la experiencia de caries (ceod, CPOD) es un factor directamente relacionado al riesgo de desarrollar nuevas lesiones. Sin embargo, Pacheco y col. ${ }^{27}$ no encontraron diferencias significativas entre los grupos de alto, mediano o bajo nivel de experiencia de caries, debido a que previo a las restauraciones los niños y sus padres reciben actividades educativas sobre higiene oral y otros temas de prevención ${ }^{13-20-22}$ 


\section{Discusión}

En los reportes de la literatura científica existen resultados diversos respecto a la supervivencia de los tratamientos basados en el TRA, por ejemplo van Gemert-Schriks MC y col $(2007)^{26}$, Lo $E$ y col $(2001)^{28}$ reportan, en un tiempo breve, resultados de éxito de 80 a $95 \%$ en una sola superficie (clases I y V), de 55 a $75 \%$ en la Clase II y 32 a $55 \%$ en las clases III y IV, Saber y col (2019) 4 en un meta-análisis desarrollado por Van't Hof y col en 2006 reportaron supervivencia del $95 \%$ en dentición decidua y $97 \%$ para dentición permanente a los 12 meses de evaluación en lesiones de una superficie utilizando un ionómero de alta viscosidad, otro autores concluyen que la duración es significativamente más baja en lesiones proximales que en lesiones oclusales..$^{14}$

De Amorin y col (2012 $)^{29}$ en un meta-análisis no encontraron diferencias significativas en la supervivencia en reportes entre los años 2005 y 2010 y una mayor retención en boca se debía al empleo de ionómero de vidrio de alta viscosidad, por el cual se hace ventajoso utilizar este material en restauraciones y sellantes, Pacheco y col $(2017)^{27}$ hallaron tasa de sobrevida de $42,74 \%$, en un año de seguimiento, en el tratamiento de lesiones de caries ocluso proximales en dientes primarios, da Franca y col $(2013)^{9}$ reportaron éxito de $94,6 \%$ en un mes y $50,6 \%$ a un año en restauraciones de una superficie y $70,1 \%$ de sobrevida en el primer mes de lesiones restauradas de clase 1 .

Existen en el mercado nuevos productos, algunos de los cuales son producidos en Brasil, como el Vitromolar (Nova DFL) que al ser comparado con el Ketac Molar (3M ESPE), no presenta diferencias significativas en la calidad de sus propiedades y presenta una supervivencia de $34,5 \%$ en restauraciones ocluso-proximales. Pacheco y col $(2017)^{27}$ en la evaluación de otras marcas de ionómeros de bajo costo, reportaron heterogeneidad de $31 \%$ y $100 \%$ en la supervivencia de restauraciones ocluso proximales. ${ }^{14}$

Olegario et al (2016) 10 evaluaron el desempeño a 12 meses de ionómeros de vidrio de las marcas GC Gold Label 9, VitroMolar y Maxxion R, reportándose sobrevida de 77,5\%, 61,1\% y $57.5 \%$ respectivamente, donde el primero mostró mejores resultados probablemente por el nivel de rugosidad del material. De Lima Navarro et al (2007)7 investigaron en infantes de 18 a 36 meses de vida la sobrevida del TRA con los materiales Ketac Molar Easy Mix ${ }^{\circledR}$ (3M ESPE) y Vitro Molar ${ }^{\circledast}(\mathrm{DFL})$, obteniéndose éxito en el $94,8 \%, 87,9 \%$ y $82,3 \%$ en 1,2 y 4 años de seguimiento respectivamente y añade resultado de un meta-análisis de 18 países donde hallaron tasa de fallas en piezas molares deciduas para superficies únicas de 3,5\% y de $19 \%$ en superficies múltiples.

De Medeiros et al $(2017)^{3}$ observaron después de 12 meses una tasa de éxito de 89,3\% sin diferencias estadísticamente significativas entre el ionómero Ketac Molar Easy Mix 3M ESPE y la resina Filtek Z250-3M ESPE, Lo y Holmgren (2001)28 reportaron después de 30 meses de seguimiento, supervivencia de $79 \%$ en clase l y $70 \%$ en clase $V$, Honkala et al $(2003)^{30}$ después de 24 meses de seguimiento, mostraron éxito en Clase I de $89.6 \%$ sin diferencia estadística con restauraciones de amalgama, Frencken et al $(1996)^{19}$ en un meta-análisis evidenciaron que 
las superficies tratadas con amalgama presentaron mayor durabilidad que las restauradas con TRA solo durante los primeros años, a los tres años no se encontraron diferencias estadísticamente significativas, Holmgren y col (2000) ${ }^{8}$ en una evaluación del Ketac Molar encontraron supervivencia en restauraciones Clase I de $91 \%$ y $79 \%$, Clase V de $79 \%$ y $70 \%$, y Clase II $75 \%$ y $51 \%$ para dos evaluaciones de 12 y 30 meses, respectivamente para cada caso, Luengas-Quintero y col. $(2013)^{25}$ hallaron que luego de 12 y 24 meses los rangos de supervivencia de restauraciones de una superficie fueron $82,1 \%$ y $74 \%$ respectivamente. Roshan et al (2011) compararon la sobrevida de restauraciones TRA en dentición decidua colocadas en la escuela y en un hospital, encontrando el $82,2 \%$ de éxito después de seis meses y $77,7 \%$ después de 12 meses en las restauraciones colocadas en escuela y del $87,7 \%$ y $81,5 \%$ a los 6 y 12 meses en las restauraciones colocadas en el hospital.

Faustino-Silva \& Figueiredo y col. (2019) $)^{31}$ en ECA a doble ciego y boca dividida analizaron la efectividad del TRA y compararon Ketac Molar Easymix ${ }^{\circledR}$ (3M ESPE) y Vitro Molar ${ }^{\circledast}$ (DFL) a 1, 2 y 4 años en molares deciduos. A un 1 año se controló 100 piezas con un éxito de $94 \%$, a los 2 años 80 piezas con un éxito de $87,5 \%$ y a los 4 años éxito final de $82,9 \%$; sin diferencias entre las dos marcas de ionómeros $(p>0,05)$ según el criterio USPHS.

Freitas et al. (2018)32 realizaron un ECA de boca dividida para el rendimiento clínico de ionómeros de vidrio Riva Self-Cure (SDI Limited) Bayswater (VIC Australia) que son administrados en kits de mezcla manual y de forma encapsulada en cavidades clase I, donde hubo una tasa de éxito de $86,2 \%$ en el rendimiento clínico del ionómero encapsulado. Menezes-Silva et al. $(2019)^{17}$ analizaron la efectividad de las restauraciones con resina compuesta frente al TRA en lesiones clase II, empleando Equia Fil-GC Corporation y Filtek Z350 XT Universal Restorative, posterior a 12 meses el éxito del TRA fue de 95,8\% y 98,7\% para la resina, según criterios TRA y USPHS modificado, no existiendo diferencia significativa estadísticamente.

Olegário et al. (2016) $)^{10}$ evaluaron la eficacia en restauraciones de una y más superficies realizados con Ketac Molar Easy Mix (3M/ESPE) con TRA y tratamiento convencional con Filtek Bulk Fill (3M/ESPE), después de 24 meses, encontrando similitud en la efectividad de ambos, pero un mejor costo efectividad del TRA; Mickenautsch \& Yengopal y col (2015) ${ }^{33}$ realizaron una revisión sistemática, con la finalidad de responder si existía superioridad de las restauraciones con cemento de ionómero de vidrio de alta viscosidad (CIVAV) frente a la técnica convencional (TC) en superficies únicas o múltiples de piezas permanentes posteriores, concluyendo que no existe evidencia de la superioridad del CIVAV sobre el TC.

Pacheco et al (2017)27 realizaron un ECA para evaluar la supervivencia a 12 meses del Ketac Molar EasyMix (3M ESPE) y Vitromolar (DFL) en restauraciones ocluso proximales realizadas con TRA, la supervivencia del Ketac Molar fue 50,85\% y 34,48\% del Vitro Molar ( $p>0,058$ ), concluyendo que no existe diferencia significativa en el rendimiento clínico entre ambos ionómeros. Mobarak et al. (2019)34 desarrollaron un ECA a triple ciego para comparar la eficacia clínica entre un ionómero reforzado con zinc (ChemFil Rock) y ionómero de vidrio de alta viscosidad (Fuji IX GP) a 2 años, la sobrevida del Fuji IX GP fue 95,4\% y 85.3\% del ChemFil Rock, ( $p=0,02)$. Silva de Moura et al. (2020) 35 compararon a 12 meses el rendimiento entre un cemento ionó- 
mero de vidrio de bajo costo (Vitro Molar ${ }^{\circledR}$ ) y el cemento ionómero de vidrio de alta viscosidad (Ketac Molar ${ }^{\circledR}$ ), en niños entre 2 y 6 años que presentaron lesiones de clase I, II, III o IV; los resultados mediante los criterios TRA fueron supervivencia del 82,2\% en Ketac Molar ${ }^{\oplus}$ y 73,4\% en Vitro $\operatorname{Molar}^{\oplus}(p=0,011)$ y mayor prevalencia en superficies pequeñas $(p=0,001)$, medianas $(p=0,005)$ y en el segundo molar $(p=0,0015)$, evidenciando que Vitro Molar ${ }^{\oplus}$ presenta menor éxito en comparación al Ketac Molar ${ }^{\circledR}$.

D'Costa et al. (2020)36 buscaron comparar la longevidad a 18 meses del CIVAV GC Gold Label 9 y el ionómero de vidrio reforzado con metal GC Mirale Mix ${ }^{\oplus}$ empleados en TRA, el éxito del GC Mirale Mix ${ }^{\circledR}$ fue de $87,2 \%$ y del GC Gold Label 9 fue $61,8 \%$ ( $\left.p=0,015\right)$ concluyendo que el ionómero de vidrio reforzado con metal presenta mayor éxito respecto al ionómero de vidrio convencional.

\section{Conclusiones}

Se ha demostrado altas tasas de éxito, mediante el desempeño clínico y la supervivencia de las restauraciones TRA para las lesiones de caries de la dentición primaria. La literatura muestra una gran heterogeneidad en las tasas de supervivencia de las restauraciones TRA ocluso-proximal en dientes primarios después de un año, pero se han encontrado altas tasas de éxito en lesiones de una superficie de piezas deciduas y permanentes con TRA que oscilan entre el $90-100 \%$ en períodos de 12 meses a más.

Los cementos de ionómero de vidrio de alta viscosidad se han desarrollado especialmente para el TRA, debido a que tienen propiedades mecánicas mejoradas, lo que resulta en una mayor longevidad y desempeño clínico de las restauraciones, tanto en dientes permanentes como en deciduos. Las tasas de supervivencia de los materiales restauradores utilizados con TRA dependerá de diversos factores, entre ellos: la experiencia y entrenamiento de los profesionales para lograr elevados índices de éxito, o la marca del ionómero seleccionado, por sus propiedades establecidas.

Una serie de marcas en el mercado, algunos producidos en Brasil y vendidos en América Latina, también son indicados para el TRA con un menor costo. Sin embargo, el desempeño clínico y la supervivencia es alta cuando se utilizan ionómeros de alta viscosidad. Aún no hay consenso acerca de las ventajas del uso de ionómeros de menor costo, encapsulados, reforzados con metal y/o con propiedades mejoradas. 


\section{Referencias Bibliográficas}

1. Ministerio de Salud. Prevalencia Nacional de caries dental, fluorosis del esmalte y urgencia de tratamiento en escolares de 6 a 8, 10, 12 y 15 años. Perú. 2001 - 2002 - 2005.

2. Jurasic MM, Marianne Jurasic M, Gibson G, Wehler CJ, Orner MB, Jones JA. Caries prevalence and associations with medications and medical comorbidities [Internet]. Vol. 79, Journal of Public Health Dentistry. 2019. p. 34-43. Available from: http://dx.doi.org/10.1111/ jphd.12292

3. de Medeiros Serpa EB, Clementino MA, Granville-Garcia AF, Rosenblatt A. The effect of atraumatic restorative treatment on adhesive restorations for dental caries in deciduous molars. J Indian Soc Pedod Prev Dent. 2017 Apr;35(2):167-73.

4. Saber A, El-Housseiny A, Alamoudi N. Atraumatic Restorative Treatment and Interim Therapeutic Restoration: A Review of the Literature [Internet]. Vol. 7, Dentistry Journal. 2019. p. 28. Available from: http://dx.doi.org/10.3390/dj7010028

5. Frencken JE, van 't Hof MA, van Amerongen $W E$, Holmgren CJ. Effectiveness of Single-surface ART Restorations in the Permanent Dentition: A Meta-analysis [Internet]. Vol. 83, Journal of Dental Research. 2004. p. 120-3. Available from: http://dx.doi. org/10.1177/154405910408300207

6. Estupiñán-Day S, Tellez M, Kaur S, Milner T, Solari A. Managing dental caries with atraumatic restorative treatment in children: successful experience in three Latin American countries. Rev Panam Salud Publica. 2013 Apr;33(4):237-43.

7. Navarro MF de L, Leal SC, Molina GF, Villena RS. Tratamento Restaurador Atraumático: atualidades e perspectivas. Rev Assoc Paul Cir Dent. septiembre de 2015;69(3):289-301.

8. Holmgren CJ, Lo ECM, Hu D, Wan H. ART restorations and sealants placed in Chinese school children - results after three years [Internet]. Vol. 28, Community Dentistry and Oral Epidemiology. 2000. p. 314-20. Available from: http://dx.doi.org/10.1034/j.16000528.2000.280410.x

9. da Franca C, Colares V, Van Amerongen E. Two-year evaluation of the atraumatic restorative treatment approach in primary molars class I and II restorations. Int J Paediatr Dent. $2011 \mathrm{Jul} ; 21(4): 249-53$

10. Olegário IC, de Brito Pacheco AL, de Araújo MP, de Miranda Ladewig N, Bonifácio CC, Imparato JCP, et al. Low-cost GICs reduce survival rate in occlusal ART restorations in primary molars after one year: A RCT [Internet]. Vol. 57, Journal of Dentistry. 2017. p. 45-50. Available from: http://dx.doi.org/10.1016/j.jdent.2016.12.006

11. Noor-Mohammed R, Basha S. Survival of Occlusal ART Restorations in Primary Molars 
Placed in School Environment and Hospital Dental Setup-One Year Follow-up Study [Internet]. Medicina Oral Patología Oral y Cirugia Bucal. 2011. p. e973-7. Available from: http://dx.doi. org/10.4317/medoral.17327

12. Delgado-Angulo EK, Ortiz EB, Sánchez-Borjas PC. Análisis de supervivencia de sellantes y restauraciones ART realizados por estudiantes de pregrado [Internet]. Vol. 15, Revista Estomatológica Herediana. 2014. p. 119. Available from: http://dx.doi.org/10.20453/reh. v15i2.1941

13. Hosoya Y, García-Godoy F. Bonding mechanism of Ketac-Molar Aplicap and Fuji IX GP to enamel and dentin. Am J Dent. 1998 0ct;11(5):235-9.

14. Menne-Happ U, Ilie N. Effect of heat application on the mechanical behaviour of glass ionomer cements [Internet]. Vol. 18, Clinical Oral Investigations. 2014. p. 643-50. Available from: http://dx.doi.org/10.1007/s00784-013-1005-4

15. Frencken JE, Leal SC, Navarro MF. Twenty-five-year atraumatic restorative treatment (ART) approach: a comprehensive overview. Clin Oral Investig. 2012 0ct;16(5):1337-46.

16. Araujo MP, Innes NP, Bonifácio CC, Hesse D, Olegário IC, Mendes FM, et al. Atraumatic restorative treatment compared to the Hall Technique for occluso-proximal carious lesions in primary molars; 36-month follow-up of a randomised control trial in a school setting. BMC Oral Health. 2020 Nov 11;20(1):1-18.

17. Menezes-Silva, R., Velasco, S.R.M., Bastos, R.S. et al. Randomized clinical trial of class II restoration in permanent teeth comparing ART with composite resin after 12 months. Clin Oral Invest 23, 3623-3635 (2019). https://doi.org/10.1007/s00784-018-2787-1

18. Zanata RL, Fagundes TC, Freitas MCC de A, Lauris JRP, Navarro MF de L. Ten-year survival of ART restorations in permanent posterior teeth. Clin Oral Investig. 2011 Apr;15(2):265-71.

19. Frencken JE, Pilot T, Songpaisan Y, Phantumvanit P. Atraumatic restorative treatment (ART): rationale, technique, and development. J Public Health Dent. 1996;56(3 Spec):135-40; discussion 161-3.

20. Dye BA, Hsu K-LC, Afful J. Prevalence and Measurement of Dental Caries in Young Children. Pediatr Dent. 2015 May;37(3):200-16.

21. Abbass MMS, Mahmoud SA, El Moshy S, Rady D, AbuBakr N, Radwan IA, et al. The prevalence of dental caries among Egyptian children and adolescences and its association with age, socioeconomic status, dietary habits and other risk factors. A cross-sectional study. F1000Res. 2019 Jan 3;8:8.

22. Hesse D, de Araujo MP, Olegário IC, Innes N, Raggio DP, Bonifácio CC. Atraumatic Restorative Treatment compared to the Hall Technique for occluso-proximal cavities in primary molars: study protocol for a randomized controlled trial. Trials. 2016 Mar 31;17:169. 
23. Hilgert LA, de Amorim RG, Leal SC, Mulder J, Creugers NHJ, Frencken JE. Is high-viscosity glass-ionomer-cement a successor to amalgam for treating primary molars? Dent Mater. 2014 0ct;30(10):1172-8.

24. Frencken JEFM, Flohil KA, de Baat C. [The history and scientific development of atraumatic restorative treatment]. Ned Tijdschr Tandheelkd. 2013 Dec;120(12):677-81.

25. Luengas-Quintero E, Frencken JE, Muñúzuri-Hernández JA, Mulder J. The atraumatic restorative treatment (ART) strategy in Mexico: two-years follow up of ART sealants and restorations. BMC Oral Health. 2013 Sep 8;13:42.

26. van Gemert-Schriks MCM, van Amerongen WE, ten Cate JM, Aartman IHA. Three-year survival of single- and two-surface ART restorations in a high-caries child population. Clin Oral Investig. 2007 Dec;11(4):337-43.

27. Anna Luisa de Brito P, Isabel Cristina 0, Clarissa Calil B, Ana Flávia Bissoto C, José Carlos Pettorossi I, Daniela Prócida R. One year Survival Rate of Ketac Molar versus Vitro Molar for Occlusoproximal ART Restorations: a RCT. Braz Oral Res. 2017 Nov 6;31:e88.

28. Lo EC, Holmgren CJ. Provision of Atraumatic Restorative Treatment(ART) restorations to Chinese pre-school children-a 30-month evaluation. Int J Paediatr Dent. 2001 Jan;11(1):310.

29. de Amorim RG, Leal SC, Frencken JE. Survival of atraumatic restorative treatment (ART) sealants and restorations: a meta-analysis. Clin Oral Investig. 2012 Apr;16(2):429-41.

30. Honkala E, Behbehani J, Ibricevic H, Kerosuo E, Al-Jame G. The atraumatic restorative treatment (ART) approach to restoring primary teeth in a standard dental clinic. Int J Paediatr Dent. 2003 May;13(3):172-9.

31. Faustino-Silva DD, Figueiredo MC. Atraumatic restorative treatment-ART in early childhood caries in babies: 4 years of randomized clinical trial. Clin Oral Investig. 2019 Oct;23(10):3721-9.

32. Freitas MCC de A, Fagundes TC, Modena KC da S, Cardia GS, Navarro MF de L. Randomized clinical trial of encapsulated and hand-mixed glass-ionomer ART restorations: one-year follow-up. J Appl Oral Sci [Internet]. 2018 Jan 18 [cited 2021 Aug 14];26. Available from: http:// www.scielo.br/j/jaos/a/wkvmgDxKRMxL4kbZ8tYQ43y/?lang=en\&format=pdf

33. Mickenautsch S, Yengopal V. Failure Rate of Direct High-Viscosity Glass-Ionomer Versus Hybrid Resin Composite Restorations in Posterior Permanent Teeth - a Systematic Review. Open Dent J. 2015 Dec 22;9:438-48.

34. Mobarak E, El-Deeb H, Daifalla LE, Ghaly M, Mustafa M, Sabry D, et al. Survival of multiple-surface ART restorations using a zinc-reinforced glass-ionomer restorative after 2 years: A randomized triple-blind clinical trial. Dent Mater. 2019 Sep;35(9):e185-92. 
35. Moura MS de, Sousa GP de, Brito MHSF, Silva MCC, Lima M de DM de, Moura L de FA de D, et al. Does low-cost GIC have the same survival rate as high-viscosity GIC in atraumatic restorative treatments? A RCT. Braz Oral Res. 2020 Jan 24;33:e125.

36. D'Costa VG, Singhal DK, Acharya S. Efficacy of GC Gold Label 9 and GC Miracle Mix ${ }^{\circledR}$ Restorations using Atraumatic Restorative Treatment (ART) in Rural Settings: A Randomized Controlled Trial. J Clin Pediatr Dent. 2020 Jan 1;44(3):148-53. 


\title{
Odontoma compuesto: reporte caso clínico
}

\section{Compound Odontoma: Clinical case report}

\author{
Alexandra' \\ 1 Docente de Odontología en la Universidad Católica de Cuenca. \\ ${ }^{2}$ Estudiante de Odontología en la Universidad Católica de Cuenca. \\ *mayale93@hotmail.es
}

Piedra-Sarmiento Xavier Bernardo;; Moncayo Pinos Jaime Bernardo²; Gonzalez Campoverde Lorena

DOI: https://

\section{Resumen}

El odontoma compuesto es una lesión, definida como un hamartoma de tejido odontogénico, es decir una proliferación de células maduras caracterizadas por diversos estados de diferenciación histológica y morfológica que se presenta con una estructura similar a una formación dental. La lesión suele presentarse asintomática y usualmente se diagnostican mediante estudios de radiográficos rutinarios, observándose una lesión radiopaca y radiolúcida aislada de bordes delimitados de morfología similar a una pieza dental. Esta dentro del grupo de los tumores odontogénicos benignos mixtos, de origen ectodérmico y mesodérmico, es indispensable el reconocimiento clínico de la lesión para efectuar el posterior procedimiento quirúrgico.

Se presenta el caso de una paciente femenina de 56 años de edad, la misma acude a consulta con el requerimiento de una prótesis total, alude que tiene una lesión en el cuadrante superior derecho que le causa molestias al momento de ingerir alimentos con su prótesis actúa, es por este motivo que se llevan a cabo exámenes radiográficos, en los mismos fue identificado una lesión radiopaca extraosea, se identifica la lesión como un odontoma en la región edéntula del cuadrante 2, el mismo que fue removido mediante un procedimiento quirúrgico en el mismo se pudo identificar un odontoma compuesto.

Palabras Clave: Odontoma compuesto, Tumor odontogénico. 


\section{Abstract}

The Compound odontoma is a lesion, which is defined as a hamartoma of odontogenic tissue, that is to say, a proliferation of mature cells characterized by various stages of histological and morphological differentiation that is similar in structure to the dental formation. The lesion is usually asymptomatic and is diagnosed by routine radiographic studies. It is seen as an isolated radio opaque and radio lucid lesion with delimited borders and a morphology similar to a dental piece. It is classified as a benign mixed odontogenic tumor of ectodermal and mesodermal origin. Clinical diagnosis of the lesion is essential for the subsequent surgical procedure.

The following case is presented. A 56-year-old female patient came for consultation requiring a total prosthesis, she mentioned having a lesion in the right upper quadrant that causes her discomfort when eating with her current prosthesis. Because of this, radiographic examinations were performed, in which an extra oseous radiopaque lesion was observed. The lesion was identified as an odontoma in the edentulous region of quadrant 2 , which was removed by a surgical procedure, identifying a compound odontoma.

Palabras Clave: Compound odontoma, Odontogenic tumor. 


\section{Introducción}

En 1867 Broca define al odontoma como un tumor benigno de origen odontogénico, considerado como una lesión de células epiteliales y mesenquimatosas, diferenciadas que forman esmalte, dentina y cemento. Esta neoplasia representa el $51 \%$ de todos los tumores odontogénicos siendo así los de mayor frecuencia de aparición. ${ }^{1-4}$

Los odontomas suelen ser clínicamente asintomáticos, de crecimiento limitado, producen retención dentaria y su hallazgo es casual en revisiones radiográficas rutinarias. Cuando presentan alguna sintomatología, los signos clínicos más frecuentes son el retraso en la erupción dental y la tumefacción a nivel del proceso alveolar afectado. ${ }^{4-6}$

La etiología esta relacionada con restos paradentales de malassez, traumatismos, infecciones, mutaciones genéticas (síndrome de Hermman, enfermedad de Tangier, nevus de células basales, el síndrome de Gardner y la adenomatosis colónica familiar), la hiperactividad odontoblástica 0 alteraciones en el gen de control del desarrollo dentario. ${ }^{4}$ La Organización Mundial de la Salud (OMS) clasifica a los odontomas en compuestos y complejos. En el compuesto se presentan todos los tejidos dentarios, formando una lesión con múltiples estructuras de aspecto dentario, el complejo se presentan todos los tejidos dentarios pero siguiendo un patrón más desordenado. ${ }^{1-6}$

El odontoma compuesto es más frecuente que el complejo y la mayoría se presentan en la segunda década de la vida. Con predilección por el sexo masculino. Habitualmente están en el sector anterior derecho del maxilar superior. ${ }^{2,3}$

Desde el punto de vista histopatológico estos tejidos y células se encuentran en el área del cuerpo donde se presenta su crecimiento, razón por la cual se les considera como hamartomas y no como neoplasias, el odontoma compuesto presenta pulpa, dentina primaria, esmalte hipocalcificado, cemento primario y un trabeculado óseo entre los dentículos. Existen formas mixtas con morfología intermedia. ${ }^{2-5}$

Radiográficamente el odontoma compuesto se presenta como una imagen radiopaca y radiolúcida, que adopta morfología similar a la dental (dentículos), rodeados por un halo radiolúcido en más del $50 \%$ de los casos. ${ }^{6-7}$

En su mayoría, los odontomas son asintomáticos, en el caso que se presente sintomatología, esta se relaciona con su presencia, dientes permanentes impactados $(57,7 \%)$, retención de dientes deciduos $(16,6 \%)$, desplazamiento de dientes adyacentes $(11,1 \%)$, expansión de corticales óseas $(8,9 \%)$ y una perdida congénita del diente $(3,3 \%)$. 2,7,8

El objetivo de este estudio es describir al odontoma compuesto a través de una revisión bibliográfica y presentación de un caso clínico, estudiado a través del diagnóstico radiográfico y su tratamiento quirúrgico. 


\section{Caso clínico}

Paciente de 56 años de edad del sexo femenino, acude a la clínica de Odontología de la Universidad Católica de Cuenca, el motivo de consulta fue la necesidad de una prótesis total superior. Al examen clínico intraoral se observa que en el cuadrante alveolar superior izquierdo presenta aumento de tamaño del reborde (Fig. 1), acompañado de una masa ulcerada (Fig.2) y sólida a la palpación. (Figura 1 y 2). La paciente refiere que la lesión le causa molestias al momento de ingerir alimentos y que la misma impedía una correcta adaptación de su prótesis antigua.
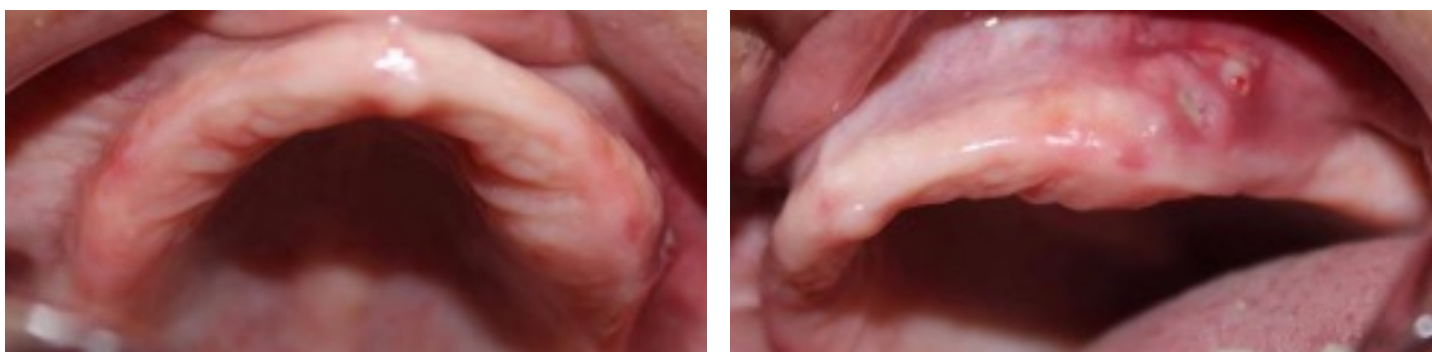

Fig. 1 y 2: Vista oclusal y lateral de la lesión.

Se realizó una radiografía panorámica y periapical (Figura 2-3), para la valoración de la lesión, llegando al diagnóstico presuntivo de un odontoma, debido a que se presenta como una lesión radiopaca de bordes delimitados (Fig. 3) y de densidades similares a las de una pieza dental (Fig. 4).

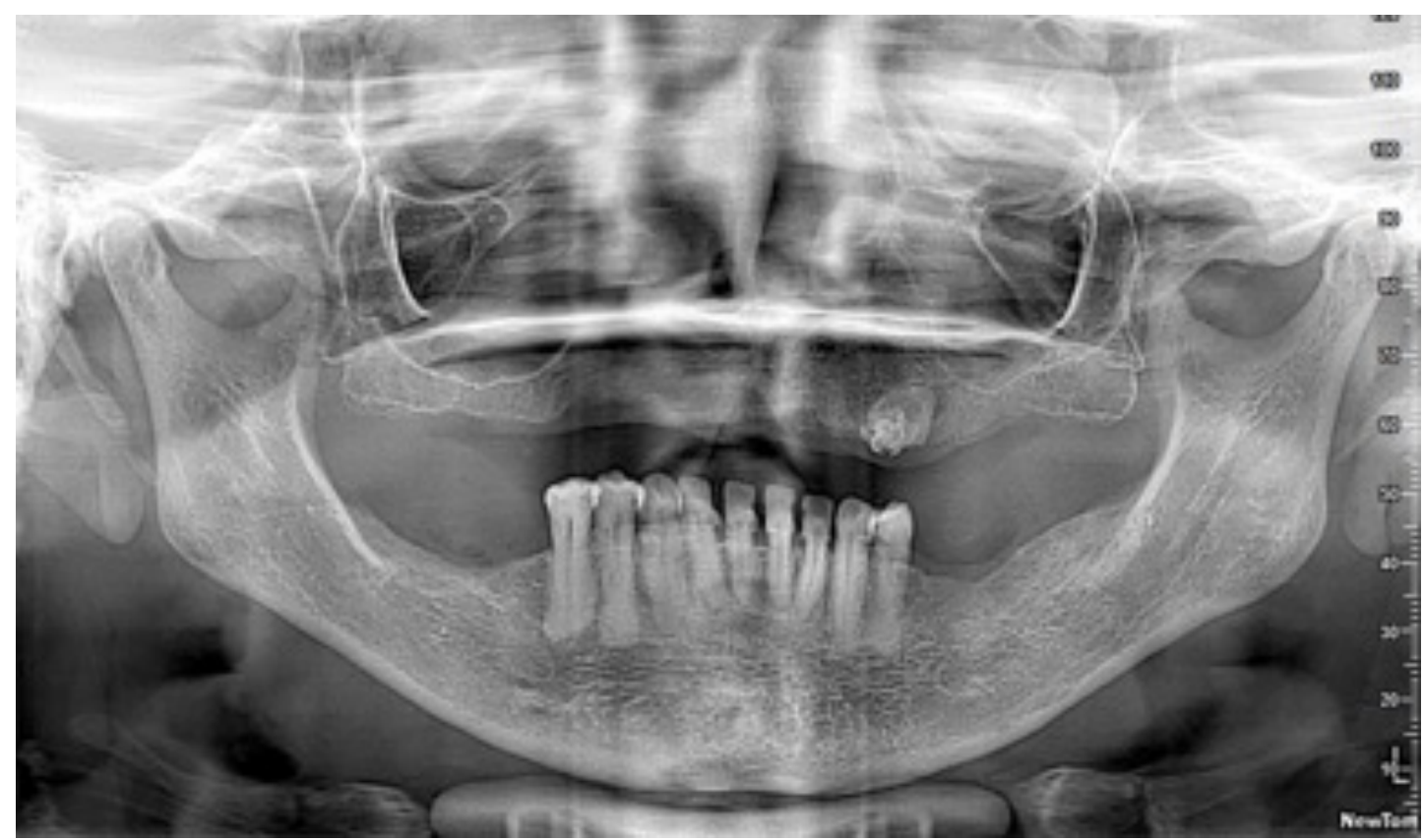

Fig. 3: Lesión radiopaca aislada en el cuadrante superior derecho 


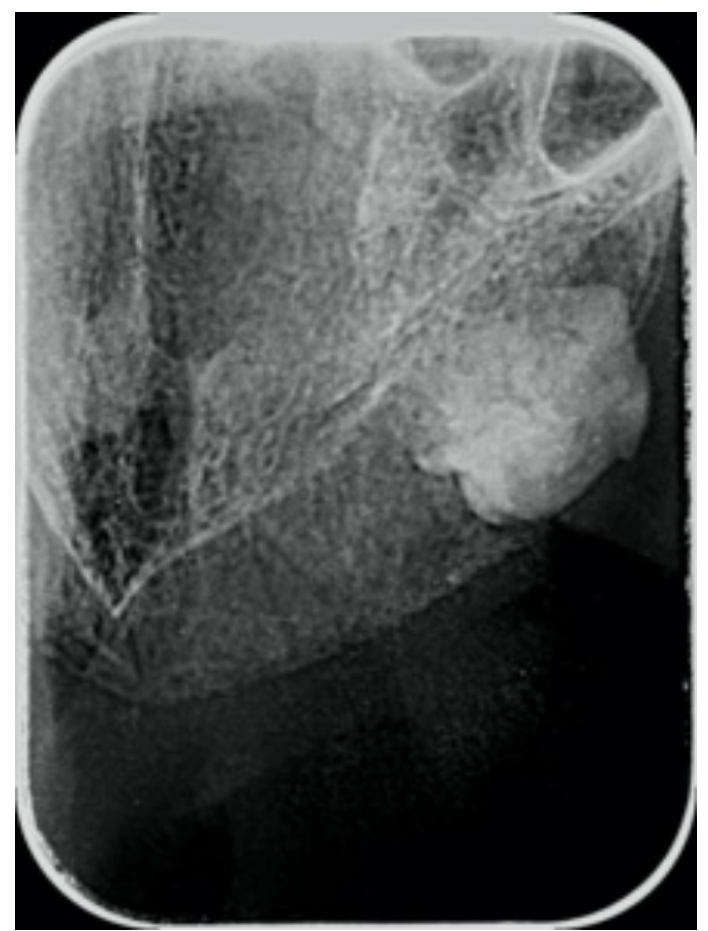

Fig. 4: Radiografía periapical oclusal muestra una lesión extra-ósea aislada

Como fue descrito por la paciente la lesión causaba molestias y se observa que el reborde aumentado de tamaño (Fig. 1 y 2) comprometiendo la adaptabilidad de la prótesis nueva, es por este motivo que se llevó a cabo el tratamiento quirúrgico.

Luego de la asepsia y antisepsia de la zona se procede a anestesiar, mediante una incisión triangular (Fig. 5), con una elevación de colgajo mucoperióstico (Fig. 6), el mismo permitió observar la presencia de elementos compatibles con teidos dentarios (Fig. 7), fue necesario llevar a cabo una osteotomía que permitió liberar la tumoración en la que se visualiza con precisión la similitud con una pieza dental (Fig. 8) llegando al diagnóstico intraquirúrgico de odontoma compuesto, el mismo que fue removido mediante una incisión del alveolo; el procedimiento finalizó con la regularización del reborde alveolar (Fig. 9) y sutura (Fig. 10).

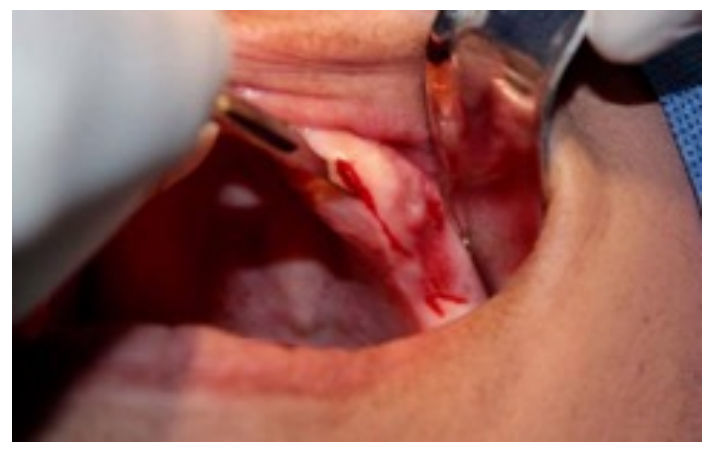

Fig 5. Incisión

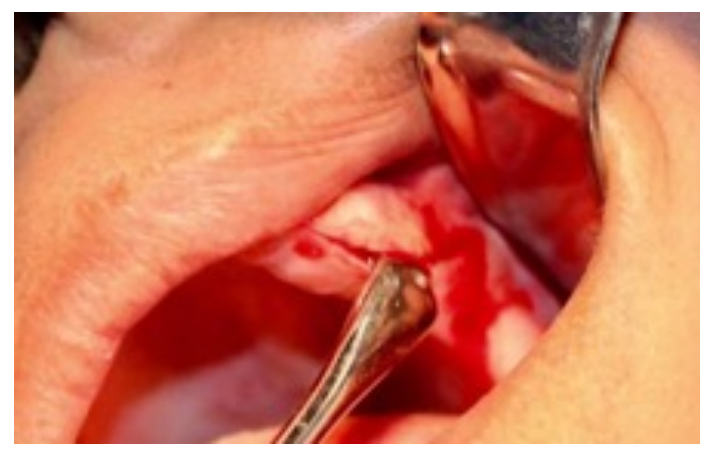

Fig 6. Sindesmotomía 


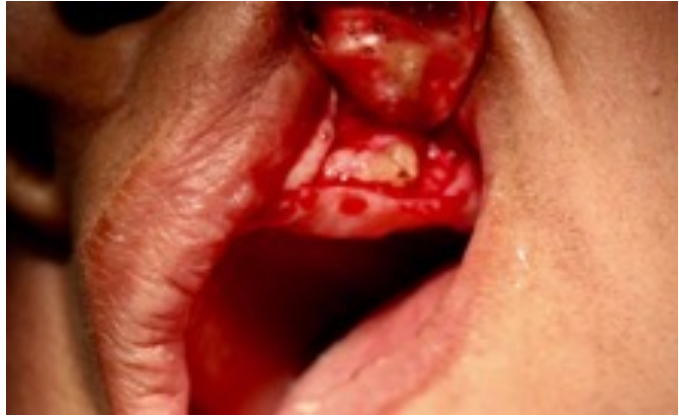

Fig 7. Visualización de la lesión

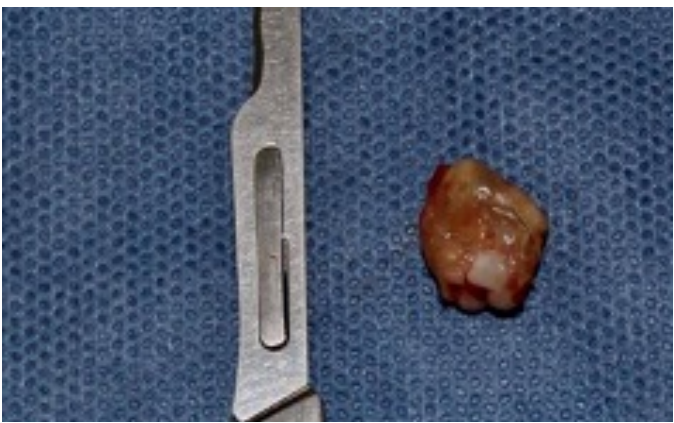

Fig 9. Regularización del reborde alveolar

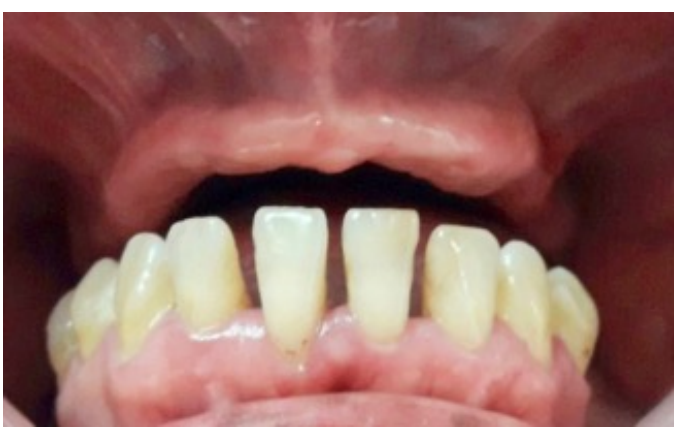

Fig 11. Posoperatorio 3 meses después

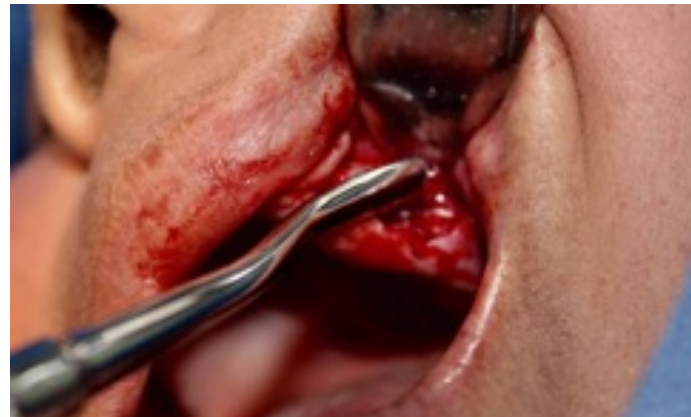

Fig 8. Odontoma compuesto de 9x7x6 mm

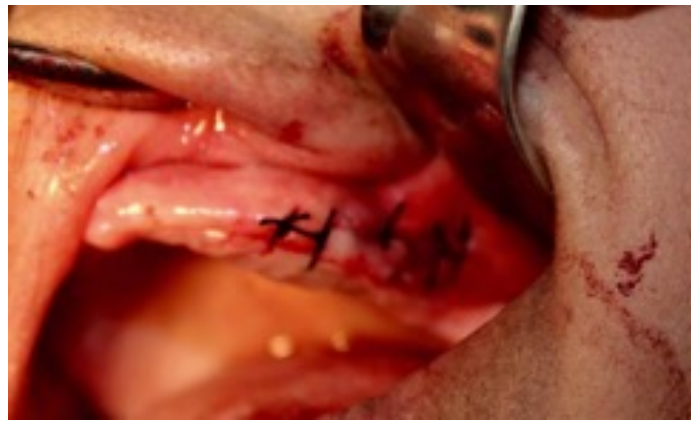

Fig 10. Sutura

Siete días después de efectuado el procedimiento se observa una recuperación sin complicaciones y se procede a retirar las suturas.

El control postoperatorio se llevo a cabo tres meses después del procedimiento, muestra una recuperación completa mostrando un reborde regular (Fig. 11). Mediante una radiografía periapical oclusal se puede observar la enucleación completa de la lesión (Fig. 12). 


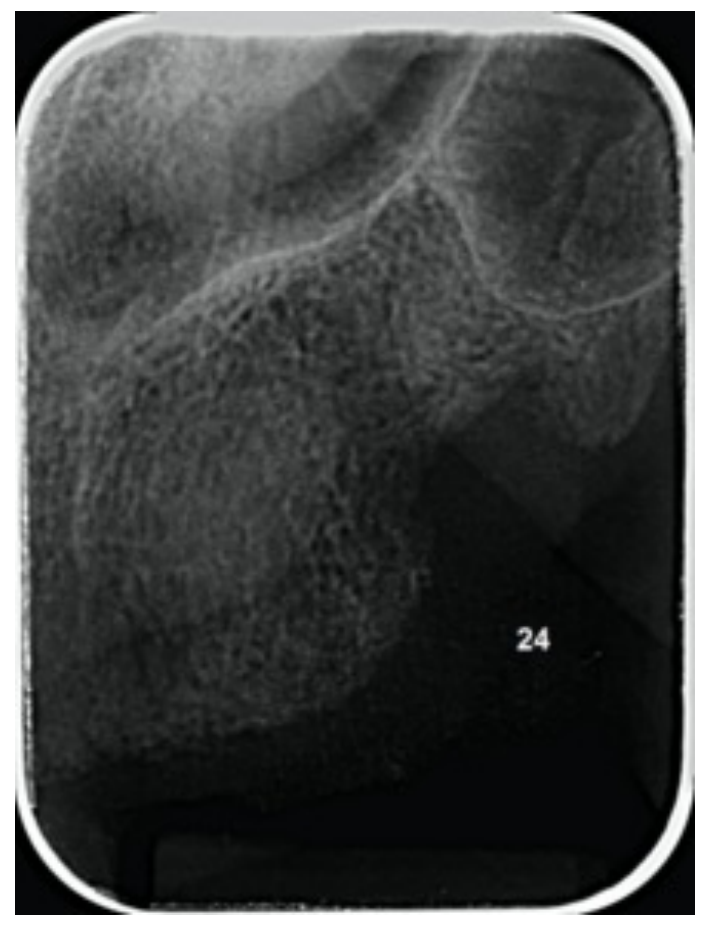

Fig. 12. Radiografia periapical oclusal 3 meses después.

\section{Discusión}

Los odontomas son tumores benignos que se observan con frecuencia en la cavidad oral, se presentan como asintomáticos y son hallazgos casuales de estudios radiográficos rutinarios, como en el caso reportado. Cuando causan sintomatología se puede observas retraso en la erupción dental o un reborde aumentado de tamaño. El diagnóstico final se realiza mediante exámenes complementarios. ${ }^{2-4}$

Radiográficamente se puede observar a los odontomas como con una lesión radiopaca densa rodeada por un halo radiotransparente delgado. ${ }^{3-6}$

El diagnóstico radiográfico de un odontoma debe ser diferenciado con lesiones de localización entre raíces como osteítis residual focal, tumores odontogénicos epiteliales calcificacantes, cementoma, tumores ontogénicos adenomatoides, dientes supernumerarios, fibroma cementante o un osteoblastoma benigno, asi tenemos que si la lesión está localizada en el periodonto debe diferenciarce con un tumor odontogénico adenomatoide, tumores odontogénicos epiteliales calcificantes, odontoameloblastoma o fibrodentinoma ameloblástico. Si la lesión se ubica en el seno maxilar puede ser confundida con sinusitis, infección periapical con pólipo antral, neoplasma mesenquimatoso benigno, papiloma inversus o carcinoma. ${ }^{10}$

Histológicamente los odontomas compuesto constan de un saco de tejido fibroso conectivo que rodea un dentículo, un dentículo está compuesto por un núcleo con tejido similar a la pulpa dental, rodeado de dentina primaria y cubierto con esmalte que se encuentra desmineralizado y cemento primario. ${ }^{10-11}$ 
Los odontomas complejos a su vez dejan ver dentina inmadura como componente predominante, suelen además presentar esmalte, con 2 posibles tipos de distribución: un área calcificada cerca del núcleo central, o en una región hipocalcificada con esmalte inmaduro, además es posible observar cemento inmaduro, con la cápsula de tejido conectivo que rodea la lesión. ${ }^{12}$

Los odontomas pueden causar expansión ósea ligera, en cambió los odontomas compuestos causan gran distensión ósea, han sido asociados a situaciones como mal posición dental, impactación o mal posición, así como la formación, reabsorción y la desvitalización de dientes adyacentes en el $70 \%$ de los casos.

La mayoría de autores reportan los odontomas en pacientes jóvenes con afectación de tejidos blandos, a diferencia del presente caso clínico la lesión la presento una paciente adulta mayor, en el caso del maxilar la mayoría de lesiones se ubican en la región anterior, creando compromiso estético. $(8,11-12)$

El diagnóstico como refiere la bibliografía fue ocasional por medio de una radiografía panorámica se pudo observar una lesión con características de un odontoma compuesto, se llevo a cabo una técnica mínimamente invasiva para la extirpación de la lesión la misma se confirmó el diagnóstico radiográfico la radiografía del posoperatorio presenta una recuperación completa asi como la devolución de la funcionalidad y estética al paciente.

A partir de la observación de las imágenes de control post operatorio, consideramos que la aplicación de la técnica elegida para el tratamiento de la lesión fue la adecuada para este caso particular y que, sumada a un tratamiento de ortodoncia, brindará a la paciente un resultado funcional y estético óptimo.

\section{Referencias Bibliograficas:}


1. Dávila-Hernández DA. Enucleación de un odontoma compuesto mandibular. Comunicación de un caso clínico. Rev Esp Med Quir 2010;15(2):92-96. Disponible en: http://www. medigraphic.com/pdfs/quirurgicas/rmq-2010/rmq102h.pdf

2. Peranovic V, Noffke CEE. Clinical and radiological features of 90 odontomas diagnosed in the Oral Health Centre at Sefako Makgatho Health Sciences University. S. Afr. dent. j. [Internet]. 2016 Nov; 71( 10 ): 489-492. Disponible en: http://www.scielo.org.za/scielo. php?script=sci_arttext\&pid=S0011-85162016001000011\&lng=en

3. Vázquez Diego J, Gandini Pablo C, Carbajal Eduardo El Odontoma compuesto: Diagnóstico radiográfico y tratamiento quirúrgico de un caso clínico 2008. Disponible en: http:// scielo.isciii.es/pdf/odonto/v24n5/original1.pdf

4. Barnes $L$, eveson JW, reichart P, Sidransky D (eds.). Pathol- ogy and Genetics of head and Neck tumours. Lyon: IArc Press; 2005:284

5. Jonathan Harris R, Diaz A y Carbonell Z. Odontoma compuesto Una patología oral a considerar. Duazary; Santa Marta 7.1 (Jan-Jun 2010): 91-94. Disponible en: http://search. proquest.com/openview/7d39c6cbf22e9c0dcbead53b1d993f20/1?pq-origsite=gscholar\&cbl=2043249

6. Guerra Treviño A. y Cols. Odontoma compuesto: Diagnóstico radiológico y tratamiento quirúrgico de un caso. Revista adm/mayo-junio 2012/ vol. Lxix no. 3. P.p. 139-141. Disponible en: http://www.medigraphic.com/pdfs/adm/od-2012/od123i.pdf

7. Harris Ricardo J, Rebolledo Cobos M, Díaz Caballero A, Carbonell Muñoz Z. Odontoma serie de casos. Revisión de literatura. Av. Odontoestomatol 2011; 27 (1): 25-32. Disponible en: http://scielo.isciii.es/pdf/odonto/v27n1/original2.pdf

8. Brenes J.“Odontoma Compuesto: Diagnóstico Radiográfico y Manejo Quirúrgico. Reporte de dos casos clínicos" caso clínico. REV. CIENT. ODONTOL. (9) 2: 39-43 2013 Disponible en : http://www.colegiodentistas.org/revista/index.php/revistaodontologica/article/ viewFile/217/327

9. Amado-Cuesta S, Gargallo-Albiol J, Berini-Aytés L, Gay-Escoda C. Revisión de 61 casos de odontoma. Presentación de un odontoma complejo erupcionado. Med Oral 2003;8:36673 http://diposit.ub.edu/dspace/bitstream/2445/103351/1/513860.pdf

10. Ide F, Shimoyama T, Horie N. Gingival peripheral odontoma in an adult: case report. J Periodontol 2000;71:830-2. http://onlinelibrary.wiley.com/doi/10.1902/jop.2000.71.5.830/ abstract;jsessionid=70AFC1B35B3EA02965967C8DA3D56D94.f02t01

11. Kaneko M, Fukuda M, Sano T, Ohnishi T, Hosokawa Y. Microradiographic and microscopic investigation of a case of complex odontoma. Oral Surg Oral Med Oral Pathol Oral Radiol Endod 1998;85:131-4. Disponible en: https://www.sciencedirect.com/science/article/ pii/S1079210498901639

12. Garcia Rivera ME y Cols. Odontoma Compuesto: Reporte de un Caso Revista Médica de la Universidad Veracruzana / Vol.15, no. 2, julio-diciembre de 2015. Disponible en: https:// www.uv.mx/rm/num_anteriores/revmedica_vol15_num2/articulos/odontoma.pdf

13. Sikes JW, Ghali GE, Troulis MJ. Expansile intraosseous lesion of the maxilla. J Oral MaxiIlofac Surg 2000; . . http://www.joms.org/article/S0278-2391(08)00267-X/fulltext 



\section{Parametrización de avances funciona- les asociados a frenectomía lingual: reporte de un caso}

\section{FUNCTIONAL ADVANCES PARAMETERIZATION ASSO- CIATED TO LINGUAL FRENECTOMY: A CASE REPORT.}

José David Aguilar" ${ }^{*}$, Doris Ofelia Gordillo², Jonathan Sebastián Altamirano², Crespo Cristina Mercedes ${ }^{3}$.

1 Cirujano y Patólogo Bucal, docente de la carrera de odontología Universidad Católica de Cuenca, Sede Azogues, Ecuador.

2 Estudiante de Odontología en la Universidad Católica de Cuenca, Sede Azogues, Ecuador.

3 Magíster en Estomatología, docente de la carrera de odontología Universidad Católica de Cuenca sede Azogues, Ecuador.

*jdaguilarm@ucacue.edu.ec

DOI: https://

\section{Resumen}

El frenillo lingual es un tejido fibroso que une la lengua al piso de la boca, que cuando su tamaño es más corto de lo normal se le denomina anquiloglosia, originado por factores genéticos 0 ambientales, caracterizado porque la lengua no protruye normalmente ocasionando dificultades en las funciones normales como de succión, fonación, masticación y deglución, su diagnóstico es clínico mediante la medición de distintos parámetros tanto estáticos como funcionales. De esta manera se clasifica en cuanto a la funcionalidad lingual en leve, moderado y severo; mientras tanto en la limitación y movilidad lingual se cataloga en clase I, II, III y IV. Objetivo presentar un reporte de caso de Anquiloglosia y los resultados luego de la frenectomía lingual en un paciente. Reporte de caso paciente de 12 años de edad sin antecedentes médicos de relevancia que presenta incapacidad de protrusión lingual total, problemas fonéticos e imposibilidad de contacto linguo-palatino en apertura bucal, y mediante los parámetros de medición estandarizados se lo diagnostico como Anquiloglosia leve grado 1, por lo que se realiza una frenectomía lingual mediante anestesia local de manera ambulatoria, y se realizan controles post operatorios a los 8,15 y 60 días en donde se toman las mediciones que emitieron el diagnóstico prequirúrgico. Mostrando un avance funcional, mejor capacidad fonética y capacidad de contacto linguo-palatino en apertura bucal. Luego de esto y según 
los parámetros de medición no categoriza como Anquiloglosia. Conclusiones: Este reporte de caso demostró de manera muy objetiva que la cirugía de resección del frenillo lingual es un procedimiento que aumenta la funcionalidad normal de la lengua mejorando su correcto desenvolvimiento en actividades como la fonación, el acto masticatorio e incluso en el futuro desarrollo de los maxilares.

Palabras clave: Anquiloglosia, parámetros, diagnóstico, frenectomía.

\section{Abstract}

The lingual frenulum is a fibrous tissue that joins the tongue to the bottom of the mouth; when it is shorter than normal, it is called Ankyloglossia. Genetic or environmental factors cause this condition. In this condition, the tongue does not normally protrude, causing difficulties in normal functions such as suction, phonation, mastication and deglutition. It is diagnosed clinically by measuring different static and functional parameters. This condition is classified as mild, moderate and severe; tongue limitation and mobility are categorized as Class I, II, III and IV. Objective: To present a case report of Ankyloglossia and its results after the lingual frenectomy procedure. Case report: Twelve-year-old patient with no severe medical history shows total lingual protrusion disability, phonetic problems and impossibility of lingual-palatal contact in open mouth. By Using standardized measurement parameters, the patient was diagnosed with mild Ankyloglossia grade 1. Therefore, an ambulatory lingual frenectomy under local anaesthesia was performed. After the operation, controls are performed, and measurements are taken at 8,15 and 60 days. The results show a functional advance, better phonetic capacity and capacity of lingual-palatal contact in an open mouth. Afterwards, and according to the measurement parameters, the condition is no longer categorized as Ankyloglossia.

Conclusions: This case report proved objectively that lingual frenulum resection surgery is a procedure that augments the tongue's normal functionality, improving its correct performance in activities such as phonation, mastication, and even in the future development of the jaws.

Key words: Ankyloglossia, parameters, diagnosis, frenectomy. 


\section{Introducción}

La lengua es un órgano muscular móvil con inervación sensitiva, sensorial y motora recubierta por mucosas y papilas que participan en la formación del bolo alimenticio y en la expresión de las palabras. Los músculos que constituyen la lengua se dividen en dos grupos: extrínsecos que se originan al exterior de la lengua y se implantan en su tejido conectivo como el hiogloso, geniogloso y estilogloso, realizan movimientos linguales hacia atrás, de lateralidad, y protrusión formando el bolo alimenticio y llevándolo hacia atrás para la deglución, Los músculos intrínsecos se originan y a la vez se insertan en el tejido conectivo de la lengua, modifican la forma y el tamaño lingual, para la deglución y el habla como el longitudinal superior, inferior, transverso y vertical de la lengua. Las superficies dorsal y lateral de la lengua, se encuentran recubiertas por papilas, tapizadas por un epitelio queratinizado., que presentan corpúsculos gustativos, y las que los carecen presentan receptores táctiles que actúan en la fricción entre la lengua y el alimento ${ }^{1,2}$

Embriológicamente aparecen en la cuarta semana de gestación por los cuatro primeros arcos faríngeos y la inervación sensitiva del trigémino, el tercio posterior está inervado por el glosofaríngeo y el hipogloso brinda la capacidad motora. ${ }^{1,2,3}$

El frenillo lingual es un tejido fibroso que une a la lengua con el piso de la boca, se lo relaciona con el conducto de Wharton de la glándula submandibular y su carúncula de salida, y con el conducto de Rivini de la glándula sublingual. Esta estructura se puede ver afectada por anomalías que cuando pequeñas porciones de tejido embrionario no se han desarrollado completamente, provocan alteraciones como; Anquiloglosia o frenillo lingual corto. ${ }^{2,4}$

La palabra Anquiloglosia etimológicamente aparece de las palabras griegas Asquillos: curvo y glossa: lengua; nombrada por primera vez en 1960, Wallace la denominó como una condición en la que la punta de la lengua no protruye normalmente por su corto frenillo que dificulta los movimientos linguales y funciones normales en el habla la alimentación y se relaciona con alteraciones craneofaciales. ${ }^{5,6,7}$

La Anquiloglosia representa un problema multidisciplinario en el campo de la odontología, que va desde la periodoncia hasta la cirugía oral. En el campo de la periodoncia se la relaciona con la recesión gingival, teniendo el periodoncista un papel importante en el tratamiento de la misma ya que también obtiene referencias sobre las ligaduras para su tratamiento quirúrgico. Esta patología está asociada a problemas de maloclusión, mordida abierta y la separación de incisivos inferiores, así como problemas mecánicos relacionados con la depuración oral., ${ }^{5,7}$ Respecto de su etiología, tiene un origen genético o por factores ambientales; el 21\% es genético por el cromosoma $X$ con mayor prevalencia en varones. ${ }^{8,9}, 10$

La prevalencia es $4 \%$, varía de $0,02 \%$ al $10,7 \%$ dependiendo al tipo de investigaciones, observándose más en personas de raza negra y en recién nacidos que niños o adultos, porque cuando es leve con el crecimiento se puede solucionar. En la mayoría de las veces se presenta de forma aislada, pero, se puede asociar a síndromes. ${ }^{5,8,10}$ 
Los criterios para su diagnóstico varía según cada autor por parámetros basados en las características físicas de la anatomía oral, el más aceptado es la visualización de una membrana anormal entre la punta de la lengua y el piso de la boca, ocasionando que al protruir la lengua adopte la forma de un corazón o de una $\mathrm{V}_{i}$ sin embargo, se debe considerar las limitaciones en la funcionalidad como el impedimento de protruir la lengua más allá de la línea gingival inferior. ${ }^{8,11,12}$

El diagnóstico es clínico y se le puede valorar indirectamente calculando la diferencia entre la apertura bucal tocando y sin tocar la papila incisiva, para clasificarlo en:

Leve: El frenillo lingual corto no interfiere en las funciones normales de succión, fonación, masticación y deglución.

Moderado: El frenillo lingual corto complica las funciones normales ya antes mencionadas, produciendo mínimos inconvenientes en el habla, periodonto y en la posición dental

Severo: El frenillo lingual corto impide las funciones normales; que se ve reflejado en el periodonto. En los grados leves y moderados al protruir la lengua, su punta se adopta en la forma de un corazón. ${ }^{6}$

Los grados de una Anquiloglosia son variables, como en el que Rosas Gustavo habla sobre la clasificación de Kotlow en nivel de limitación y movilidad, mediante el uso de una regla milimetrada, sugiriendo que mayor a 16 mm es clínicamente aceptable:

- Clase I: anquiloglosia ligera de 12 a $16 \mathrm{~mm}$.

- Clase Il: anquiloglosia moderada de 8 a $10 \mathrm{~mm}$.

- Clase III: anquiloglosia severa entre 3 a $7 \mathrm{~mm}$.

- Clase IV: anquiloglosia completa entre $3 \mathrm{~mm}^{10}$.

"Hazelbaker" es una herramienta que se usa en la función del frenillo lingual, mediante un análisis cuantitativo y cualitativo para cumplir con ciertos aspectos como se visualiza en la llustración 1, caracterizado por la evaluación de:

Criterio anatómico: mediante la palpación de la membrana anterior a la base lingual, extendida hasta el piso de la boca.

Criterio funcional: con las herramientas Hazelbaker se analiza: la lateralización, elevación y extensión de la lengua, incluyendo los aspectos anatómicos en 5 categorías y en los aspectos funcionales en 7 categorías, en 3 rangos de Anquiloglosia: discapacidad funcional, aceptable o perfecta. ${ }^{10.12 .13 .14 .15}$ 
Aspectos anatómicos

\section{Aspecto lingual cuando se levanta}

2: Redonda o cuadrada

1: Ligera hendidura en la punta de la lengua

0 : Forma de $\mathrm{V}$

\section{Elasticidad del frenillo}

2: Muy elástico

1: Moderadamente elástico

0 : Poca o nula elasticidad

\section{Longitud del frenillo lingual}
2: $>1 \mathrm{~cm}$
1: $1 \mathrm{~cm}$
$0:<1 \mathrm{~cm}$

\section{Inserción del frenillo en la lengua}

2: Posterior a la punta lingual

1: En la punta lingual

0 : Punta lingual hendida

\section{Inserción del frenillo lingual al reborde al- veolar inferior}

2: Inserción en el piso de la boca

1: Inserción por debajo del reborde alveolar inferior

0 : Inserción en el reborde alveolar inferior
Aspectos funcionales

\section{Lateralización}

2: Completa

1: Cuerpo lingual sin movimiento de la punta

0: Nulo

\section{Elevación de la lengua}

2: La punta se eleva a la mitad de la boca

1: Sólo los bordes linguales se elevan

0 : La punta lingual se mantiene en el reborde alveolar inferior

\section{Protrusión lingual}

2: La punta lingual sobrepasa el labio inferior

1: La punta lingual sobrepasa el reborde alveolar inferior

0 : La punta lingual no sobrepasa el reborde alveolar inferior

\section{Expansión de la porción lingual anterior}
2: Completa
1: Parcial
0 : Nula

\section{Convexidad lingual}

2: Bordes completos

1: Sólo bordes laterales

0 : Nulo

\section{Peristalsis}

2: Completa (anterior a posterior)

1: Parcial (originándose en la parte posterior)

0 : Nula

\section{Retracción lingual}

2: Nula

1: Periódica

0 : Frecuente o con cada succión

Ilustración 1: Herramienta de evaluación Hazelbaker ${ }^{12}$. 
Gomes concuerda con Ballard y sus colaboradores que, por medio de esta herramienta, los diagnósticos de Anquiloglosia se le atribuyen un puntaje total de 8 o menos, para indicaciones de frenectomía, pero, aun no se comprueba este contexto. ${ }^{16,17,18,19,20,21}$

Distintos investigadores encionan que la funcionalidad normal del frenillo puede o no alterarse por su tamaño ya que en ocasiones este tiene la flexibilidad indicada, pero puede causar diastema interincisivo inferior, como también conlleva a problemas durante la lactancia tanto para el lactante que debido a la deficiente succión de la leche por la dificultad de los movimientos linguales producen bajo peso y deshidratación, como también para la persona que amamanta que puede experimentar sintomatología dolorosa en los pezones. ${ }^{22,23,24,25,26,27}$

Por tal razón el objetivo de este artículo es presentar un reporte de caso de anquiloglosia en un paciente niño de 12 años de edad.

\section{Reporte de Caso}

Paciente masculino de 12 años de edad asintomático, mellizo nacido a término por cesárea, acude al centro de especialidades odontológicas de la Universidad Católica de Cuenca sede Azogues para la valoración de la limitación funcional de la lengua por lo que se elabora el formulario MPS - 033 (historia clínica odontológica).

Al examen clínico se le observó dentición mixta segunda etapa, sin alteraciones en mucosas, al examen intraoral, reveló alteración en la posición dentaria por la presencia de moderado apiñamiento antero inferior. La valoración funcional de la lengua mostró incapacidad de protrusión total (Figura 1) e imposibilidad de contacto linguo-palatino en apertura bucal. (Figura 2) El frenillo era moderadamente elástico de 16 milímetros de largo (Figura 3), la distancia entre la inserción superior y la punta de la lengua fue de $13 \mathrm{~mm}$ (Figura 4), la inserción del frenillo en el margen gingival fue de -3 mm, en lateralización lingual no existió movimiento del apéndice lingual. La apertura bucal máxima del paciente fue de $40 \mathrm{~mm}$ (Figura 5) y mientras existió contacto linguo-palatino fue de 15 mm (Figura 6).

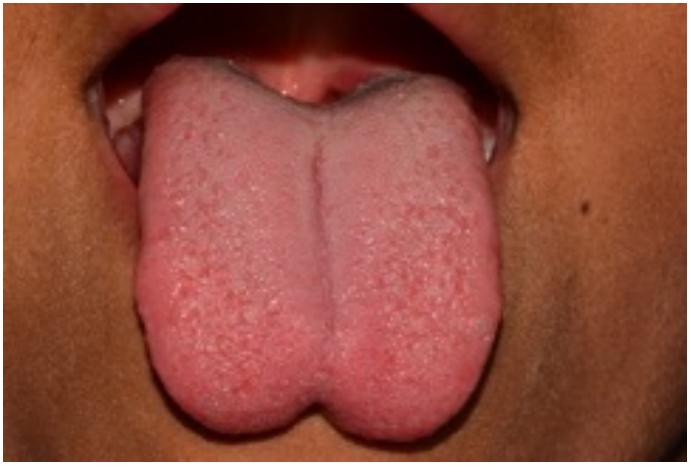

Figura 1: Se observa una limitación en la protrusión lingual con el borde anterior de la lengua toma una forma acorazonada

Fotografía: Dr. Paúl Vergara Sarmiento

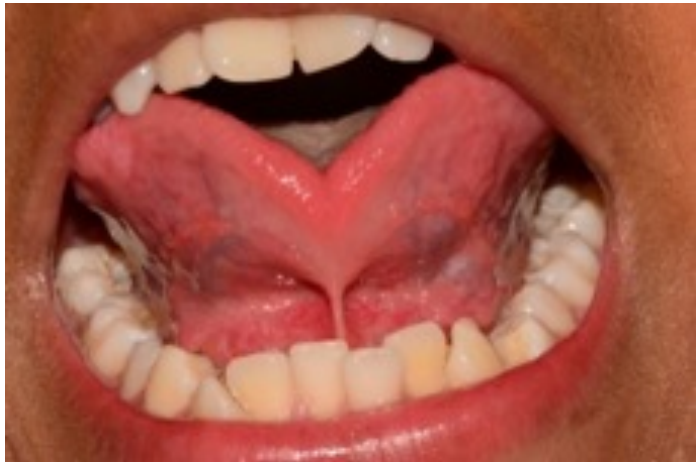

Figura 2: No existe contacto del apéndice lingual con el paladar en la apertura bucal

Fotografía: Dr. Paúl Vergara Sarmiento 

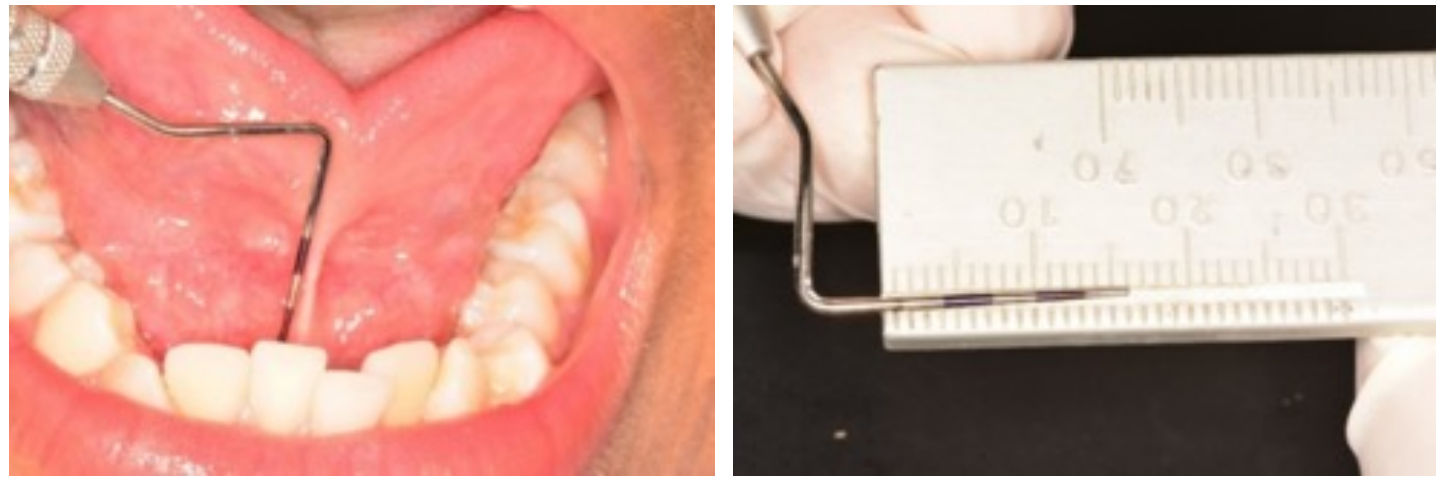

Figura 3: La longitud total del frenillo entre sus inserciones fue de $16 \mathrm{~mm}$

Fuente: los autores

Fotografía: Dr. Paúl Vergara Sarmiento

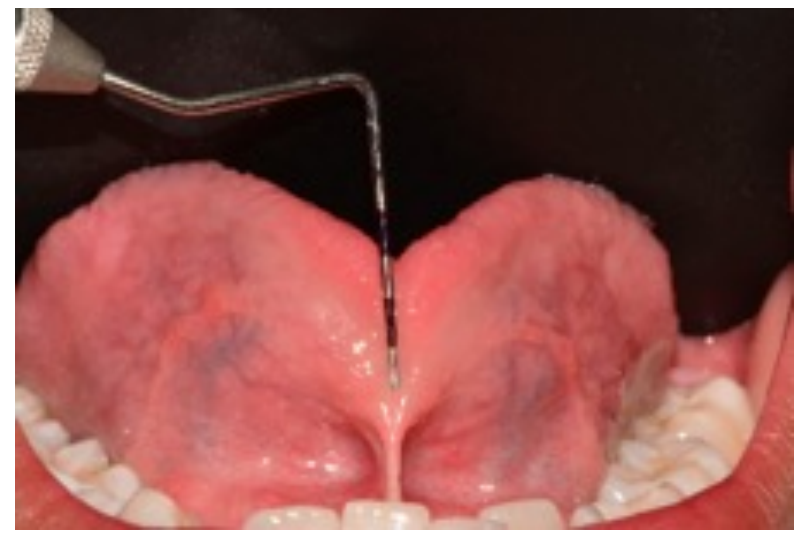

Figura 4: Distancia de $13 \mathrm{~mm}$ medida con sonda periodontal

Fuente: los autores

Fotografía: Dr. Paul Vergara Sarmiento

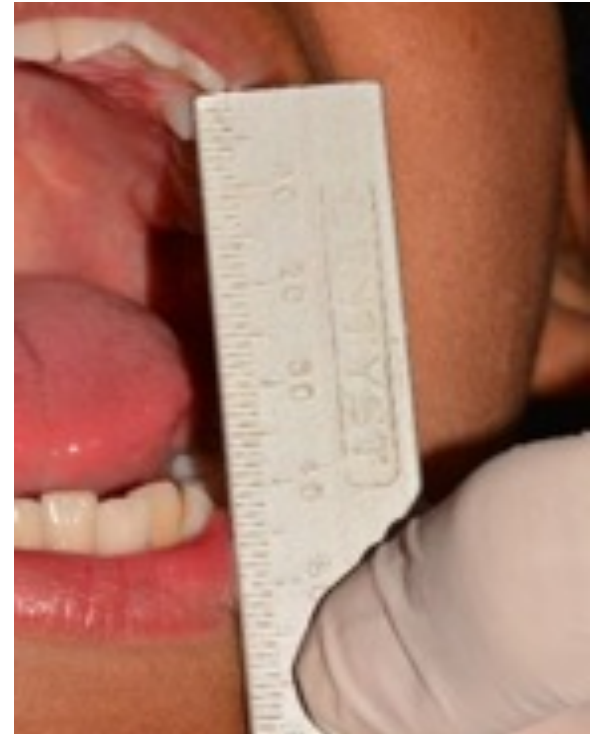

Figura 5: Apertura bucal máxima, no asistida Fotografía: Dr. Paúl Vergara Sarmiento

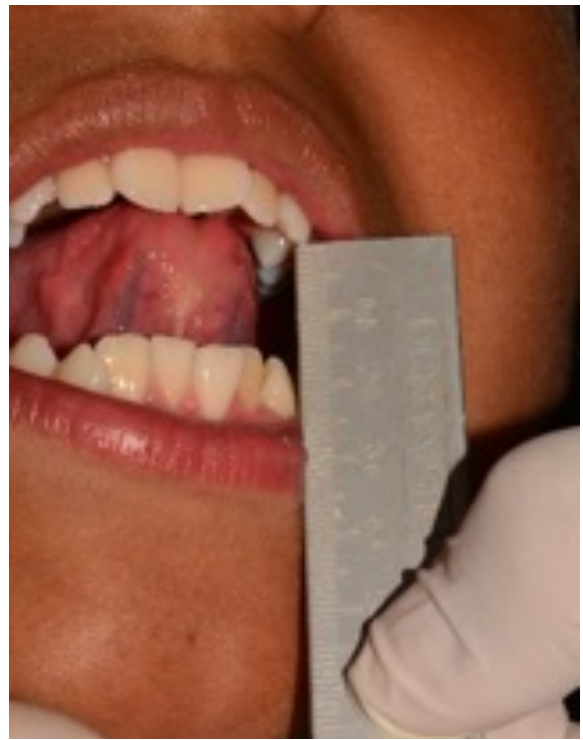

Figura 6: Apertura bucal de $15 \mathrm{~mm}$ al existir contacto linguo-palatino

Fotografía: Dr. Paúl Vergara Sarmiento 
Todas estas mediciones se tomaron con el objetivo de valorar la anquiloglosia mediante distintos clasificaciones determinando grados de anquiloglosia por diversos parámetros, los cuales se detallan en la tabla número 1.

Tabla 1. Parámetros para definir grados de anquiloglosia

\begin{tabular}{|c|c|c|c|}
\hline Parámetro & Unidad de medición & Resultados & Interpretación \\
\hline $\begin{array}{c}\text { Tamaño del frenillo } \\
\text { Inserción del margen } \\
\text { gingival al frenillo }\end{array}$ & $\mathrm{mm}$ & $16 \mathrm{~mm}$ & Mayor a un centímetro \\
\hline $\begin{array}{c}\text { Inserción del frenillo a la } \\
\text { punta de la lengua }\end{array}$ & $\mathrm{mm}$ & $3 \mathrm{~mm}$ & $\begin{array}{c}\text { (inserción en el } \\
\text { margen gingival) }\end{array}$ \\
\hline $\begin{array}{c}\text { Apertura máxima de la } \\
\text { boca medida entre los } \\
\text { caninos }\end{array}$ & $\mathrm{cm}$ & $1.40 \mathrm{~cm}$ & Clase 1 \\
\hline $\begin{array}{c}\text { Apertura al tocar la } \\
\text { papila con la punta de la } \\
\text { lengua }\end{array}$ & $\mathrm{mm}$ & $15 \mathrm{~mm}$ & Anquiloglosia leve \\
\hline
\end{tabular}

Diagnóstico pre quirúrgico: Anquiloglosia leve grado 1 según De la Teja y López, mientras tanto la clasificación de Kotlow alude que la clase de anquiloglosia es 1.

Se programa una cirugía de resección del frenillo lingual (frenectomía) bajo anestesia local de manera ambulatoria en el quirófano odontológico de las instalaciones del centro de especialidades odontológicas de la Universidad Católica de Cuenca sede Azogues.

\section{Etapa Pre quirúrgica}

Se solicitó al paciente un hemograma completo y un test de hemostasia que mostraron valores dentro de los rangos de normalidad y parámetros funcionales. Se administra $7.5 \mathrm{mg}$ de meloxicam via oral dos horas antes del procedimiento quirúrgico.

\section{Etapa quirúrgica}

En el intraoperatorio se realiza anestesia infiltrativa local para terminaciones nerviosas del nervio lingual en la cara ventral de la lengua utilizando lidocaína al 2\% con epinefrina 1:80.000 (Figura 7), se coloca un punto de reparo con sutura poliglactina (vicryl) 4-0 a nivel de la punta de la lengua (Figura 8) para facilitar la manipulación y la maniobrabilidad quirúrgica debido a la edad del paciente, se procedió a la prensión mediante una pinza hemostática de la inserción superior del frenillo lingual, luego mediante la utilización de un bisturí frío № 15 se procedió a la diéresis del frenillo (Figura 9).

Se producen movimientos de lateralidad y protrusión lingual apoyados en el punto de reparo mostrando inmediatamente una mejora notable en su funcionalidad (Figura 8). Una vez valorado esto se procede a suturar la herida quirúrgica mediante la colocación de tres puntos 
simples discontinuos con material de sutura poliglactina (vicryl) 5 - 0 (Figura 10), se comprueba la correcta hemostasia y se prescribe amoxicilina de $500 \mathrm{mg}$ por 7 días TID y meloxicam 7.5 mg UID por 3 días.

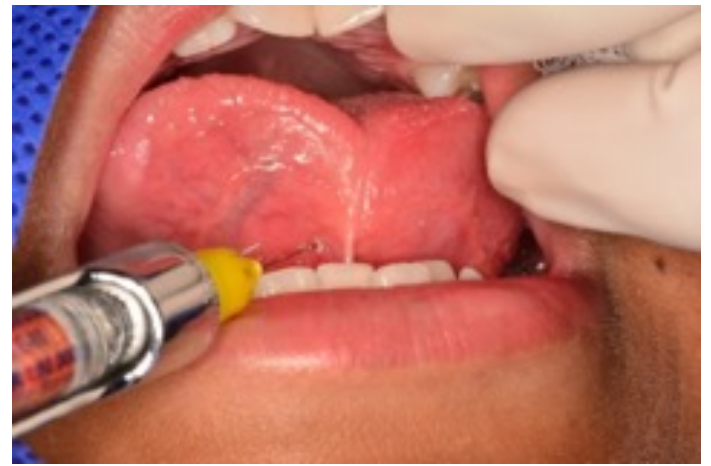

Figura 7: Anestesia infiltratíva local Fotografía: Dr. Paúl Vergara Sarmiento

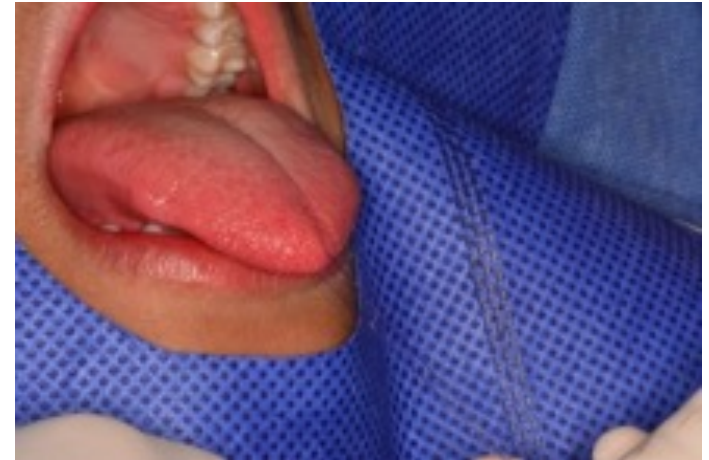

Figura 8: Punto de reparo en apéndice lingual Fotografia: Dr. Paúl Vergara Sarmiento

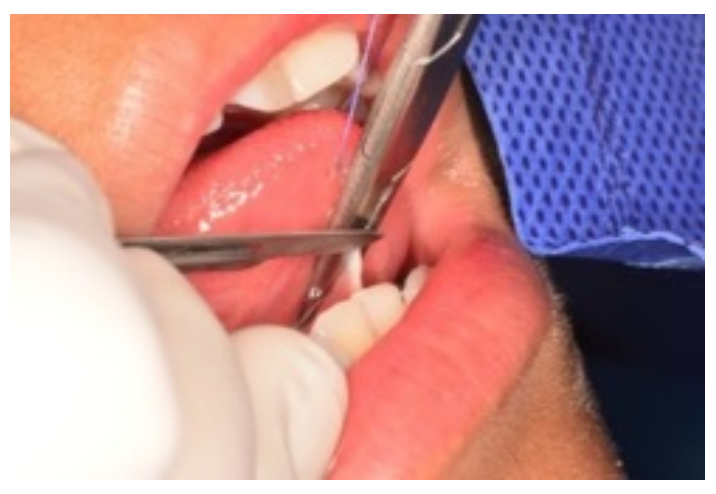

Figura 9: Frenectomía con bisturí frío Fotografía: Dr. Paúl Vergara Sarmiento
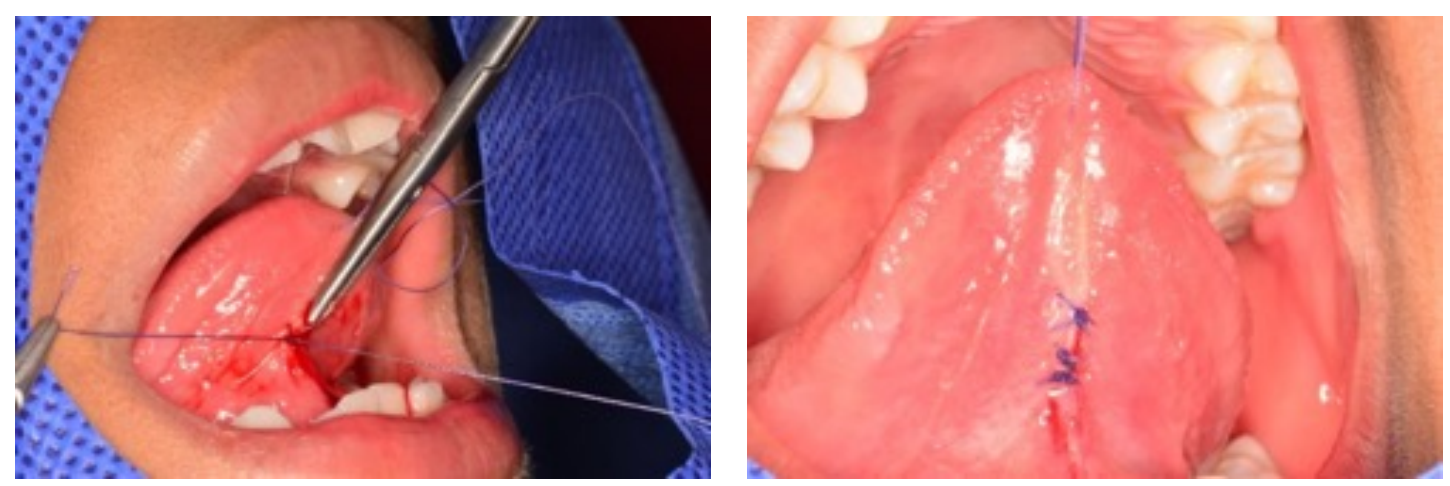

Figura 10: Sutura discontínua simple

Fuente: Ios autores

Fotografía: Dr. Paúl Vergara Sarmiento 


\section{Control post quirúrgico}

Control a los 8 días los puntos de sutura siguen en su sitio y la cicatrización de la herida quirúrgica es altamente favorable sin signos de infección o sangrado.

Control a los 15 días presenta ausencia de sutura donde el paciente manifiesta que los perdió de manera espontánea.

Control a los 2 meses, (figura 11) donde se evalúan nuevamente los siguientes parámetros (tabla 2):

Tabla 2. Cuadro comparativo e interpretativo de resultados

\begin{tabular}{|c|c|c|c|c|}
\hline Parámetro & Pre quirúrgico & $\begin{array}{c}\text { Post quirúrgico } \\
2 \text { meses }\end{array}$ & Diferencia & Interpretación \\
\hline $\begin{array}{c}\text { Inserción del } \\
\text { frenillo a la punta } \\
\text { de la lengua }\end{array}$ & $13 \mathrm{~mm}$ & $16 \mathrm{~mm}$ & $3 \mathrm{~mm}$ & $\begin{array}{c}\text { No categoriza } \\
\text { como } \\
\text { anquiloglosia }\end{array}$ \\
\hline $\begin{array}{c}\text { Apertura al tocar la } \\
\text { papila con la punta } \\
\text { de la lengua }\end{array}$ & $15 \mathrm{~mm}$ & $26 \mathrm{~mm}$ & $11 \mathrm{~mm}$ & $\begin{array}{c}\text { No categoriza } \\
\text { como } \\
\text { anquiloglosia }\end{array}$ \\
\hline $\begin{array}{c}\text { Inserción del } \\
\text { margen gingival al } \\
\text { frenillo }\end{array}$ & $3 \mathrm{~mm}$ & $12 \mathrm{~mm}$ & $9 \mathrm{~mm}$ & $\begin{array}{c}2 \text { (Inserción en } \\
\text { piso de la boca) }\end{array}$ \\
\hline
\end{tabular}

\section{Antes}
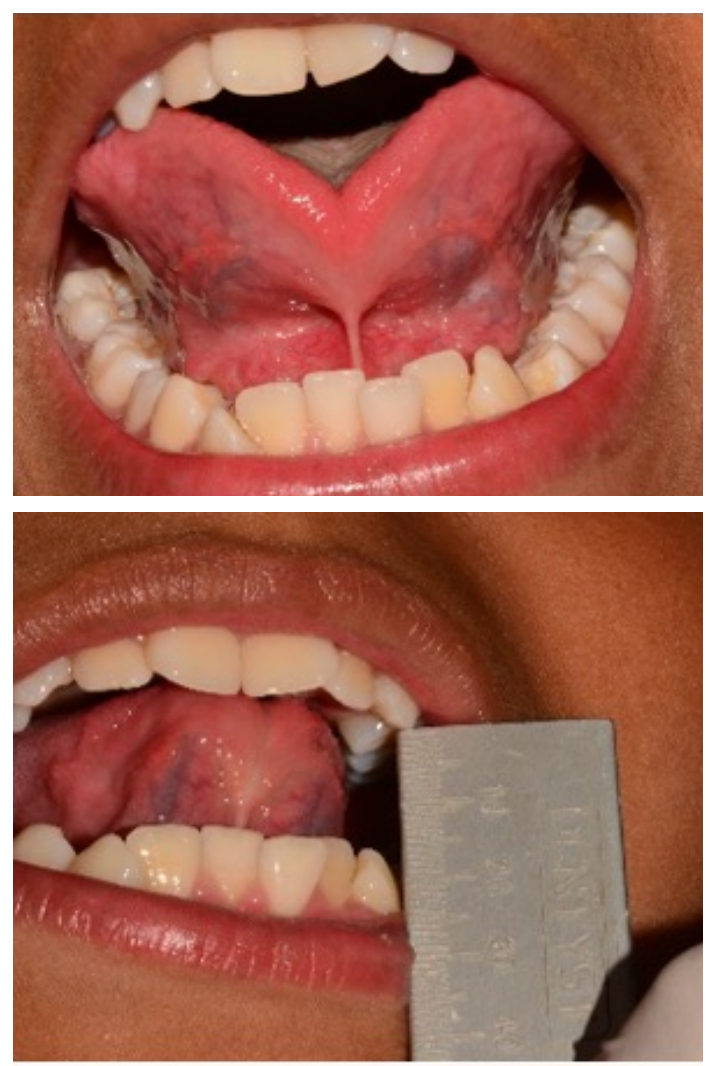

Después
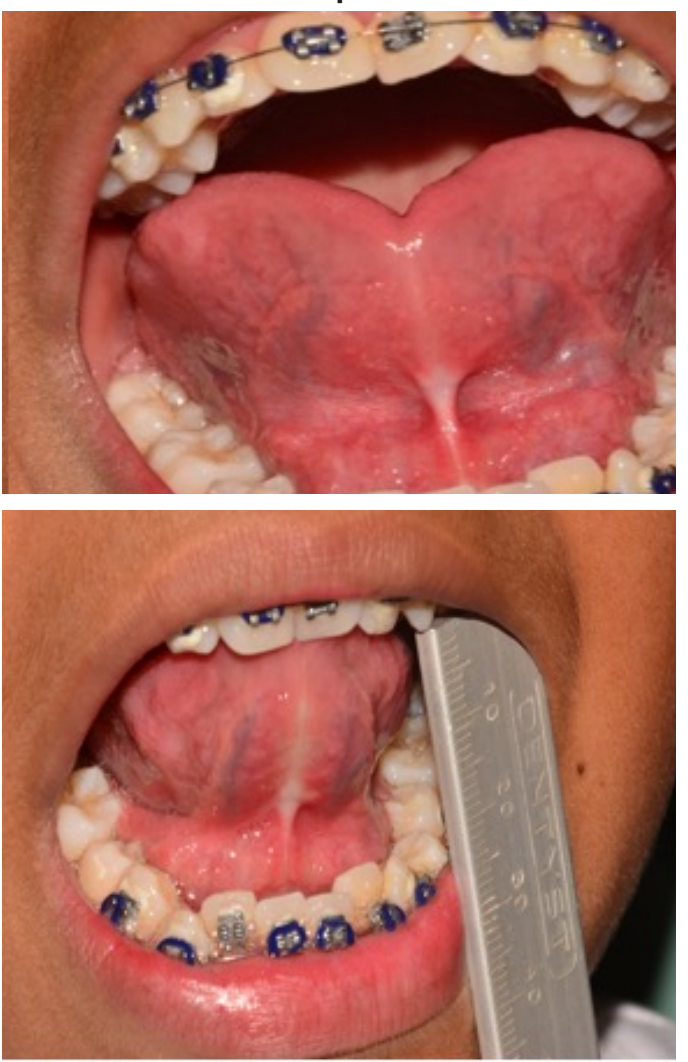

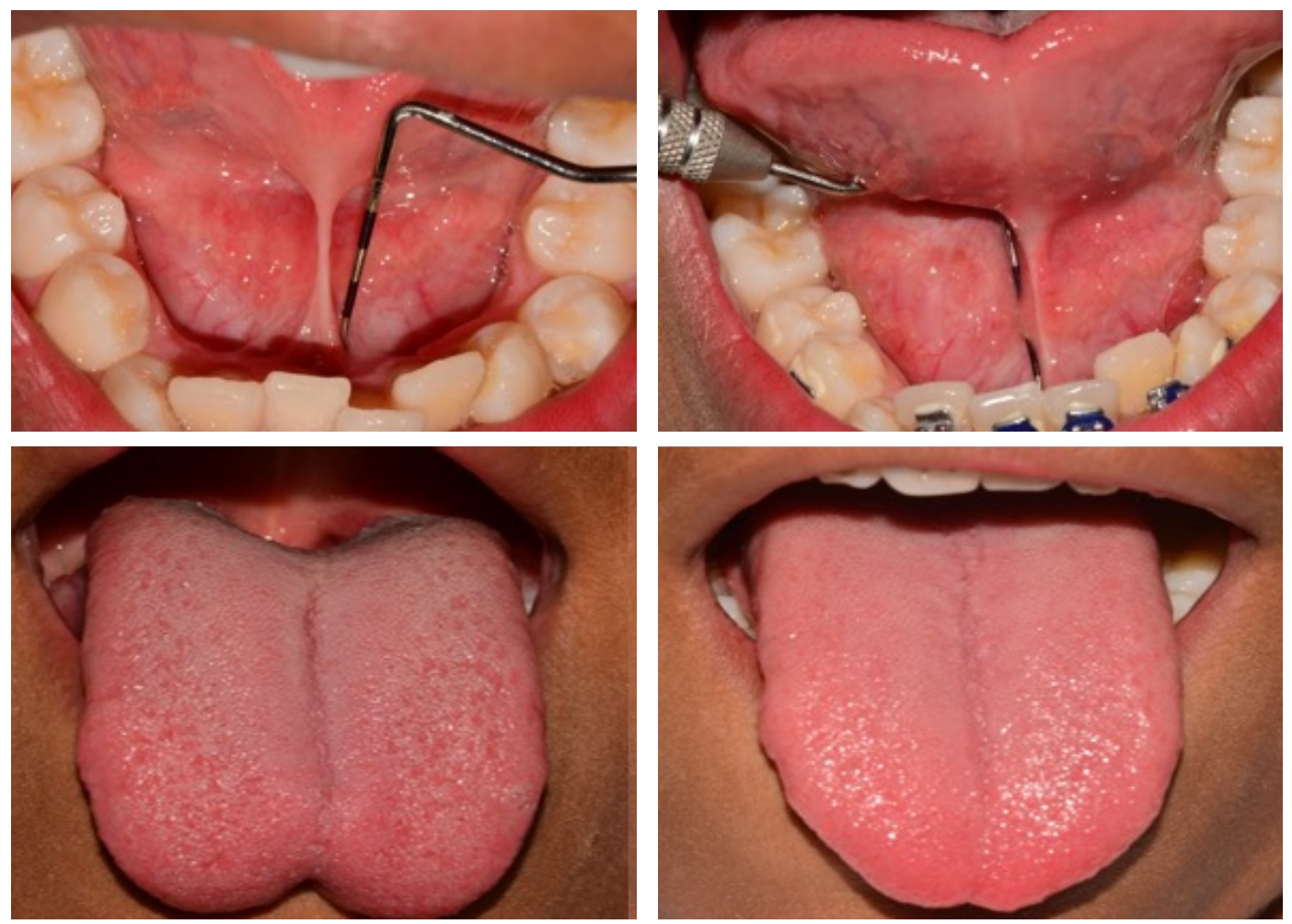

Figura 11: Resultados finales post operatorios

Fotografía: Dr. Paúl Vergara Sarmiento

Luego de la valoración y con estabilidad dimensional de los tejidos a los 2 meses se observó en términos generales un amplio aumento de la funcionalidad lingual y la ausencia de anquiloglosia según los parámetros evaluados y comparados (tabla 2)

\section{Discusión}

Con respecto a las consecuencias funcionales en el reporte de caso el paciente no presentó dificultades en las funciones normales 0 alteraciones del desarrollo del maxilar inferior como lo describe Cuervo en el año 2008 confirmando la importancia de una evaluación funcional ya que existen casos que el frenillo lingual es corto pero su elasticidad permite desarrollar las funciones con normalidad sin alteraciones ${ }^{8}$ por otro lado Geraldine y Bornsetein en el año 2009 indican que esta anomalía, puede provocar una serie de alteraciones funcionales en la fonación, la higiene, dificultades para amamantar en recién nacidos y problemas en el crecimiento normal de la mandíbula. ${ }^{5}$

En este reporte de caso la edad de diagnóstico fue a los 11 años, debido a la ausencia de alteraciones funcionales, esto, se aleja de lo que relata Carril, Hereñuz y Perez en el 2015 los cuales demostraron que el diagnóstico es más frecuente niños comprendidos entre las edades de $5 \mathrm{a}$ 7 años. ' pero Rosas y González manifiestan que el diagnóstico comunmente es en niños recién nacidos neonatos. ${ }^{10}$ 
Blanco en el 2005 reporta que existe mayor prevalencia de anquiloglosia en pacientes de sexo masculino, aunque esta no es marcada con respecto al sexo femenino ${ }^{28}$, entre tanto en el reporte del caso clínico la anquiloglosia se presentó en un paciente de sexo masculino.

Hong en el 2009 reporta informes de la edad del tratamiento en niños mayores a 10 años y adultos sometidos a la liberación del frenillo lingual corto ${ }^{29}$. Por el contrario Gay y Berini en 2004 relata que se puede recurrir a un tratamiento conservador en una edad temprana, menor a los 8 años de edad ${ }^{30}$. Sin embargo en este reporte de caso la edad del tratamiento al paciente se lo realiza a los 12 años de edad avalando el criterio de Hong.

Correa, Abanto y Alves en el 2008 indican un tratamiento conservador, que resulta ser seguro y efectivo ya que cuando la anquiloglosia es de un grado leve-moderado con el desarrollo normal en el crecimiento, se puede regularizar la función del frenillo, evitando así la cirugía ${ }^{26}$. A modo que Salete, Abanto, Correa y Bonini en el 2009 promueven que la frenectomía es indicada solamente en casos de imposibilidad para realizar las funciones habituales. ${ }^{22}$ No obstante en este artículo el tratamiento es una frenectomía, sin la necesidad que el paciente muestre signos de anomalías en la funcionalidad normal del frenillo.

Hong en el 2013 indica que luego de la frenectomía se deberían realizar ejercicios como: Colocar la lengua en el paladar, protruir la lengua o presionar un objeto como mínimo 10 series cada una tres veces al día ${ }^{29}$, a pesar de esto Pastor, Rodríguez y Ferréz en el 2017 mencionan que no se deben realizar movimientos bruscos después de la operación quirúrgica ya que esta puede producir ruptura de los puntos de sutura, sangrado o una infección post operatoria. ${ }^{24}$ Entonces luego de la evidencia científica analizada en los controles post operatorios de nuestro caso se le recomienda al paciente realizar movimientos de arriba-abajo y laterales de la lengua, además se observa que los puntos de sutura no se desalojaron hasta después del día 8.

\section{Conclusión}

Este reporte de caso demuestra de manera muy objetiva que la cirugía de resección del frenillo lingual es un procedimiento que aumenta notablemente la funcionalidad normal de la lengua mejorando de manera significativa su correcto desenvolvimiento en actividades como la fonación, el acto masticatorio e incluso en el futuro desarrollo de los maxilares.

\section{Agradecimientos}

Los autores agradecen a la Universidad Católica De Cuenca Sede Azogues por permitir el acceso a las diferentes bases científicas para realizar la investigación, además de los servicios prestados por parte de los docentes en el centro de especialidades odontológicas de la universidad. 


\section{Referencias Bibliograficas:}

1. Carril N. Hereñuz J. Pérez M. Anquiloglosia en Adultos Reporte de un caso. Servicio de prácticas Odontológicas Integradas Facultad de Odontología. 2015; 27: 1-4.

2. Chaviano J, Cores A, Ortiz J, Robles J, Rodríguez M. Frenectomía Lingual: Reporte de un caso. Educación y Salud del ICSA. 2015; 4(7).

3. Tortora G. Derrickson B. principios de anatomía y fisiología. Aparato digestivo. Editorial médica panamericana.2014; 13ed: 976-977.

4. Gomes E, Borba F, Rodríguez J. Freno lingual: enfoque clínico interdisciplinario de la Fonoaudiología y Odontopediatría. Revista de la Asociación de Cirujanos Dentistas. 2015; 69(1).

5. Geraldine V. Bornsetein M. Ankyloglossia facts and myths in diagnosis and treatment. Journal of periodontology. 2009. 80 (8); 1204-1217.

6. De la Teja-Ángeles E. López-Fernández R. Durán-Gutiérrez L. Cano-de Gómez A. Téllez-Rodríguez J. Frenillo lingual corto o anquiloglosia. Acta Pediátrica Mexicana 2011; 32(6):355-356.

7. Sivakumar C. and contributors. Treatment of Ankyloglossia for Reasons Other Than Breastfeeding: A Systematic Review. Vanderbilt Evidence-based Practice Center, Institute for Medicine and Public Health, Vanderbilt University Medical Center. 2017; 6 (135):67-69.

8. Cuervo L. Anquiloglosia (frenillo lingual corto): sugerencias para el diagnóstico y el manejo clínico. Revista Hospital de niños. Buenos aires. Argentina. 2008. 50 (228); 125-128.

9. Salgado T, Obando J, Salgado P, Salgado W. Tratamiento quirúrgico de la anquiloglosia recidivante: A propósito de un caso. Revista Científica Mundo de la Investigación y el Conocimiento. 2017; 1(4), 777-790.

10. Rosas Ortiz G., González Magaña F., González López B. Anquiloglosia parcial (incompleta) Reporte de un caso y revisión de la literatura.Revista ADM. 2009 abril; 65(2).

11. Lauren M. Randolph S. Martin D. Perle F. Prevalence, diagnosis and treatment of ankyloglossia. Canadian Family Phsycian. 2007; 53: 1027-1033.

12. Robles-Andrade Manuel Salvador, Guerrero-Sierra Cecilia. Impacto de la anquiloglosia y la frenectomía lingual en la alimentación neonatal. Perinatol. Reprod. Hum. 2014 Septiembre: 28 (3): 154-158.

13. Rakesh B, Eesha J, Rameshkumar P, Rakeshkumar C. Labial ankyloglossia: A rare case report. Contemporary Clinical Dentistry. 2016; 7(4).

14. González Jiménez D., Costa Romero M., Riaño Galán I., González Martínez M., Prevalence of ankyloglossia in newborns in Asturias. Anales de pediatría. 2013 octubre; 81(2).

15. Chandrashekar L., Kashinath KR., Suhas Setty. Labial Ankyloglossia Associated with Oligodontia: A Case Report Journal of Dentistry, Tehran University of Medical Sciences. 2014 julio; 11(4). 
16. Agarwal P, Raina VK. Tongue- tie: an update. Indian Pediatr 2003; 40(5): 404-5.

17. Ballard JL, Auer CE, Khoury JC. Ankyloglossia: assessment, incidence, and effect of frenuloplasty on the breastfeeding dyad. Pediatrics 2002; 110: e63.

18. Wright JE. Tongue-tie. Paediatr Child Health 1995; 31: 276-8.

19. Kotlow LA. Ankyloglossia (tongue-tie): A diagnostic and treatment quandary. Quintessence Int 1999; 30:259-62.

20. Barros Espadero D. Efectos de las intervenciones liberadoras del frenillo sublingual sobre la lactancia al pecho y sobre la articulación del lenguaje hablado: una revisión sistemática. Evidencia pediatrica.2014:10:72

21. Marmet $\mathrm{C}$, Shell $\mathrm{E}$, Marmet R. Neonatal frenotomy may be necessary to correct breastfeeding problems. J Hum Lact 1990;6:117-21

22. Correa María Salete Nahás Pires, Abanto Alvarez Jenny, Correa Fernanda Nahás Pires, Bonini Gabriela Azevedo de Vasconcelos Cunha. Anquiloglosia: ¿cuándo intervenir? Revisión y reporte de caso. Acta odontológica venezolana. 2009; 47(3): 173-178.

23. Nevárez A, Medina J, Nevárez M, Vargas J, Consdtance D, Guzmán D et al. Tratamiento para el Problema del Lenguaje de Rotacismo Mediante Cirugía Oral y Terapia Vibroestimulatoria - Reporte de un Caso. International journal of odontostomatology. 2013; 7(1).

24. Pastor T, Rodriguez P, Ferréz E, Ferréz Padro E. Anquiloglosia y problemas de succión, tratamiento multidisciplinar: terapia miofuncional orofacial, sesiones de lactancia materna y frenectomía. Revista de Logopedia, Foniatría y Audiología. 2017; 37(1):4-13.

25. Gonzales Orte Eva María, Laura Alba-Giménez, Berta Serrano-Alvar. La anquiloglosia y las dificultades que presenta en el amamantamiento. Matrona. Atención primaria. Centro de Salud. 2017 junio; 18(3):50-57.

26. Correa M, Abanto J, Correa F, Bonini G, Alves F. Anquiloglosia y amamantamiento: Revisión y reporte de caso. Revista Estomatol Herediana. 2008; 18(2):123-127.

27. Brisque F, Martins D, De Araújo J, Issler H. Desmame precoce: Implicaciones para el desenvolvimento motor-oral. Journal Pediatric 2004; 79(1):7-12.

28. Blanco G. Anquiloglosia: revisión de la literatura y reporte de caso. Revista Estomatólica 2005; 13(2):50-8.

29. Hong P. Ankyloglossia (tongue-tie); Short Lingual Frenulum. Canadian Medical Association or its licensors.2013; 185(2):127-129.

30. Gay C, Berini L. Tratado de Cirugía bucal. 1ª̣ed.Madrid: Ergón; 2004.

\section{Recibido:}

\section{Aceptado:}




\title{
Reimplante dentario ulterior a su avulsión: reporte de caso clínico
}

\section{Reimplantation of the tooth after its avulsion: clinical case report}

\author{
Byron Morales*', Ma. Augusta Cordero ', Patricia Pinos ' \\ ${ }^{1}$ Docente de la carrera de odontología de la Universidad Católica de Cuenca. \\ *byronmorales@yahoo.com
}

DOI: https://

\section{Resumen}

En el presente artículo, detallamos el caso clínico de un paciente de sexo femenino de 29 años de edad aproximadamente, que acude a la consulta para que se le realice un puente fijo en la zona de los dientes perdidos ya que su estética se vio afectada y no puede sonreír debido a que sufrió una caída como consecuencia de un ataque de epilepsia y se produjo la avulsión de las piezas dentarias 1.1 y 2.1 .

Durante la consulta la paciente comenta que luego del incidente fue atendida inmediatamente por un neurólogo y un cirujano máxilo facial porque presentaba heridas cortantes en el labio, y se le envió a la casa sin reimplantarle los dientes, y dio un dato relevante al mencionar que ella tiene los dientes en su casa guardados en suero fisiológico. Por lo que inmediatamente se solicitó traer los dientes y así cambiar el plan de tratamiento y proceder con el protocolo de reimplante.

A los ocho días de transcurrido el accidente se procede a realizar las endodoncias de los dientes avulsionados, y su posterior reimplantación en el alvéolo.

Palabras clave: avulsión, reimplante, endodoncia 


\section{Abstract}

Next, we detail the clinical case of a female patient of 29 years of age, who comes to the consultation to have a fixed bridge in the area of lost teeth since her aesthetic was affected and cannot smile because she suffered a fall as a result of an attack of epilepsy and there was avulsion of the dental pieces 1.1 and 2.1.

During the consultation, the patient commented that after the incident she was attended immediately by a neurologist and a maxillo facial surgeon because she had sharp cuts on her lip, and she was sent to the house without reimplanting her teeth, and she gave relevant information when mentioning that she has the teeth stored in physiological serum at home. We requested Immediately to bring the teeth and change the treatment plan and proceed with the reimplantation protocol.

Eight days after the accident, the endodontics of the avulsed teeth are carried out, and their subsequent reimplantation in the alveolus.

Keywords: Avulsion, reimplantation, endodontics 


\section{Introducción}

Las lesiones dentarias generalmente son provocadas por accidentes debido a golpes, traumatismos en donde se ven afectados dientes del sector anterior, ocasionando daños del ligamento periodontal del 15 al $61 \%$ de las lesiones orofaciales. A pesar de que sus efectos físicos son tratables y más importante aún, pueden prevenirse, sólo el $4 \%$ de los pacientes es atendido por un especialista en odontología. Así el 47\% de estos dientes reciben tratamiento, pero éste es inadecuado en el $59 \%$ de los casos. ${ }^{1-4}$

La avulsión dental es la expulsión de un diente fuera de su alveolo, causado generalmente por un traumatismo violento, provocando la subsecuente ruptura abrupta de las fibras periodontales y paquete vasculonervioso esto ocurre cuando el diente es desplazado. ${ }^{5-6}$

Cuando la avulsión afecta un diente anterior pueden producirse severas consecuencias psicológicas. ${ }^{7}$ el medio y las condiciones en las que se mantiene el diente avulsionado hasta el reimplante son básicos en el éxito o fracaso del tratamiento. Si la pieza dental tiene un tiempo extra oral inferior a 60 minutos se puede lograr una efectividad del procedimiento superior al $90 \%$ de los casos, no asi cuando el tiempo extraoral sobrepasa a 120 minutos. ${ }^{8,9}$ Se concluye que la premura en el cumplimiento y ejecución del protocolo a desarrollar son transcendentales para disminuir las probabilidades de fracaso o perdida de las piezas dentarias avulsionadas. ${ }^{10-11}$

En este caso clínico, el reimplante se realizó transcurridas 192 horas (8 días) y el diente permaneció en suero fisiológico, por lo que se le explico al paciente el posible fracaso del tratamiento por el tiempo transcurrido. Lo ideal para reimplantar un diente será alrededor de $15 \mathrm{a}$ 20 minutos, ya que, si no se mantiene en un medio adecuado, se producirá una necrosis de las células periodontales, así como de sus fibras periodontales.

Existen varias disyuntivas referentes a la conservación de los dientes avulsionados, como medios de conservación podemos mencionar la leche, ya que puede mantener al ligamento periodontal aproximadamente por 3 horas, otro medio es el suero fisiológico, la saliva no se recomienda ya que daña las células periodontales. ${ }^{12-13}$

\section{Presentación del Caso Clínico}

Paciente de sexo femenino de 29 años de edad, acude a la consulta ya que sufrió una caída como consecuencia de un ataque de epilepsia y se produjo la avulsión de las piezas dentarias 1.1 y 2.1 .

Fue atendida inmediatamente por un neurólogo y un cirujano máxilo facial porque presentaba heridas cortantes en el labio, y se le envió a la casa sin reimplantarle los dientes, los mismos que habían sido conservados en suero fisiológico. 
Transcurrido 8 días del accidente la paciente acude a la consulta y refiere el deseo de realizarse un puente fijo en la zona de los dientes perdidos, ya que su estética se ve afectada y no puede sonreír. Pero al saber que aún conservaba los dientes en suero fisiológico, se le dio la posibilidad de colocarle nuevamente sus propios dientes mediante la reimplantación de los mismos, es importante mencionar que es de suma importancia el espacio de tiempo que permanece los dientes fuera de su alvéolo antes del tratamiento, así como su mantenimiento en un medio adecuado.

En el análisis clínico oral se observa la avulsión de las piezas dentarias 1.1 y 2.1, corte desde el bermellón hasta el surco naso-mento-labial en la parte derecha cercana a la línea media facial.

Se elabora la propuesta del plan de tratamiento y se lo hace conocer al paciente.

A los ocho días de transcurrido el accidente se procede a realizar las endodoncias de los dientes avulsionados, y su posterior reimplantación en el alvéolo.

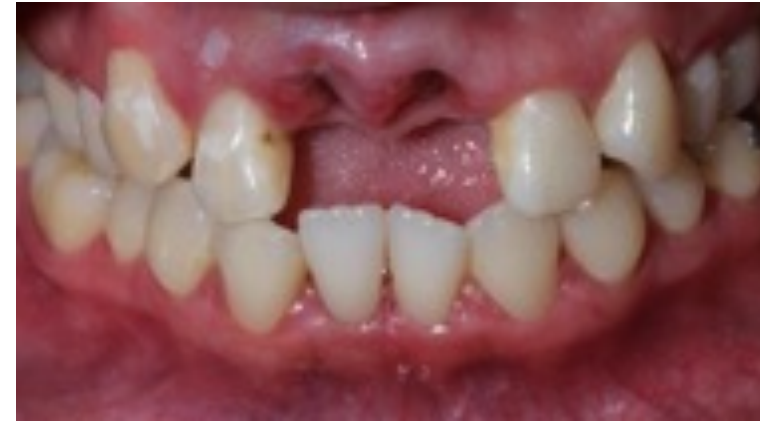

Figura 1.- Aspecto tras la avulsión de las piezas 1.1 y 2.1 ocho días después del incidente.

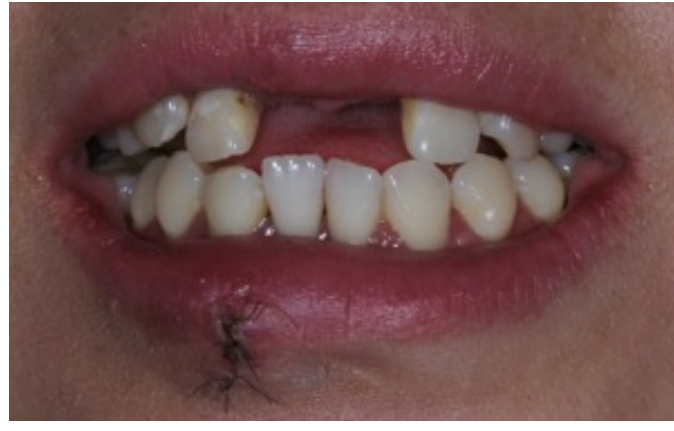

Figura 2.- Avulsión 1.1 y 2.1 Corte desde el bermellón hasta el surco naso-mento-labial

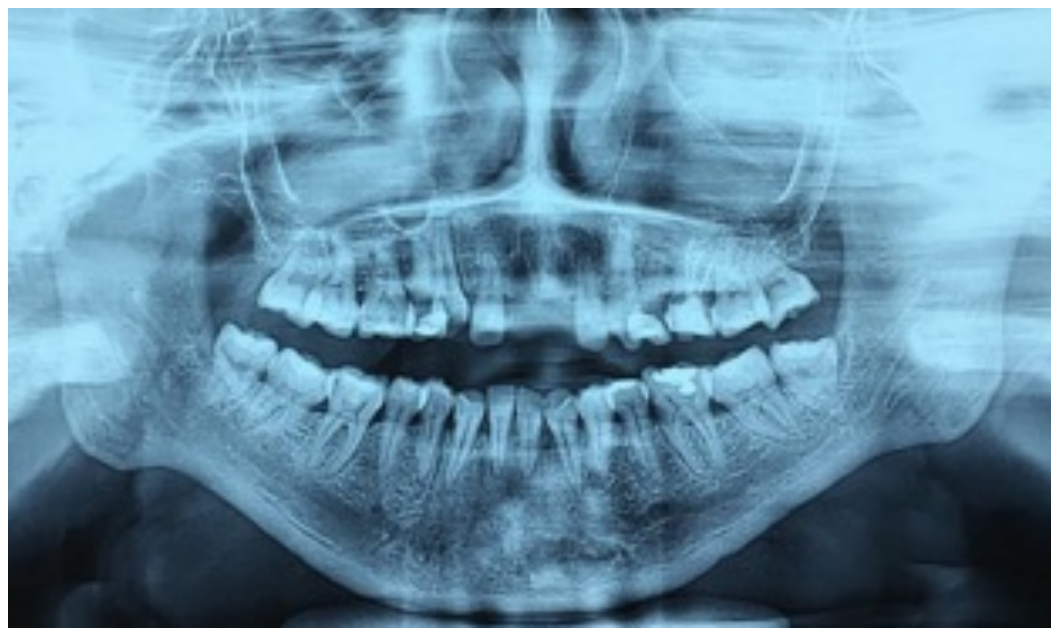

Figura 3.- Radiografía inicial 


\section{Ejecución del plan de tratamiento}

\section{Endodoncia de los dientes avulsionados}

Luego de haber receptado los dientes, se realiza el tratamiento de conducto de la pieza 1.1 y 2.1 con la técnica apico coronal y la obturación correspondiente con técnica de condensación lateral, se sella en la entrada del conducto con ionómero de vidrio y proceder al reimplante.

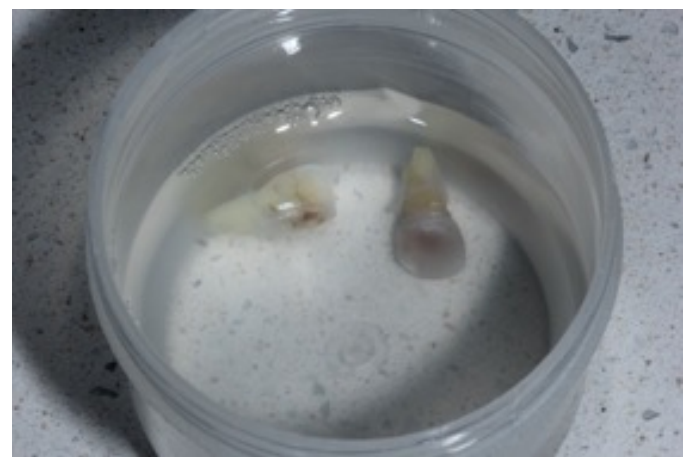

Figura 3.- Condición en la que llegan los dientes en suero fisiológico a los 8 días

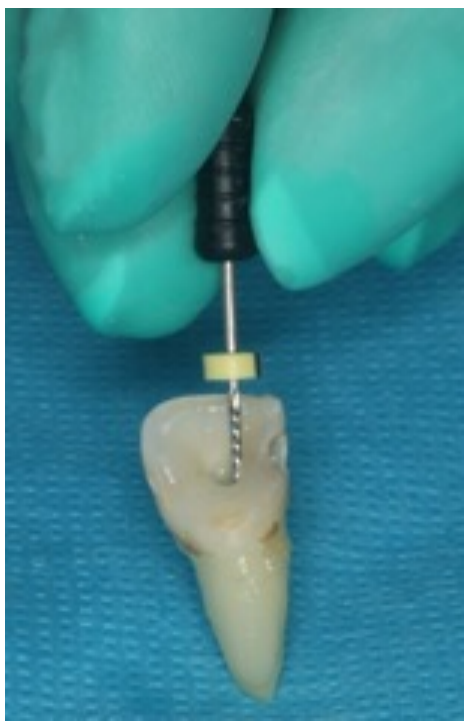

Figura 5.- Permeabilización e instrumentación del conducto extraoral

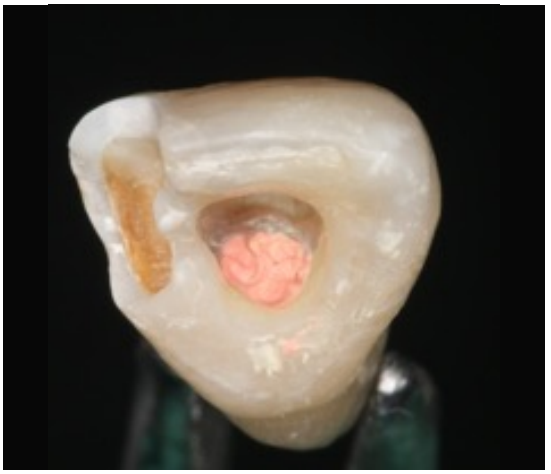

Figura 7.- Eliminación del exceso de cemento y gutapercha

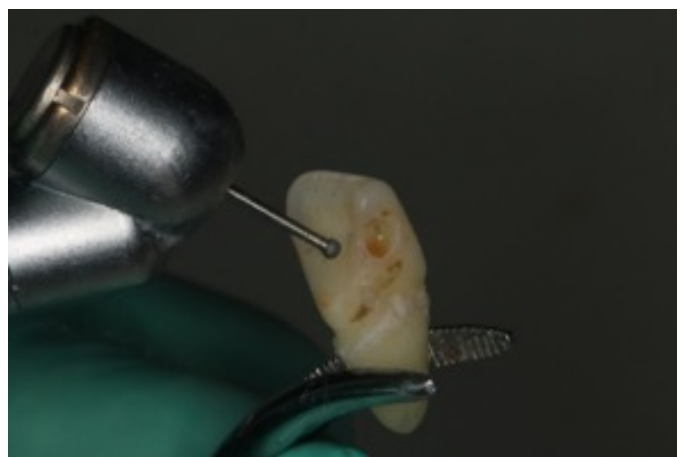

Figura 4.- Acceso coronario extraoral

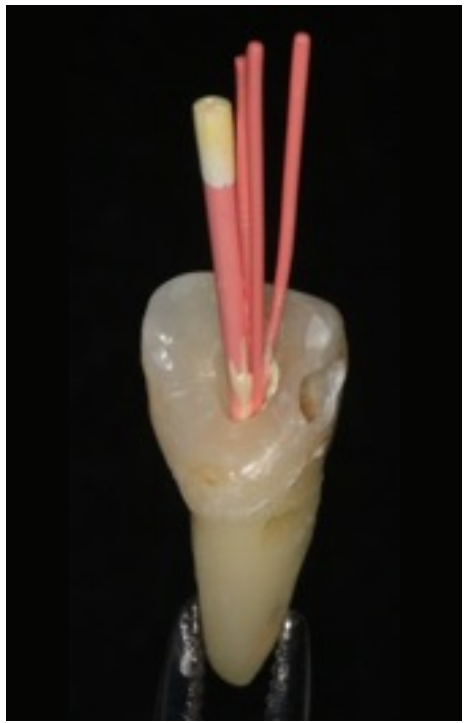

Figura 6.- Obturación radicular técnica de compactación lateral en frío extraoral

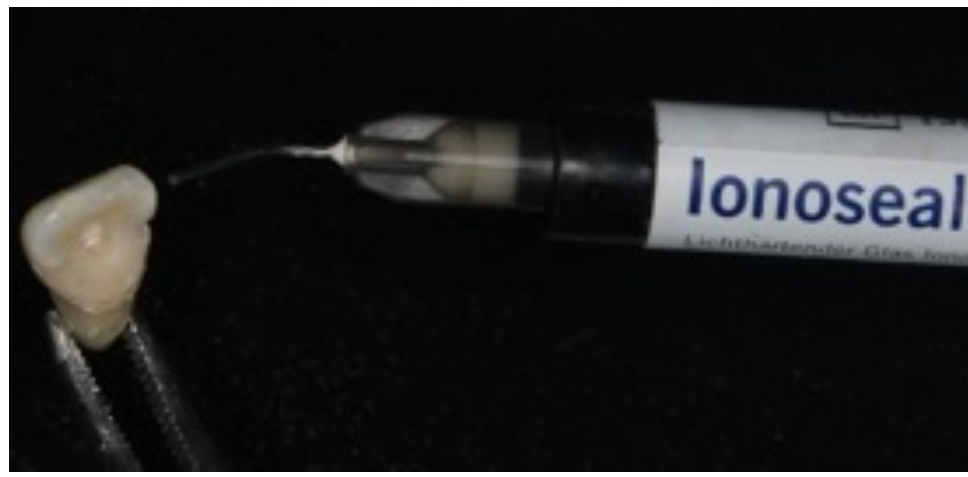

Figura 8.- Sellado coronal con ionómero de vidrio 


\section{Reimplantación}

Los incisivos se reimplantaron posterior a la preparación de los alveolos, sujetándolo suavemente por la corona, se suturaron los tejidos blandos con seda 3-0 y se procedió a realizar ligadura en 8 con alambre № 10, se realiza el grabado ácido por 20 seg con ácido fosfórico al $37 \%$, se lava el doble de tiempo, para eliminar cualquier residuo, se seca con chorro de aire a $1 \mathrm{~cm}$ de distancia por $5 \mathrm{seg}, 37$ y procedemos al bondeado y colocación de resina aufotopolimerizable Z100 de 3M.

Se prescribió terapia antibiótica durante siete días y se recomendó la protección antitetánica, insistiendo en la importancia de mantener la máxima higiene bucal; limpiar y retirar cuidadosamente los restos alimenticios de dientes y férula evitando la retención de los mismos, lavados de colutorios de clorhexidina acuosa 0,12 \% para evitar la contaminación microbiana. 6,12

Al paciente se dio las siguientes recomendaciones: dieta blanda, evitar morder con los dientes afectados y ferulizados durante 4 semanas, en este periodo los alimentos se cortarían en fragmentos pequeños y se masticarían con los otros dientes ${ }^{14,15}$. Una semana después se retiraron los puntos de sutura. La férula se retiró al mes una vez comprobada la estabilidad del diente en su alvéolo.

Doce meses después del reimplante se toma la radiografía panorámica y se observa signos radiográficos de reabsorción ósea. ${ }^{10,13}$

Después del reimplante, se forma un coágulo entre las dos zonas del ligamento periodontal seccionado. La solución de continuidad generalmente se encuentra en la mitad del ligamento, pero puede ocurrir a nivel del cemento o en el hueso alveolar. Dos semanas después, la herida está cicatrizada y las fibras de colágeno se extienden desde el cemento hasta el hueso. En este momento se comienzan procesos de reabsorción a lo largo de la superficie radicular, pudiendo evolucionar a una nueva reparación con cemento dando lugar a una reabsorción superficial 0 a procesos de reabsorción inflamatoria 0 anquilosis. ${ }^{26}$

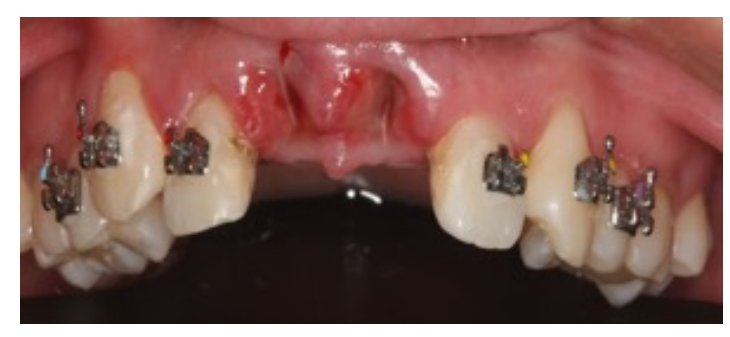

Figura 9.- Bondeado de braquets en las piezas vecinas

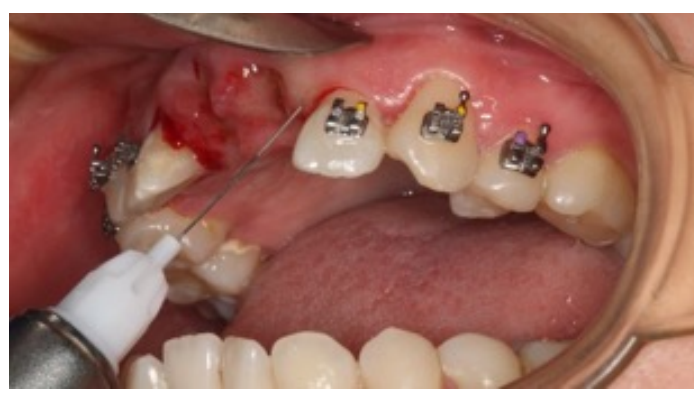

Figura 10.- Anestesia locorregional 


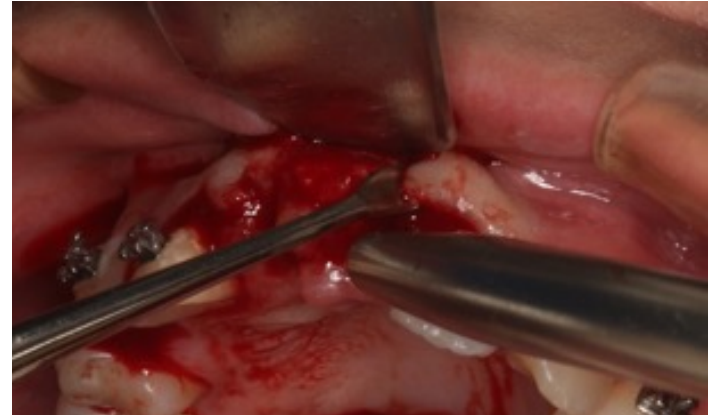

Figura 11.- Levantamiento de colgajo y curetaje

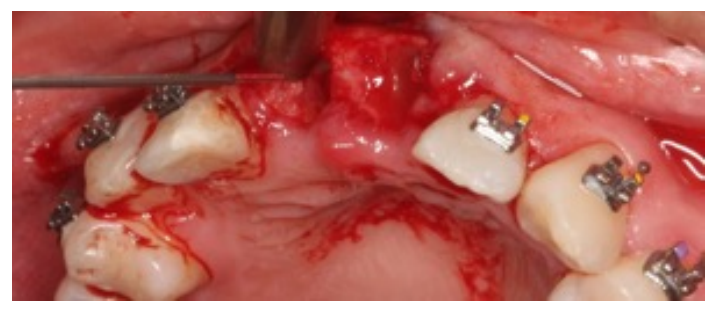

Figura 13.- Irrigación con suero fisiológico

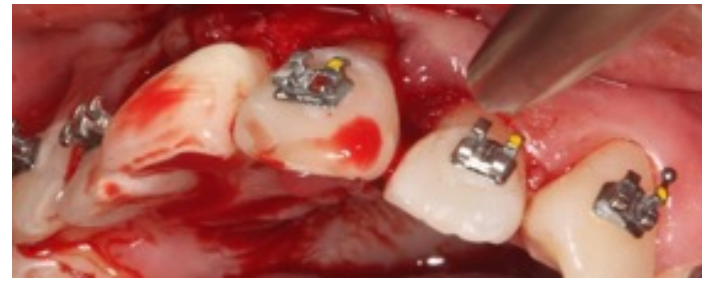

Figura 15.- Reimplantación de la pieza 2.1

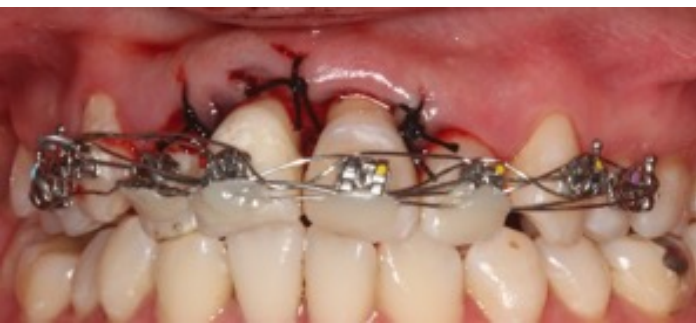

Figura 17.- Ligadura en 8 y bondeado con resina como férula

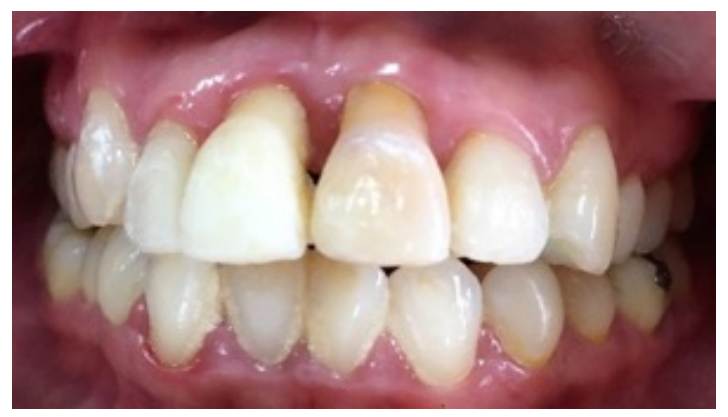

Figura 19.- Control clínico al año

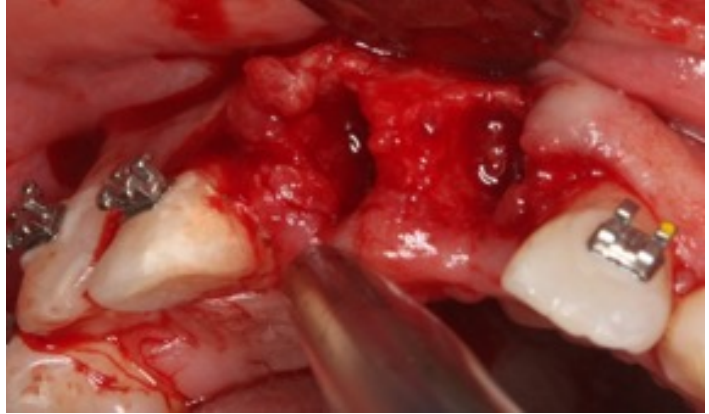

Figura 12.- Formación del lecho alveolar

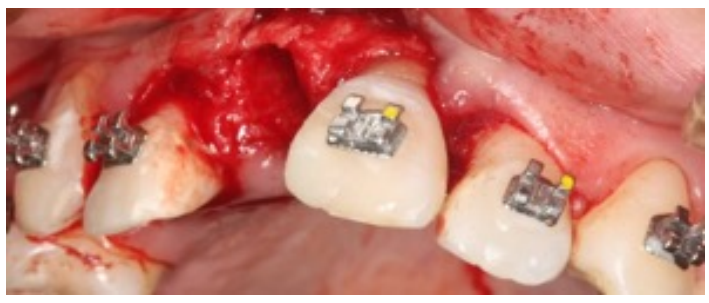

Figura 14.- Reimplantación de la pieza 1.1

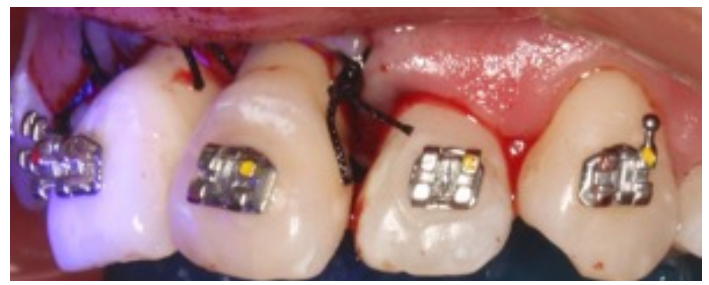

Figura 16.- Sutura

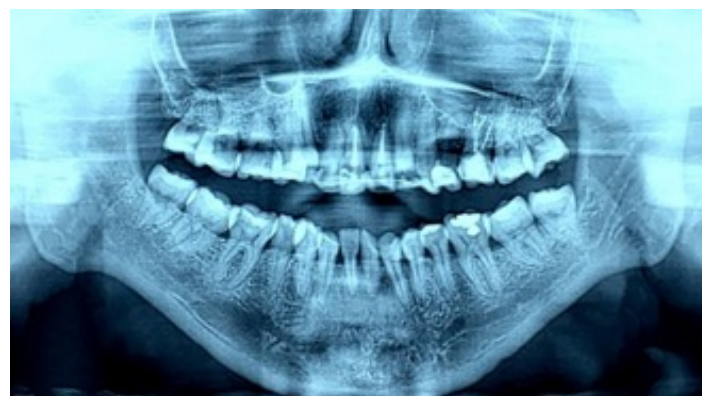

Figura 18.- Radiografía control al año 


\section{Discusión}

Los resultados de este procedimiento no fueron del todo satisfactorios luego de 1 año de haber sido realizado, presentando deficiencias en el aspecto estético y periodontal, aun así, el paciente conserva sus dientes a pesar de lo descrito por otros autores donde se indica que transcurridos periodos largos de tiempo después del trauma, presenta un mal pronóstico. ${ }^{17-21}$

Es importante mencionar que la edad es un factor predisponente ya que en edades tempranas se obtiene mejores resultados ${ }^{22,23}$ debido a que las características del hueso alveolar es más laxo, además de la respuesta inmunológica regenerativa y vascular ${ }^{24,18-19,25-26}$ en nuestro caso la paciente es adulto y con tratamiento tardío presentando pronósticos desfavorables y con desconocimiento de cómo proceder ante esta situación, 27,19,28 la decisión de realizar el reimplante dentario depende tanto del paciente como del profesional, en la bibliografía revisada no se encuentran casos registrados de reimplantes realizados con más de 72 horas de avulsionado el diente ${ }^{29}$ por lo que consideramos que el resultado obtenido está relacionado tanto con la edad como con el tiempo de espera para la reimplantación, aun así el paciente se siente satisfecho de haber podido mantener sus piezas dentarias en boca.

Con este resultado se puede optar posteriormente a realizar un tratamiento de rehabilitación menos complejo y con mejores resultados tanto estéticos como funcionales, manteniendo de esta manera el espacio, los tejidos óseos y mucosos del diente perdido, los mismos que se ven afectados el momento de la avulsión dental, hay que considerar que el objetivo es lograr prevenir la reabsorción ósea y la perdida de dimensión del alveolo ${ }^{30}$ a diferencia de lo que sucede al realizar un tratamiento definitivo con implantes dentales, ya que no se puede obtener un buen contorno alveolar y altura ósea, ocasionando un problema estético de difícil tratamiento. ${ }^{31}$

El mejor tratamiento es la reimplantación del propio diente del paciente. ${ }^{32-33}$

Acompañado con lo que menciona Andreasen, acerca de que la intervención antibiótica inicial es un factor significativo para controlar la infección de los tejidos blandos. ya que los dientes contaminados fueron casi tres veces más propensos de sufrir resorción que los dientes no contaminados. ${ }^{34,35}$

En el presente trabajo, enfatiza la importancia de un tratamiento inmediato y el seguimiento de pautas clínicas protocolizadas basadas en la evidencia son claves en el éxito del tratamiento de los dientes avulsionados. ${ }^{36}$ 


\section{Referencias Bibliograficas:}

1. Cortés GM, Hernández PJ, Valenzuela EE. Tratamiento del diente avulsionado: Caso clínico, seguimiento a 5 años. Rev Odont Mex [Internet]. 2010 [citado 16 ene 2018]; 14(4):249-257. Disponible en: http://www.scielo.org.mx/pdf/rom/v14n4/1870-199Xrom-14-04-00249.pdf

2. Padilla R, Dorney B, Balikov S. Prevention of oral injuries. CDA J [Internet]. 1996 [citado 16 ene 2018]; 24(3): 30-36. Disponible en: https://www.ncbi.nlm.nih.gov/pubmed/9063191

3. Oulis CJ, Berdouses ED. Dental injuries of permanent teeth treated in private practice in Athens. Endod Dent Traumatol [Internet]. 1996 [citado 17 ene 2018]; 12(2): 60-65. Disponible en: https://www.ncbi.nlm.nih.gov/pubmed/9028198

4. Dewhurst SN, Mason S, Roberts GJ. Emergency treatment of orodental injuries: a review. Br J Oral Maxillof Surg [Internet]. 1998 [citado 17 ene 2018 ]; 36(3): 165-175. Disponible en: https://www.ncbi.nlm.nih.gov/pubmed/9678879

5. Casals GY, Montero del Castillo ME, González NG. Prevalencia de secuelas de traumatismos en dientes temporales en niños institucionalizados del municipio Playa. Rev Cub E [Internet]. 2011 [citado 17 ene 2018]; 48 (1): 14-21. Disponible en:http://scielo.sld.cu/scielo.php?script=sci_abstract\&pid=S0034-75072011000100004\&lng=es\&nrm=iso\&tlng=es

6. Ruiz de Gopegui-FJ. Incisivo central permanente avulsionado. Conducta y caso clínico. RCOE [Internet] 2003 [citado 18 ene 2018]; 8(4):429-437. Disponible en: http://scielo. isciii.es/pdf/rcoe/v8n4/429\%20incisivo.pdf

7. Zhao Y, Gong Y. Knowledge of emergency management of avulsed teeth: a survey of dentist in Beijing, China. Dental Traumatology. [Internet]. 2010 [citado 17 ene 2018]; 26(3): 281-284. Disponible en: http://onlinelibrary.wiley.com/wol1/doi/10.1111/j.16009657.2010.00877.x/full

8. Andreasen JO, Borum MK, Jacobsen HL, Andreasen FM. Replantation of 400 avulsed permanent incisors. 2. Factors related to pulpal healing. Endod Dent Traumatol [Internet]. 1995 [citado 18 ene 2018]; 11 (2): 59-68. Disponible en: https://www.ncbi.nlm.nih.gov/ pubmed/7641620

9. Barrett EJ, Kenny DJ. Survival of avulsed permanent maxillary incisors in children following delayed replantation. Endod Dent Traumatol [Internet].1997 [citado 18 ene 2018];13(6):269-275. Disponible en: https://www.ncbi.nlm.nih.gov/pubmed/9558508

10. Malhotra N, Cyriac R, Acharya S. Clinical implications of storage media in dentistry: a review. Endo. EPT [Internet]. 2010 [citado 22 ene 2018]; 4(3) 179-188. Disponible en: http:// quintpub.com/journals/endo/abstract.php?iss2_id=906\&article_id=10363\&article=3\&title=clinical\%20implications \%20of\%20storage \%20media\%20in \%20dentistry:\%20 a\%20review\#.

11. Flores MT, Cols. Guidelines for the management of traumatic dental injuries. II. Avulsion of permanent teeth. Dental Traumatology [Internet]. 2006 [citado 22 ene 2018]; 14(1); 110-118. Disponible en: https://www.ncbi.nlm.nih.gov/pubmed/17511833

12. Bae JH, Choi YH, Cho BH, Kim YK, Kim SG.Autotransplantation of teeth with complete root formation: a case series. J Endod [Internet]. 2010 [citado 22 ene 2018]; 36(8):1422- 
14226. Disponible en: https://www.ncbi.nlm.nih.gov/pubmed/20647110

13. Pfadt E, Carlson DS. Avulsión dental. Dialnet [Internet]. 2012 [citado 22 ene 2018]; 30(10):7. Disponible en: https://dialnet.unirioja.es/servlet/articulo?codigo=4137575

14. Rosenblatt A. The best treatment for avulsed permanent teeth. Evid Based Dent. [Internet]. 2010 [citado 22 ene 2018];11(2):42-3. Disponible en: https://www.researchgate. net/publication/44799281_The_best_treatment_for_avulsed_permanent_teeth

15. Trope M. Avulsion of permanent teeth: theory to practice. Dent Traumatol. [Internet]. 2011 [citado 22 ene 2018];27(4):281-294. Disponible en: https://pdfs. semanticscholar.org/8131/ccb3644bdd26950f8d0e884ac53762971315.pdf?_ ga=2.193450477.1570266061.1521132454-1294684429.1521132454

16. Mori GG, Nunes DC, Castilho LR, de Moraes IG, Poi WR.Propolis as storage media for avulsed teeth: microscopic and morphometric analysis in rats. Dent Traumatol. . [Internet] 2010 [citado 22 ene 2018]; 26(1):80-85.disponible en: https://www.ncbi.nlm.nih.gov/ pubmed/20089064

17. Watanabe Y. Long-term observation of autotransplanted teeth with complete root formation in orthodontic patients. Am J Orthod Dentofacial Orthop. [Internet] 2010 [citado 22 ene 2018];138(6):720-726. Disponible en: https://www.ncbi.nlm.nih.gov/pub$\operatorname{med} / 21130330$

18. García MI, Palma J, Espinozaii E. Tratamiento del diente avulsionado: Casoclínico, seguimiento a 5 años. Revista Odontológica Mexicana. 2010; 14(4):249-257.

19. Roig A. Análisis Morfométrico del Número de Odontoblastos en Recubrimientos Directos con Hidróxido de Calcio y Propóleos en Canes. Int. J. Morphol. 2011;29(3):799-805.

20. Petrovic B. Factors related to treatment and outcomes of avulsed teeth. Dent Traumatol. 2010; 26(1):52-59.

21. Wang Y. The Effect of Cultured Autologous Periodontal Ligament Cells on the Healing of Delayed Autotransplanted Dog's Teeth. J Endod. 2010; 36(2):264-267.

22. Andersson L. International Association of Dental Traumatology guidelines for the management of traumatic dental injuries: 2. Avulsion of permanent teeth. Dent Traumatol. $2012 ; 28(2): 88-96$.

23. Park JH, Tai K, Hayashi, D. Tooth autotransplantation as a treatment option: A review. J Clin Pediatr Dent. 2010; 35(2):129-135.

24. Tolentino LS. Incisivo permanente avulsionado-reimplante após dois dias do trauma: relato de um caso. Revista odontológica Universidad de la Ciudad de Sao Paulo. 2010; 22(1):70-7.

25. Hecova H, Tzigkounakis V, Merglova V, Netolicky J.A retrospective study of 889 injured permanent teeth. Dent Traumatol. 2010; 26(6):466-475.

26. Rosenblatt A. The best treatment for avulsed permanent teeth. Evid Based Dent. 2010; $11(2): 42-43$.

27. Arroyo S,Martínez J,Brau E, Berástegui E. Avulsión y reimplante en paciente joven: 15 años de evolución. REDOE. 2014; 15: 13-31 
28. Savi A, Turillazzi O, Cocconi R, Bonanini M, Pizzi S, Manfredi M. Central incisor loss after delayed replantation following avulsion: a contemporary restorative and adjunctive orthodontic management approach. Dent Traumatol. 2012; 28: 161-165

29. Andreasen J0, Andreasen FM, Skeie A, Hjørting-Hansen E,Schwartz O. Effect of treatment delay upon pulp and periodontal healing of traumatic dental injuries -a review article. Dental Traumatol 2002; 18: 116-128.

30. Gómez PC, Linares IA, M.D. HuertaS, Mendoza MA. Protocolo de actuación y tratamiento adecuado de las complicaciones para el éxito del reimplante tras una avulsión dental. Caso clínico. Odontol Pediátr. 2014; 22(3): 183-194

31. Roig A. Análisis Morfométrico del Número de Odontoblastos en Recubrimientos Directos con Hidróxido de Calcio y Propóleos en Canes. Int. J. Morphol. 2011;29(3):799-805.

32. Watanabe Y, Mohri, M Takeyama, M Yamaki Long-term observation of autotransplanted teeth with complete root formation in orthodontic patients. Am J Orthod Dentofacial Orthop. 2010;138(6):720-726.

33. Trope M. Avulsion of permanent teeth: theory to practice. Dent Traumatol. 2011;27(4):281294.

34. Mori GG. Propolis as storage media for avulsed teeth: microscopic and morphometric analysis in rats. Dent Traumatol. 2010;26(1):80-85.

35. HuertaS, Mendoza MA. Protocolo de actuación y tratamiento adecuado de las complicaciones para el éxito del reimplante tras una avulsión dental. Caso clínico. Odontol Pediátr. 2014; 22(3): 183-194

36. Morales BB, Pinos NP, Cordero LM. Dental fragments collage adhesion. Rev Kill.2017; 1(3): 7-14.

Recibido:

Aceptado: 


\section{Paralelismo entre plano de Camper y el plano oclusal según biotipo facial en una población del sur de Perú}

\section{Parallelism between Camper's plane and the occlusal plane according to facial biotype in a population of southern Peru}

Juan-Eduardo Huamani-Cantoral, ${ }^{\text {2*,a,b,c, }}$ Jorge-Raúl Colchado-Carhuavilca, ${ }^{2, a, b, c}$ Cecil-Massiel Candela-Levano, ${ }^{3, d}$ José-Luis Huamani-Echaccaya ${ }^{4, d}$

1 Escuela de Odontología de la Universidad Privada Norbert Wiener.

2 Facultad de Odontología de la Universidad Nacional Mayor de San Marcos

3 Programa de enfermería, Universidad Autónoma de Ica.

4 Escuela de Estomatología de la Universidad Privada San Juan Bautista. Ica, Perú.

a Magíster en Odontología

b Doctorando en Estomatología. Universidad Nacional Mayor de San Marcos.

c Especialista en Rehabilitación Oral.

d Magíster en Salud Pública

\section{ORCID iD}

https://orcid.org/0000-0002-9197-2563

ORCID iD

https://orcid.org/0000-0002-2227-0381

ORCID iD

https://orcid.org/0000-0003-2616-0670

ORCID iD

https://orcid.org/0000-0002-0261-2049 


\section{Resumen}

Objetivo: Evaluar el paralelismo entre el plano de Camper cefalométrico y el plano oclusal según biotipo facial. Materiales y métodos: Estudio de enfoque cuantitativo, tipo observacional, retrospectivo, transversal. Nivel descriptivo comparativo. Para el cálculo del tamaño muestral se utilizó la fórmula para comparar grupos con promedio del paralelismo del plano de camper/oclusal en el biotipo braquifacial $-5,8379 \pm 3,8$ y mesofacial $-3,8433 \pm 2,7 ; \alpha=0,05$, potencia estadística $80 \%$, margen de error de $5 \%$ y ajustado al $34 \%$ se obtuvo una muestra de 52 radiografías cefalométricas por grupo G1=braquifacial, G2=dolicofacial, G3=mesofacial; pareados según edad 10 adolescentes, 26 jóvenes, 16 adultos y según sexo 26 varones y 26 mujeres. Los criterios de inclusión fueron radiografías cefalométricas de buena calidad, datos completos y se excluyeron radiografías de pacientes con aparatología ortododóntica, con patologías en el lugar de análisis visual, ausencia del primer molar permanente mandibulares o piezas anteriores. Las radiografías cefalométricas se digitalizaron y analizaron mediante el Software DENTAL STUDIO NX ${ }^{\circledR}$. Resultados: El análisis cefalométrico del paralelismo del plano de camper y el plano oclusal según grupo etario reportó en adolescentes una media $-4,203^{\circ}$ $\pm 3,23^{\circ} I_{95 \%}=[-5,360 \text { a }-3,045]_{i}$ joven $-4,701^{\circ} \pm-2,72^{\circ} I C_{95 \%}=[-5,306$ a $-4,095]$ y adultos $-4,452^{\circ}$ $\pm 3,29^{\circ} \quad \mathrm{IC}_{95 \%}=[-5,384$ a $-3,519](\mathrm{p}=0,727)$. Asimismo, respecto al sexo, se encontró en el grupo masculino $\quad-4,765^{\circ} \pm 3,26^{\circ} \mathrm{IC}{ }_{95 \%}=[-5,490$ a $-4,039]$; femenino $-4,292^{\circ} \pm 2,70^{\circ} \mathrm{IC} 95 \%=[-$ 4,891 a -3,692] sin diferencia estadística significativa $(p=0,326)$. Conclusión: con un $p=0,000$ podemos concluir que el paralelismo del plano de Camper cefalométrico con el plano oclusal más cercano a cero se encontró en el biotipo dolicofacial $\quad-3,192^{\circ} \pm 2,418^{\circ} \mathrm{IC}_{95 \%}=[-3,8493$ a $-2,5346]$ y mesofacial $-4,150^{\circ} \pm 2,668^{\circ} \mathrm{IC}_{95 \%}=[-4,8732 \mathrm{a}-3,4267]$ diferente al biotipo braquifacial $-6,244^{\circ} \pm 3,068^{\circ} \quad \mathrm{IC}_{95 \%}=[-7,0779 \mathrm{a}-5,4100]$.

Palabras clave: biotipo facial, braquifacial, dolicofacial, mesofacial, plano oclusal, plano de Camper

\section{Abstract}

Objective: To evaluate the parallelism between the cephalometric Camper plane and the occlusal plane according to facial biotype. Materials and methods: Quantitative, observational, retrospective, cross-sectional study. Comparative descriptive level. For the calculation of the sample size, the formula was used to compare groups with average camper/occlusal plane parallelism in the brachyfacial biotype $-5,8379 \pm 3.8$ and mesofacial $-3,8433 \pm 2,7 ; \alpha=0,05$, statistical power $80 \%$, margin of error $5 \%$ and adjusted to $34 \%$ a sample of 52 cephalometric radiographs were obtained per group $\mathrm{G1}=$ brachyfacial, $\mathrm{G} 2=$ dolicofacial, $\mathrm{G} 3=$ =mesofacial; matched according to age 10 adolescents, 26 young adults, 16 adults and according to sex 26 males and 26 females. The inclusion criteria were cephalometric radiographs of good quality, complete data and radiographs of patients with orthodontic appliances, with pathologies in the place of visual analysis, absence of the mandibular first permanent molar or anterior pieces were excluded. The cephalometric radiographs were digitized and analyzed using DENTAL STUDIO NX software ${ }^{\oplus}$. Results: The cephalometric analysis of the parallelism of the camper plane and the occlusal plane according to age group reported in adolescents a mean $-4.203^{\circ}$ 
$\pm 3,23^{\circ} \mathrm{Cl}_{95 \%}=[-5,360 \text { to }-3,045]_{;}$youth $-4.701^{\circ} \pm-2,72^{\circ} \mathrm{Cl}_{95 \%}=[-5,306$ to $-4,095]$ and adults $-4,452^{\circ} \pm 3,29^{\circ} \mathrm{Cl}_{95 \%}=[-5,384$ to $-3,519](p=0,727)$. Likewise, with respect to sex, it was found in the male group $-4.765^{\circ} \pm 3.26^{\circ} \mathrm{Cl}_{95 \%}=[-5,490$ to $-4,039]$; female $-4,292^{\circ} \pm 2,70^{\circ} \mathrm{Cl}_{95 \%}=[-4,891$ to $-3,692]$ with no significant statistical difference $(p=0,326)$. Conclusion: with a $p=0,000$ we can conclude that the parallelism of the cephalometric Camper's plane with the occlusal plane closest to zero was found in the dolichofacial biotype $-3,192^{\circ} \pm 2,418^{\circ} \mathrm{Cl}_{95 \%}=[-3,8493$ to $-2,5346]$ and mesofacial $-4,150^{\circ} \pm 2,668^{\circ} \mathrm{Cl}_{95 \%}=[-4,8732$ to $-3,4267]$ different from the brachyfacial biotype $-6,244^{\circ} \pm 3,068^{\circ} \mathrm{Cl}_{95 \%}=[-7,0779$ to $-5,4100]$.

Key words: facial biotype, brachyfacial, dolichofacial, mesofacial, occlusal plane, Camper's plane

\section{Introducción}

Clínicamente el plano oclusal es una línea que se extiende desde la cúspide distal del segundo molar inferior hasta la punta cuspídea del canino inferior' ${ }^{1}$ desde un punto vista cefalométrico W.B Downs en 1948 planteó el plano oclusal como una línea proyectada desde el punto oclusal medio (superficie de contacto entre el 1er molar superior e inferior) hasta el punto incisal medio (entre los bordes de los incisivos inferiores y superiores). ${ }^{2}$ Este plano ha sido relacionado con distintos planos faciales con el fin de establecer su orientación; la dificultad común en esta búsqueda es la falta de estructuras anatómicas reproducibles, los desgastes dentarios severos, las maloclusiones, el edentulismo total y parcial. ${ }^{3}$

Diferentes escuelas de odontología utilizan distintas guías para determinar el plano oclusal. ${ }^{4}$ Estos parámetros corresponden a la altura de la papila retromolar, el borde lateral de la lengua, la comisura labial, el bermellón del labio inferior, parámetros estéticos y referencias craneométricas. ${ }^{5-6}$

El glosario de términos prostodónticos actualmente establece que el plano de Camper se orienta desde el borde inferior del ala de la nariz hasta el borde superior del tragus ${ }_{i}^{7}$ sin embargo, los estudios muestran que, al buscar paralelismo con el plano oclusal, este trazado varía en las distintas poblaciones estudiadas.

Karkasis (1987) realizó un estudio radiográfico donde propone el borde inferior del meato auditivo externo como punto cefalométrico para trazar el plano de Camper, ya que sería más cercano al paralelismo con el plano oclusal. ${ }^{8}$

En cuanto al plano de Camper clínico, Kumar S. (2013), en un estudio fotográfico utilizando la platina de Fox en individuos dentados con perfil ortognático, sugiere que la línea trazada desde el ala nasal hasta el borde inferior del tragus es más cercana al paralelismo con el plano oclusal, coincidiendo con los resultados de Venugopalan et al. (2012) en su estudio radiográfico para individuos clase I y clase III. ${ }^{9-10}$

Por otra parte, Abi-Ghosn et al. (2014) realizaron un estudio cefalométrico a individuos den- 
tados completos clase I de Angle, y describieron la línea ala de la nariz- tragus medio como la más paralela con el plano oclusal. " Finalmente, Sadr K. \& Sadr M. (2009) en un estudio fotográfico en individuos dentados clase I de Angle, con una platina de Fox interpuesta y Al Quran et al. (2010) en un estudio cefalométrico en individuos dentados, proponen el borde superior del tragus como referencia posterior para trazar el plano de Camper. ${ }^{12-13}$

Diversos autores, en la búsqueda de parámetros aplicables en la población, han definido el plano oclusal bajo sus propios términos, relacionándolo con distintos planos craneales y faciales, estableciendo normas entre ellos. Steiner, en 1949, define el plano oclusal como la línea de intercuspidación de los primeros molares y un punto equidistante de los bordes incisales de los incisivos superiores e inferiores, y propone que entre el plano oclusal y el plano SiIla-Nasion se forma un ángulo de $14^{\circ}$. Ricketts, en 1950 define el plano oclusal como la línea que pasa por los puntos $\mathrm{C}$ y $\mathrm{T}$ (cúspide mesiovestibular del primer molar permanente y cúspide del canino mandibular, respectivamente), estableciendo como norma un ángulo de $7,5^{\circ}$ entre el plano oclusal y el plano de Frankfort. ${ }^{14}$ Por otra parte, tradicionalmente el plano oclusal se ha considerado paralelo al plano de Camper, el cual se orienta desde el borde inferior del ala de la nariz hasta el borde superior del tragus. ${ }^{7}$

Un estudio cefalométrico realizado por van Niekerk et al. en 33 pacientes desdentados ${ }^{15}$, encontraron angulaciones de $3,45^{\circ}$ entre el plano oclusal y el plano de Camper mientras que Kotler et al. ${ }^{16}$ y Karkazis \& Polyzois ${ }^{17-18}$ Io informaron como 7,00 y $10,00^{\circ}$ respectivamente.

Debido a las múltiples controversias sobre la localización del plano oclusal tanto en la dentición natural como artificial, el presente estudio tiene como propósito brindar información para el clínico que le permita toma de decisiones sobre estas controversias y determinar la mejor referencia posterior del plano de Camper. El paralelismo de estos dos planos se realizó con el Software Dental Studio NX ${ }^{\circledR}$ mientras que el biotipo facial mediante el análisis cefalométrico del coeficiente de variación vertical (VERT) de Ricketts utilizando el programa Nemoceph.

El objetivo del presente estudio fue evaluar el paralelismo del plano de Camper cefalométrico con el plano oclusal según el biotipo facial.

\section{Materiales y Métodos.}

\section{Tipo de estudio}

Se realizó un estudio de enfoque cuantitativo, tipo observacional, retrospectivo, transversal. Nivel descriptivo. Diseño comparativo.

Cálculo de tamaño muestral y selección de la unidad de análisis

Para el cálculo del tamaño muestral se realizó una prueba piloto en 357 radiografías cefalométricas del área de Tomografía Oral y Máxilofacial de la clínica odontológica de la Universidad 
Nacional San Luis Gonzaga de Ica en el periodo 2016 a 2018; obteniéndose un promedio de paralelismo entre el plano de camper/plano oclusal en el biotipo braquifacial $-5,8379 \pm 3,86$ y mesofacial $-3,8433 \pm 2,77$; que se reemplazó en una fórmula para comparar grupos basado en una variable numérica en la que se considero $\alpha=0.05$, potencia estadística $80 \%$, margen de error de $5 \%$ y ajustado al $13 \%$ se obtuvo una muestra de 52 radiografías cefalométricas por grupo G1=braquifacial, G2=dólicofacial, G3=mesofacial.

La selección de la muestra por cada grupo de estudio se parearon según edad y sexo quedando distribuidos radiografías cefalométricas para 10 adolescentes, 26 jóvenes, 16 adultos y 26 varones, 26 mujeres; tomándose en cuenta los siguientes criterios:

\section{Criterios de inclusión}

1. Se incluyeron radiografias cefalometricas de buena calidad.

2. Radiografias con datos completos del paciente.

\section{Criterios de exclusión:}

1. Radiografías de pacientes con aparatología ortododóntica.

2. Patologías en el lugar de analisis visual.

3. Ausencia del primer molar permanente mandibulares o piezas anteriores

4. Piezas dentarias extruídas

5. Portadores de prótesis.

\section{Calibración del investigador}

Las mediciones fueron realizadas por un docente especialista en ortodoncia y ortopedia dentofacial y para controlar sesgos se procedió a una calibración interobservador con personal logístico para el dominio del Software Dental Studio $N{ }^{\circledR}(\mathrm{CCl}=0,8)$, en seguida se procedió a establecer concordancia intraobservador $(\mathrm{CCl}=0,9)$ obteniendo un coeficiente de fiabilidad alta.

\section{Instrumento de medición}

Las radiografías cefalométricas se digitalizaron y analizaron mediante el Software DENTAL STUDIO NX ${ }^{\circledR}$, con el objetivo de evaluar el paralelismo entre Plano de Camper (Po- ENA) y Plano Oclusal (Plano tangente a las superficies oclusales de los dientes posteroinferiores delimitado por los bordes incisales de los dientes anteriores mandibulares y la punta de las cúspides vestibulares de los premolares), después de importar el caso, se calibró la imagen a través de la proyección del nasión equivalente a $10 \mathrm{~mm}$ de altura, luego se utilizó un análisis automatizado por el Software y personalizado por el investigador. 
Se reconoció los siguientes puntos cefalométricos: Na (Nasion), Si (Silla turca, Me (Mentoniano), Or (Orbital), Po, Pt (Pterigomaxilar Post-Sup), ENP (espina nasal posterior), ENA (espina nasal anterior), A (punto A), Ba (Basion), Ag (Antigonión), Go (Gonion), Co (Cóndilo), Ar (punto Articular, línea básión, línea posterior cóndilo), R3 (escotadura condilar), R1 (línea anterior de la rama mandibular), A6 (primer molar superior distal) A6M (primer molar superior mesial), B6 (primer molar inferior distal), B6M (primer molar inferior mesial), IS(incisivo Superior), ISR (raíz incisivo superior) II(Incisivo Inferior), IIR(Raíz incisivo inferior), OP (punto posterior del plano oclusal), OA (punto anterior del plano oclusal), Pg (pogonion), Pm (suprapogonion), B (Punto B), C (Cervical), Me' (Mentón Blando) Pg' (pogonion blando), LI (Labio inferior anterior),SLI (surco Labial inferior), LS (Labio superior anterior), Stm (Stomion superior), Sn (subnasal), SLS (surco labial superior), EN (Nasal blando), $\mathrm{Na}$ (Nasion en tejido blando), G (Glabela).

Una vez terminado el reconocimiento de los puntos en el software se hizo una revisión y ajuste fino de los puntos para aceptar el trazado realizado y que se proporcione el ángulo formado por el plano camper/plano oclusal, además del diagnóstico y clasificación del biotipo facial según el análisis cefalométrico del coeficiente de variación vertical (VERT) de Ricketts, utilizando cinco ángulos: Profundidad facial. Ángulo formado por el plano facial y el plano de Frankfurt. Eje facial. Ángulo constituido entre el eje facial y el plano (Basion-Nasion). Altura facial inferior. Ángulo constituido entre los planos (Xi-Ans) y(Xi-Pm).

Ángulo del plano mandibular. Ángulo constituido entre el plano mandibular y el plano horizontal de Frankfurt. Arco mandibular. Ángulo constituido entre el eje del cuerpo y el eje condilar.

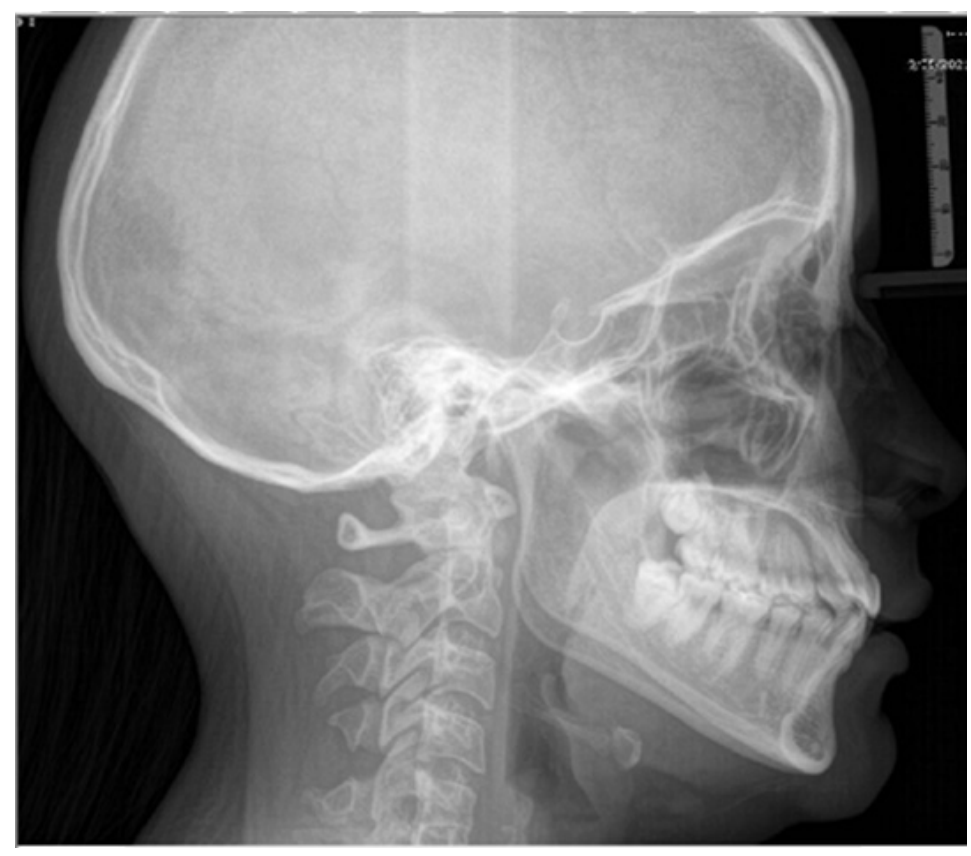




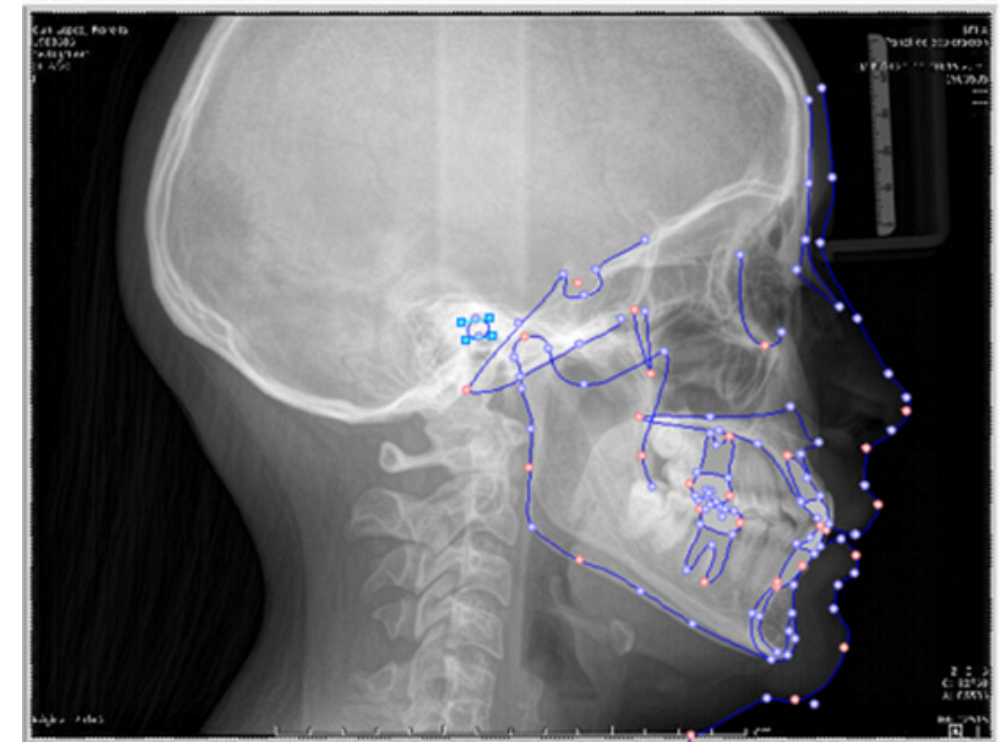

Figura 1: A. Posición natural de la cabeza B. Trazado cefalométrico para determinar el biotipo facial

Aspectos éticos

La investigación fue revisada por el Comité de Ética de la Universidad "San Luis Gonzaga" CIEI-UNICA N 002/05-2021 


\section{Resultados:}

El análisis cefalométrico del paralelismo del plano de camper y el plano oclusal según grupo etario reportó en los adolescentes una media $-4,203^{\circ} \pm 3,23^{\circ} \mathrm{IC}_{95 \%}=[-5,360$ a $-3,045]$; joven $-4,701^{\circ} \pm-2,72^{\circ} \mathrm{IC} \mathrm{g5 \%}_{\%}=[-5,306$ a $-4,095]$ y adultos $-4,452^{\circ} \pm 3,29^{\circ} \mathrm{IC} \mathrm{C}_{95 \%}=[-5,384 \mathrm{a}-3,519]_{i}$ com paración de medias que no encontró diferencia estadística significativa $(p=0,727)$. Asimismo, respecto al sexo, se encontró en el grupo masculino $-4,765^{\circ} \pm 3,26^{\circ} \mathrm{IC}_{95 \%}=[-5,490$ a $-4,039] ;$ femenino $-4,292^{\circ} \pm 2,70^{\circ} I_{95 \%}=[-4,891$ a $-3,692]$ sin diferencia estadística significativa $(p=0,326)$. (Tabla 1)

Tabla 1: Comparación de medias del paralelismo del plano de camper y el plano oclusal según grupo etario, sexo.

\begin{tabular}{|c|c|c|c|c|c|c|c|c|c|}
\hline \multirow{2}{*}{ Variable } & \multirow{2}{*}{ Categoría } & \multirow{2}{*}{$\mathrm{n}$} & \multirow{2}{*}{ Media } & \multirow{2}{*}{ DS } & \multicolumn{2}{|c|}{ Valor $\left({ }^{\circ}\right)$} & \multirow{2}{*}{\multicolumn{2}{|c|}{ IC $95 \%$}} & \multirow{2}{*}{ p-valor } \\
\hline & & & & & Mínimo & Máximo & & & \\
\hline \multirow{3}{*}{ Grupo etario } & Adolescente & 30 & $-4,203^{\circ}$ & 3,23 & $-9,9$ & 4,4 & $-5,360$ & $-3,045$ & \multirow{3}{*}{$0,727^{*}$} \\
\hline & Joven & 78 & $-4,701^{\circ}$ & 2,72 & $-10,8$ & $-2,0$ & $-5,306$ & $-4,095$ & \\
\hline & Adulto & 48 & $-4,452^{\circ}$ & 3,29 & $-12,1$ & 4,2 & $-5,384$ & $-3,519$ & \\
\hline \multirow{3}{*}{ Sexo } & Masculino & 78 & $-4,765^{\circ}$ & 3,26 & $-12,1$ & 4,2 & $-5,490$ & $-4,039$ & \multirow{2}{*}{$0,326^{* *}$} \\
\hline & Femenino & 78 & $-4,292^{\circ}$ & 2,70 & $-11,4$ & 4,4 & $-4,891$ & $-3,692$ & \\
\hline & Total & 156 & $-4,529^{\circ}$ & 2.99 & $-12,1$ & 4,4 & $-4,999$ & $-4,058$ & \\
\hline
\end{tabular}

n: muestra; DS: desviación estándar; IC 95\%: Intervalo de confianza al 95\%, *ANOVA de un factor p>0.05, ${ }^{* *} T$ Student para muestras independientes $p>0,05$

El análisis del paralelismo del plano de Camper cefalométrico con el plano oclusal más cercano a cero según la prueba post hoc de Tukey se encontró en el biotipo dolicofacial $-3,192^{\circ} \pm 2,418^{\circ} I C_{95 \%}=[-3,8493$ a $-2,5346]$, seguido de mesofacial $-4,150^{\circ} \pm 2,668^{\circ} \mathrm{IC}_{95 \%}=[-4,8732$ a $-3,4267]$ diferente al biotipo braquifacial $-6,244^{\circ} \pm 3,068^{\circ} \mathrm{IC}_{95 \%}=[-7,0779$ a $-5,4100]$; comparación que demostró ser estadísticamente significativo $(p=0,000)$. (tabla 2$)$ 
Tabla 2: Comparación de medias del paralelismo del plano de camper y el plano oclusal según perfil facial

\begin{tabular}{|c|c|c|c|c|c|c|c|c|}
\hline \multirow{3}{*}{$\begin{array}{c}\text { Perfil facial } \\
\text { Braquifacial }\end{array}$} & \multirow{3}{*}{$\begin{array}{l}n \\
52\end{array}$} & \multirow{3}{*}{$\begin{array}{l}\text { Media } \\
-6,244^{\circ}\end{array}$} & \multirow{3}{*}{$\begin{array}{c}\text { DS } \\
3,068^{\circ}\end{array}$} & \multicolumn{2}{|c|}{ Valor } & \multirow{2}{*}{\multicolumn{2}{|c|}{ IC 95\% }} & \multirow{3}{*}{ p-valor* } \\
\hline & & & & \multirow{2}{*}{$\begin{array}{l}\text { Mínimo } \\
-12,1^{\circ}\end{array}$} & \multirow{2}{*}{$\begin{array}{c}\text { Máximo } \\
4,2^{\circ}\end{array}$} & & & \\
\hline & & & & & & $-7,0779$ & $-5,4100$ & \\
\hline Dolicofacial & 52 & $-3,192^{\circ}$ & $2,418^{\circ}$ & $-7,5^{\circ}$ & $4,4^{\circ}$ & $-3,8493$ & $-2,5346$ & 0,000 \\
\hline Mesofacial & 52 & $-4,150^{\circ}$ & $2,668^{\circ}$ & $-10,2^{\circ}$ & $2,9^{\circ}$ & $-4,8732$ & $-3,4267$ & \\
\hline
\end{tabular}

n: muestra; DS: desviación estándar; IC 95\%: Intervalo de confianza al 95\%, *ANOVA de un factor $p=0.000$ (estadísticamente significativo)

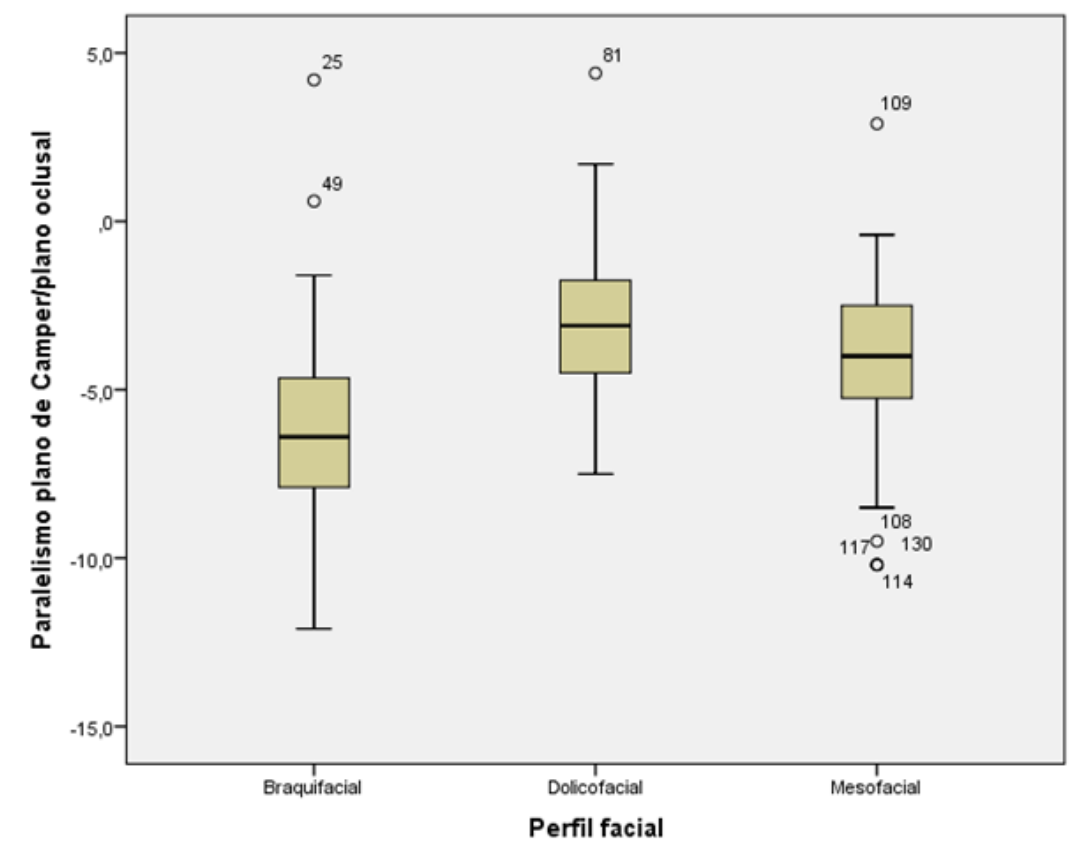

Figura 2: Comparación de medias del paralelismo del plano de camper y el plano oclusal según perfil facial 


\section{Discusión}

Los resultados heterogéneos de las investigaciones sobre la localización del plano oclusal tanto en dentición natural como artificial, motiva el presente estudio aportar información para el clínico que; le permita esclarecer estas controversias y determinar la mejor referencia posterior del plano de Camper.

Para evaluar el paralelismo se consideró; en el plano de Camper el Po (porion) y ENA (espina nasal anterior) y en el plano oclusal; la línea tangente a las superficies oclusales de los dientes posteroinferiores delimitado por los bordes incisales de los dientes anteriores mandibulares y la punta de las cúspides vestibulares de los premolares, una vez importado los casos, se calibró la imagen a través de la proyección del nasión equivalente a $10 \mathrm{~mm}$ de altura

El paralelismo de estos dos planos según el biotipo facial se determinó mediante el análisis cefalométrico del coeficiente de variación vertical (VERT) de Ricketts utilizando el Software Dental Studio NX ${ }^{\circledR}$.

Uno de los procedimientos importantes a considerar en la presente investigación es el pareamiento o matching que se realizó de las variables edad y sexo; cuyo análisis cefalométrico del paralelismo del plano de camper y el plano oclusal según edad evidenció que los adolescentes presentaron una media $-4,203^{\circ} \pm 3,23^{\circ}$; joven $-4,701^{\circ} \pm-2,72^{\circ}$ y adultos $-4,452^{\circ} \pm 3,29^{\circ}$ ( $p=0,727)$; sexo masculino $-4,765^{\circ} \pm 3,26^{\circ}$; femenino $-4,292^{\circ} \pm 2,70^{\circ}(p=0,326)$; en ambos casos sin alcanzar diferencia estadística significativa, lo que demuestra el control de las variables en mención.

Nuestros hallazgos demostraron que la referencia posterior porion (parte superior del meato auditivo externo) en el biotipo dolicofacial presentaron mayor paralelismo entre el plano de camper y plano oclusal $-3,192^{\circ} \pm 2,418^{\circ} I C_{95 \%}=[-3,8493$ a $-2,5346]$ y mesofacial $-4,150^{\circ} \pm 2,668^{\circ}$ $\mathrm{IC}_{95 \%}=[-4,8732$ a $-3,4267]$. Estos hallazgos se pueden explicar debido a las diferentes características de crecimiento según el biotipo facial, así por ejemplo el mesofacial la dirección de crecimiento es vertical y transversal proporcionado y el dolicofacial presenta un crecimiento más de tipo vertical, mientras que el braquifacial es de tipo horizontal ${ }^{19}$, la contrastación de nuestros hallazgos presentó limitación en el sentido de que no fue posible comparar con lo reportado por Kumar S (2013) y Venugopalan et al. (2012), Abi-Ghosn et al. (2014), Sadr K. \& Sadr M. (2009), y Al Quran et al. debido a que estos investigadores utilizaron como referencia posterior puntos tegumentarios como el borde inferior, medio, y superior del tragus respectivamente; finalmente señalamos que nuestros hallazgos no fueron coincidentes con lo reportado por Karkasis que; en el año 1987 señaló que el borde inferior del meato auditivo externo es el más cercano al paralelismo entre el plano de camper y plano oclusal ${ }^{8}$; este hecho podría explicarse por las características propias de la población de estudio, siendo la presente realizado en una población peruana el clínico deberá tener en cuenta este hecho para la interpretación y aplicación de nuestros hallazgos.

Conflicto de intereses: Los autores declaran no tener conflictos de interés 
Referencias Bibliográficas.

1. Alonso A, Albertini J, Bechelli A. Oclusión y diagnostico en rehabilitación oral. Buenos aires: Médica Panamericana; 2011.

2. Martínez V. Estudio comparativo entre el plano oclusal según la definición de Ricketts y su paralelismo con tres planos cefalométrico-propuestos en una población eugnásica chilena [tesis] Chile: universidad de Chile: facultad de odontología;2014

3. López-Garrido J. Estudio comparativo del paralelismo entre el plano oclusal y tres definiciones del plano de Camper en una población eugnásica chilena, 2014

4. Ed M. Results of a survey taught in American An update. 1985;54(August).

5. González-Lafita P, Álvarez-Fernández M de los Á, Fernández-Vázquez JP, González-González I. Planos bioscópicos de interés protésico y su influencia en la altura coronal. Rcoe. 2003;8(5):501-7.

6. Wright CR. Evaluation of the factors necessary to develop stability in mandibular dentures. J Prosthet Dent. 2004;92(6):509-18.

7. The Glossary of Prosthodontic Terms. J Prosthet Dent [Internet ]. 2005;94(1):10-92. Available from: http://www.sciencedirect.com/science/article/pii/S0022391305001757

8 Karkazis HC. A study of the occlusal plane orientation in complete denture construction. 1987;14(4).

9. S K, S G, S G. A determination of occlusal plane comparing different levels of the tragus to form ala-tragal line or Camper's line: A photographic study. J Adv Prosthodont [Internet]. 2013;5(1):9-15. Available from: https://pubmed.ncbi.nlm.nih.gov/23508203/

10. Venugopalan SK, SatishBabu CL, Rani MS. Determination of the relative parallelism of occlusal plane to three ala-tragal lines in various skeletal malocclusions: A cephalometric study. Indian J Dent Res [Internet]. 2012;23(6):719. Available from: http://search.ebscohost.com/ login.aspx?direct=true\&AuthType $=s s 0 \& d b=e d b \& A N=87848488 \&$ lang=es\&site=eds-live\&custid $=s 1248620$

11. Abi-Ghosn C, Zogheib C, Younes R, Makzoumé JE. The ala-tragus line as a guide for orientation of the occlusal plane in complete dentures. J Contemp Dent Pract. 2014;15(1):108-11.

12 Sadr K, Sadr M. A study of parallelism of the occlusal plane and ala-tragus line. J Dent Res Dent Clin Dent Prospects. 2009;3(4):107-9.

13. Ouran Famal, Hazza'a A, Nahass N Al. The Position of the Occlusal Plane in Natural and Artificial Dentitions as Related to Other Craniofacial Planes. J Prosthodont [Internet]. 2010;19(8):601. Available from: http://search.ebscohost.com/login.aspx?direct=true\&db=ed- 
b\&AN=55594559\&lang=es\&site=eds-live

14. Ricketts RM. Variations of the temporomandibular joint as revealed by cephalometric laminagraphy. Am J Orthod. 1950;36(12):877-98.

15. Vera MV. Determinación y localización del plano oclusal en la rehabilitación de pacientes adultos mayores usuarios de prótesis completas. [Tesis doctoral]. Córdoba: Escuela de posgrado Universidad Nacional de Córdoba; 2015. 124 p.

16. Van Niekerk FW, Miller VJ, Bibby RE. La línea ala-tragus en prótesis dentales completas. J ProsthetDent. 1985; 53 : 67-9. [PubMed: 3856023]

17. Karkazis HC, Polyzois GL. Plano oclusal predicho cefalométricamente: Implicaciones en la prótesisremovible. J Prosthet Dent. 1991; 65 : 258-64. [PubMed: 2051362]

18. Koller MM, Merlini L, Spandre G, Palla S. A comparative study of two methods for the orientation ofthe occlusal plane and the determination of the vertical dimension of occlusion in edentulous patients. JOral Rehabil. 1992; 19:413-25. [PubMed: 1432356]

19. Gregoret J. Instrumentación de la cefalometría estática lateral. En: Ortodoncia y cirugía ortognática, diagnóstico y planificación. Barcelona. Ed. Espaxs S.A 1997. p. 227 
